\title{
The Relationship between Student Perceptions of Satisfaction of Social, Teaching, and Cognitive Presence with Asynchronous Communication Tools for Online Learning in a Region $\mathbf{V}$ Community College
}

Torie L. Jackson

Follow this and additional works at: https://researchrepository.wvu.edu/etd

Part of the Curriculum and Instruction Commons

\footnotetext{
Recommended Citation

Jackson, Torie L., "The Relationship between Student Perceptions of Satisfaction of Social, Teaching, and Cognitive Presence with Asynchronous Communication Tools for Online Learning in a Region V Community College" (2014). Graduate Theses, Dissertations, and Problem Reports. 5867.

https://researchrepository.wvu.edu/etd/5867

This Dissertation is protected by copyright and/or related rights. It has been brought to you by the The Research Repository @ WVU with permission from the rights-holder(s). You are free to use this Dissertation in any way that is permitted by the copyright and related rights legislation that applies to your use. For other uses you must obtain permission from the rights-holder(s) directly, unless additional rights are indicated by a Creative Commons license in the record and/ or on the work itself. This Dissertation has been accepted for inclusion in WVU Graduate Theses, Dissertations, and Problem Reports collection by an authorized administrator of The Research Repository @ WVU. For more information, please contact researchrepository@mail.wvu.edu.
} 
The Relationship between Student Perceptions of Satisfaction of Social, Teaching, and Cognitive Presence with Asynchronous Communication Tools for Online Learning in a Region V Community College

Torie L. Jackson

Dissertation submitted to the College of Education and Human Services

at West Virginia University

in partial fulfillment of the requirements for the degree of

Doctor of Education

In

Educational Leadership Studies

\author{
Helen M. Hazi, Ph.D., Chair \\ Patricia Gaston, Ph.D. \\ Ugur Kale, Ph.D. \\ John Oughton, Ed.D. \\ Nathan Sorber, Ph.D.
}

Department of Educational Leadership Studies

Morgantown, West Virginia

2014

Keywords: asynchronous communication, community college, Community of Inquiry, online learning, and social, teaching and cognitive presence 


\begin{abstract}
The Relationship between Student Perceptions of Satisfaction of Social, Teaching, and Cognitive Presence with Asynchronous Communication Tools for Online Learning in a Region V Community College
\end{abstract}

Torie L. Jackson

As a commonplace medium for instructional content in community colleges, the use of online courses is prevalent in higher education and is expected to continue to grow. While online classes offer a number of benefits to students, drawbacks of online education also exist. Because participants in an online classroom are not physically present together, they rely on communication tools to allow for interaction and collaboration. This study addressed the relationship between community college student perceptions of satisfaction of the use of asynchronous communication tools and community college student perceptions of satisfaction of social, teaching, and cognitive presence in a Region $\mathrm{V}$ community college. This study also addressed how that relationship varied depending on particular demographics of student program of study, age, gender, GPA, and prior online experience.

The Community of Inquiry (CoI) instrument was utilized to measure social, teaching, and cognitive presence in the online classroom environment. A survey based on the literature review was developed to gather the perceptions of students' satisfaction with the use of asynchronous communication tools in the online classroom. Tools included e-mail, discussions or forums, blogs or weblogs, wikis, and podcasting.

The study population was the 1,363 enrolled students in the Spring 2014 semester who were taking at least one online course at the time the survey was conducted. The return rate was $31.5 \%$.

The study found eight conclusions: (1) these community college students are more satisfied with the use of three asynchronous communication tools: e-mail, discussions or forums, and podcasts, and less satisfied with the use of two asynchronous communication tools: wikis and blogs in online courses; (2) podcasts had the highest satisfaction among these community college students; (3) students who had taken three or more online courses were more satisfied with asynchronous communication tools in online courses; (4) students indicated a strong positive correlation in regards to student satisfaction with social, teaching, and cognitive presence; (5) not one specific presence emerged as more satisfying than the others for students; (6) demographics did not have a significant effect on student satisfaction with social, teaching, and cognitive presence; (7) students indicated a strong positive correlation between student satisfaction with the use of asynchronous communication tools and student satisfaction with social, teaching, and cognitive presence; and (8) students indicated a higher satisfaction with the use of e-mail and discussions when they had taken three or more online courses. Recommendations for practice and future research are included. 


\section{Acknowledgments}

Making it to this point in the dissertation process is very rewarding. It is a long and daunting process to obtain a doctorate degree. Understandably so. I am blessed to have received much support in my journey. First, I want to thank my family.

Todd, my beloved husband, is probably ready to get to know his wife without the stress of doctorate assignments. During the dissertation process (especially through five different chairs of my committee), I felt like giving up a few times. He always encouraged me - despite my sometimes cranky, tired and overworked attitude. I am so thankful to have that support in my life. My children, Creed, Heath and Ruger, also deserve appreciation for all the times they had to give mommy a few minutes of quiet or eat somewhere else because the dining room table was covered with papers. Also to the rest of my family and to my students and friends for always supporting me and encouraging me to keep going, like the actual kick in the butt from my step-mother during a lull in a Chapter 4 revision.

I also appreciate the efforts of my committee members - Chair Dr. Helen Hazi, and members Dr. John Oughton, Dr. Ugur Kale, Dr. Nathan Sorber, and Dr. Patricia Gaston, as well as former members Dr. Andrea Weber, Dr. Richard Walls, and Dr. Ernest Goeres. Summer meetings with Dr. Hazi and Dr. Oughton to gain direction quickly developed into a topic and a plan. It is with utmost gratitude that I offer my thanks to these individuals, especially Dr. Hazi, for countless hours of assistance and guidance during this arduous process.

I also am thankful to God for giving me the ability to complete this task, allowing me to remain sane during the process, and surrounding me with such wonderful people. 


\section{Table of Contents}

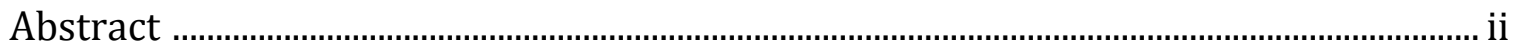

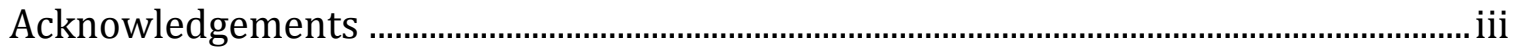

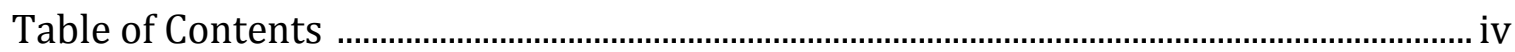

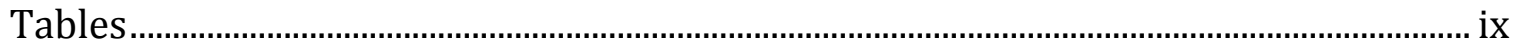

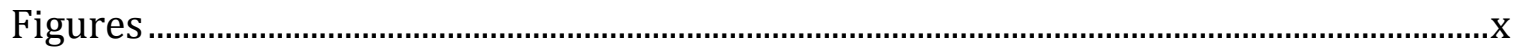

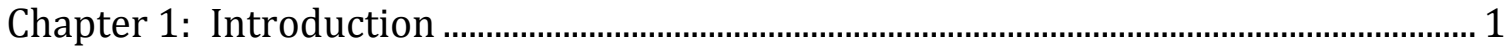

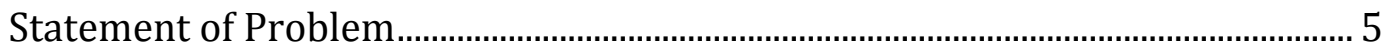

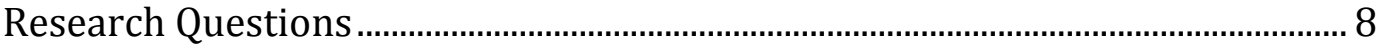

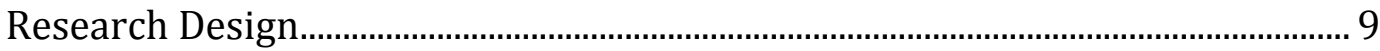

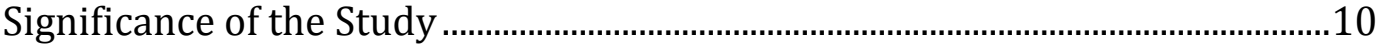

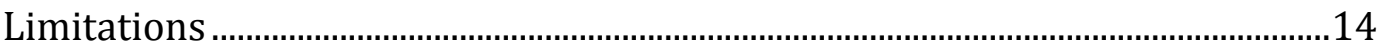

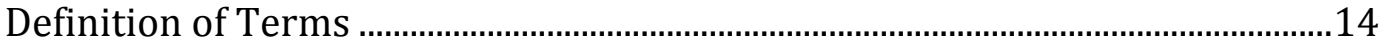

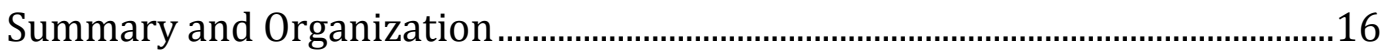

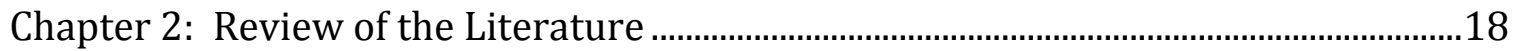

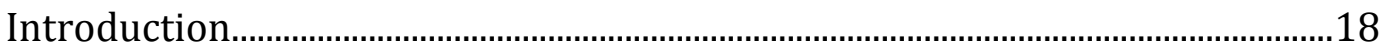

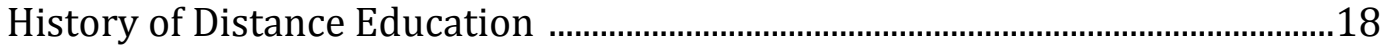

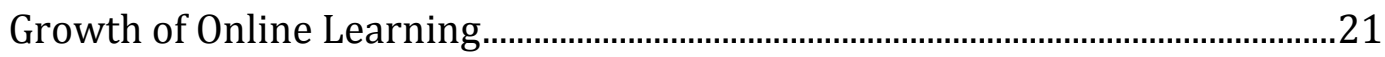

Advantages/Disadvantages of Online Learning........................................................27

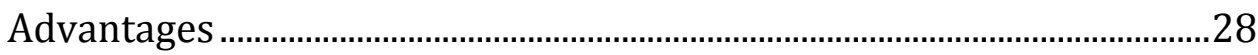

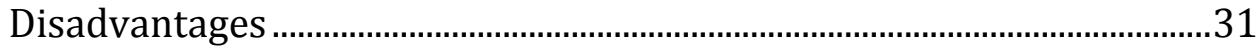

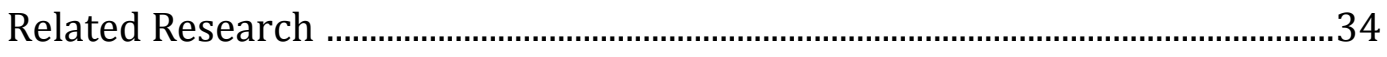

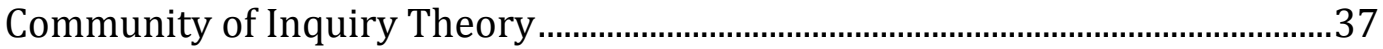


The CoI Model .37

Asynchronous Communication Tools ……...........................................................43

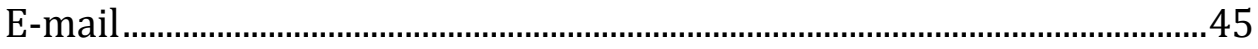

Discussion boards/forums .......................................................................4 49

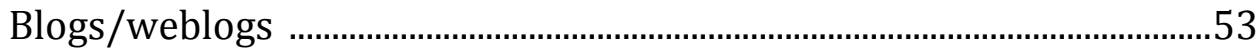

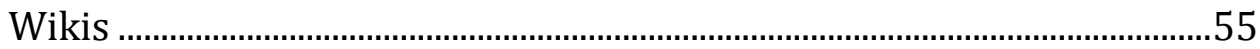

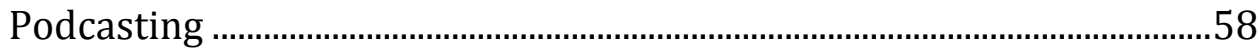

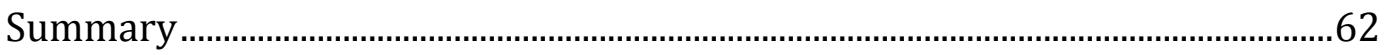

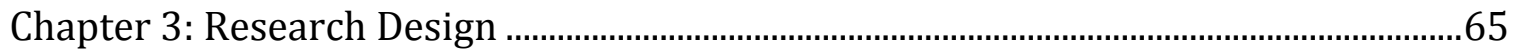

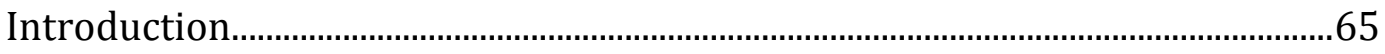

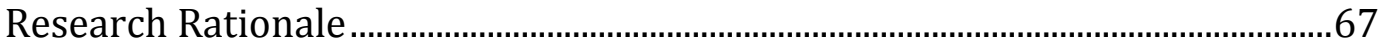

Research Theoretic ..................................................................................67

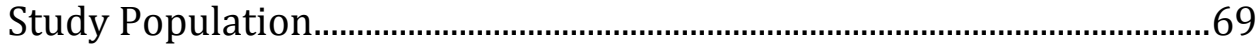

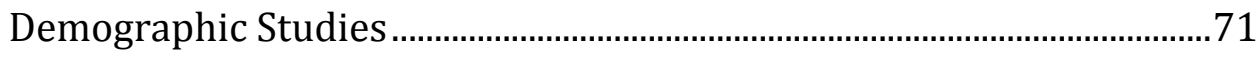

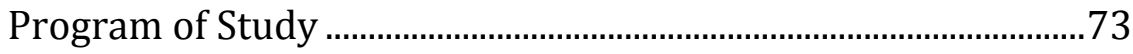

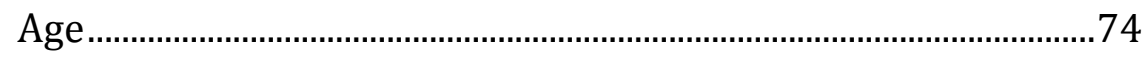

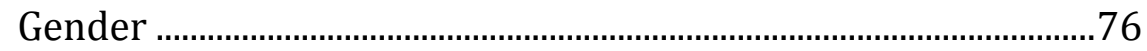

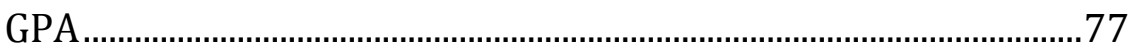

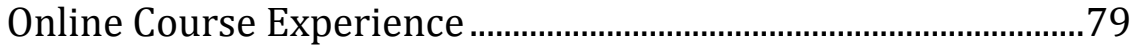

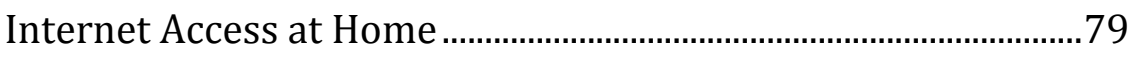

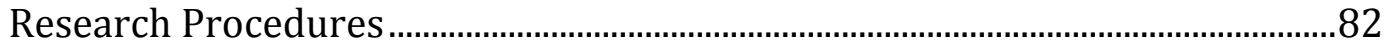

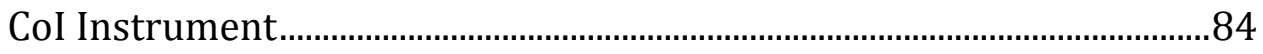

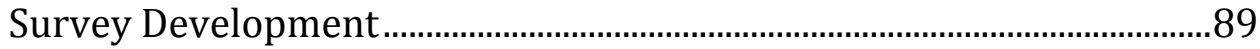


Validity and Reliability in this Study ........................................................90

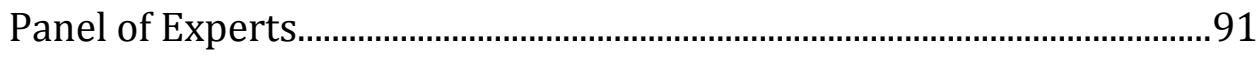

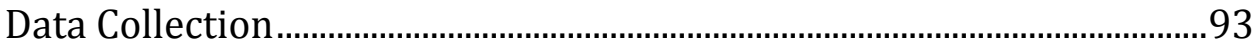

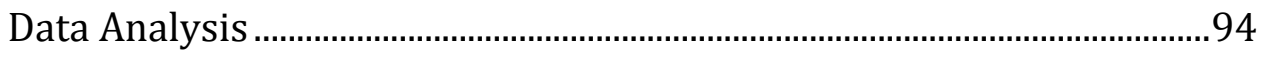

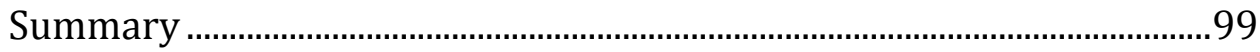

Chapter 4: Data Analysis and Interpretation .................................................................103

Introduction .......................................................................................................

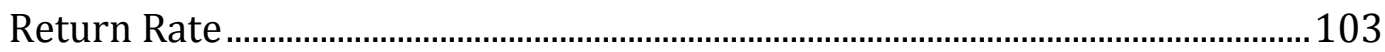

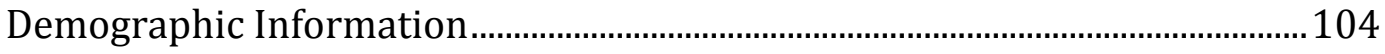

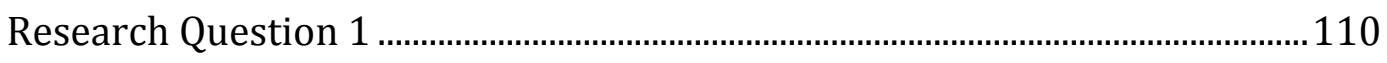

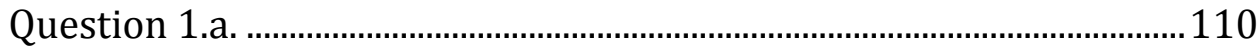

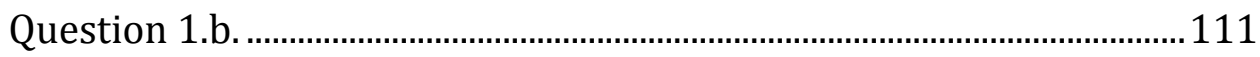

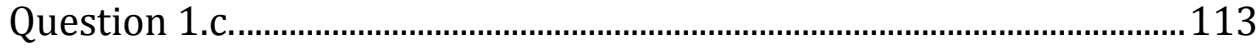

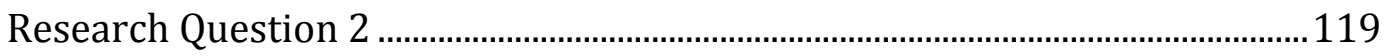

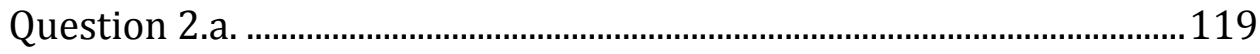

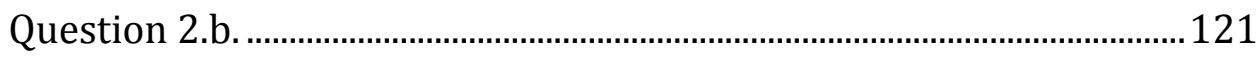

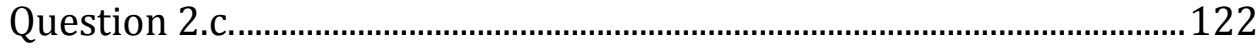

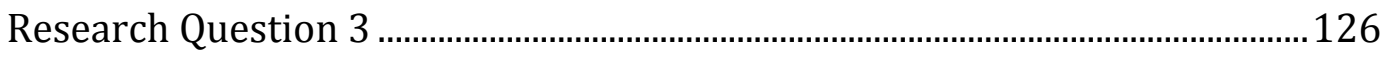

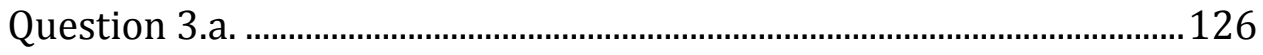

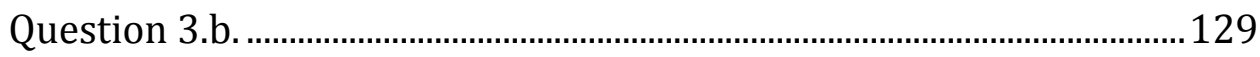

Summary of Findings

Chapter 5: Summary, Conclusions, Discussion, and Recommendations ......................135

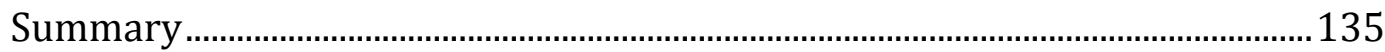


Conclusions.

Research Question 1.a. .............................................................................. 137

Research Question 1.b................................................................................. 137

Research Question 1.c...........................................................................138

Research Question 2.a..........................................................................138

Research Question 2.b...........................................................................138

Research Question 2.c..............................................................................139

Research Question 3.a...........................................................................139

Research Question 3.b..........................................................................139

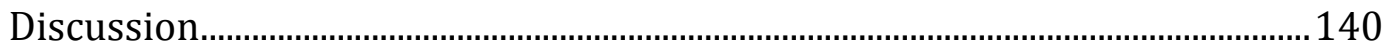

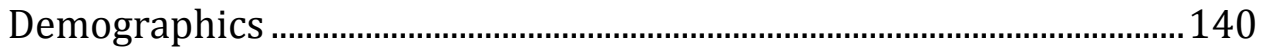

Community College Student Perceptions of Satisfaction with the use of Asynchronous Communication Tools........................................................141

Community College Student Perceptions of Satisfaction with

Social, Teaching, and Cognitive Presence ...............................................144

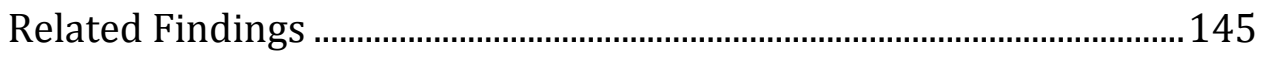

Recommendations for Practice ................................................................................ 146

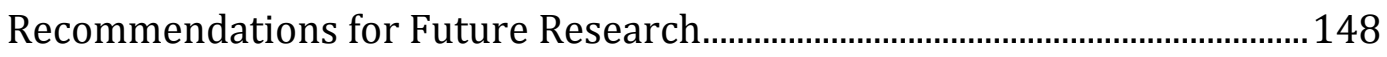

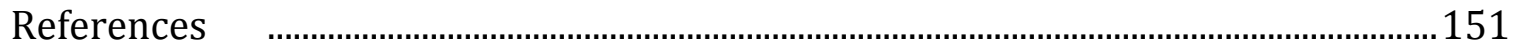

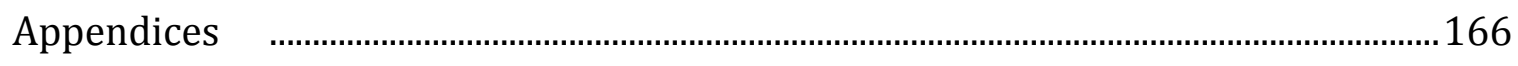

A - Community of Inquiry Survey Instrument ……............................................ 166

B - Asynchronous Communication Questionnaire............................................170

C - E-mail requesting permission to use CoI survey instrument.....................175 
D - E-mail granting permission to use CoI survey instrument

E - Invitation to Panel Experts to Participate in Survey Review

F - Draft Copy of Survey.

G - Panel of Experts Response Form 186

$\mathrm{H}$ - Letter to Survey Participants

I - Frequency of Responses to ACQ

J - Repeated Measures ANOVA, Post-Hoc Results for ACQ

K - Independent T-Test Results Comparing Tools with Demographics ........199

L - Single-Factor ANOVA Results for GPA, Internet Access ...............................205

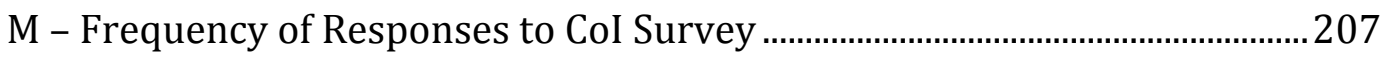

N - Repeated Measures ANOVA, Post-Hoc Results for CoI Survey...................210

O - Independent T-Test Results Comparing Presences w/Demographics ... 212

P - Single-Factor ANOVA Results for GPA, Internet Access................................216 


\section{Tables}

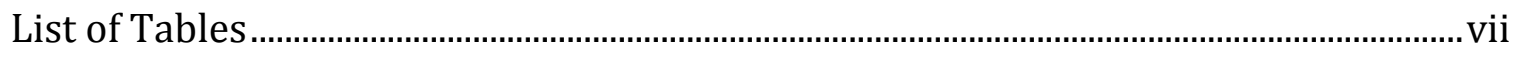

1. Asynchronous Communication Tools and Corresponding Studies ......................44

2. Online Courses Offered and Student Enrollment Per Term ..................................70

3. Demographic Variables and Corresponding Studies ..............................................72

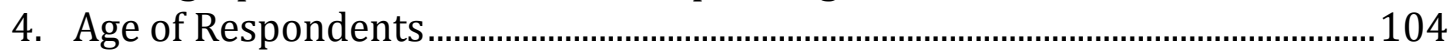

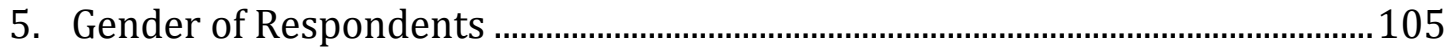

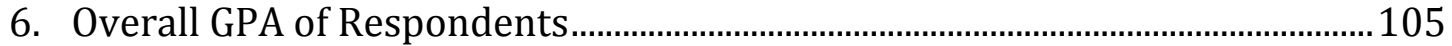

7. Online Course Experience of Respondents ..............................................................106

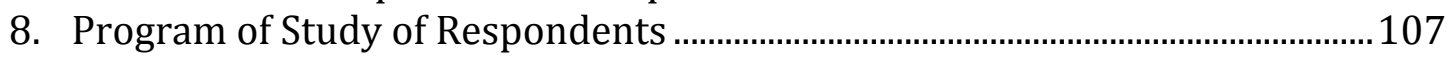

9. Type of Internet Access of Respondents at their Homes ....................................110

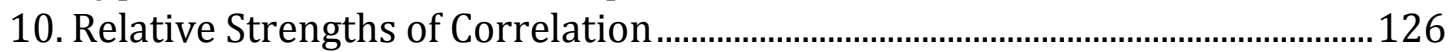

11. Correlations of Asynchronous Communication Tools

With Varying Presences............................................................................. 127 


\section{Figures}

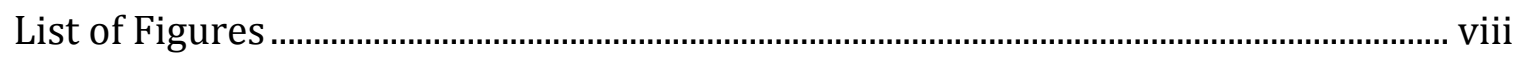

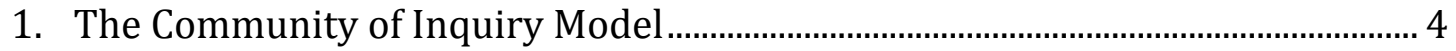




\section{Chapter 1 \\ Introduction}

The Internet is becoming a commonplace medium for instructional content in community colleges. The most recent Pearson Foundation Community College Student Survey cited online courses as a standard learning technique for many community college students. Online learning is prevalent in today's higher education systems. More than 7.1 million students took at least one online course during the Fall 2012 term, an increase of 411,757 students over the previous year. Thirty-three percent of higher education students now take at least one course online, an all-time high (Allen \& Seaman, 2014). Some universities and community colleges are built on web-based courses alone. OnlineCommunityColleges.org began in 2012 to help students discover online programs at community colleges by providing a marketing outlet for member colleges, according to Community College Times.

Even before the marketing plan began, community colleges were experiencing growth with online learning. In the most recent Pearson Foundation Community College Student Survey (2011), six in 10 community college students (57\%) had taken college classes online. In the Fall 2011 semester, nearly one-half of the respondents were presently taking an online course. Two out of five students (39\%) agreed they would like to take all of their courses online, and some do. In the Fall 2011 semester, 13\% of the community college students surveyed were taking all of their courses online.

Online courses become appealing to community college students as they provide accessibility to a student population where $80 \%$ of the full-time students are employed, and $87 \%$ of the part-time students are employed. The American Association of Community Colleges (AACC) touts a reputation of its 1,132 member colleges that is built on that ideal of 
accessibility, coupled with affordability, and diversity of programs and services. Part of the accessibility and diversity at community colleges is the offering of online courses to students whose work schedules present a need for more flexibility in the classroom. More community colleges are now offering full academic programs online, instead of just freestanding courses. As a result, students at $41 \%$ of public community colleges can earn a degree completely online (AACC, 2013). The AACC reports online enrollment increases with each new survey, and growth is predicted to continue.

For community college presidents, student demand is the number one reason for increasing online offerings (Green, 2010a). Online programs offer opportunities for community college students who, studies show, have other responsibilities. The classes allow for access to course material any time and anywhere, providing opportunities that some community college students otherwise would not be able to attempt. Other advantages include: the determination of time and place of learning by the student, completion of coursework at places other than a college setting, flexible scheduling, access to global resources and experts, and the ability to track progress (Burgess, 2003; Hampton, 2010; Morris, 2010; Slevin, 2008).

While online classes offer a number of benefits to students, drawbacks of online education also exist. Some of the most commonly expressed disadvantages throughout many varying studies include little or no in-person contact and feelings of isolation (Aragon \& Johnson, 2008; Bradley, 2009; Burgess, 2003; Keller \& Cernerud, 2002). Because participants in an online classroom are not physically present together, they rely on communication tools to allow for interaction and collaboration. Several studies focus on the examination of interaction in the form of social presence, teaching presence, and 
cognitive presence in the online classroom (Garrison, Anderson, \& Archer, 2001; Garrison, Cleveland-Innes, \& Fung, 2010; Shea \& Bidjerano, 2009; Swan, 2001; Tabar-Gaul, 2008). These researchers believe the essential feature of online learning extends beyond access to information. It should build on the communicative and interactive features in the online classroom. Thus, quality online classes should create a learning community (Garrison \& Anderson, 2003).

Garrison and Anderson suggested an online classroom based on the idea of a community of learners as they developed the widely accepted Community of Inquiry model. The CoI model provides a comprehensive theoretical framework to inform both research on online learning and the practice of online instruction. It assumes that student satisfaction with online learning requires the development of a community that supports meaningful inquiry and deep learning. The CoI theoretical framework represents a process of creating a deep and meaningful learning experience through the development of three interdependent elements: social presence, cognitive presence, and teaching presence, as shown in Figure 1. 
Figure 1. The Community of Inquiry Model

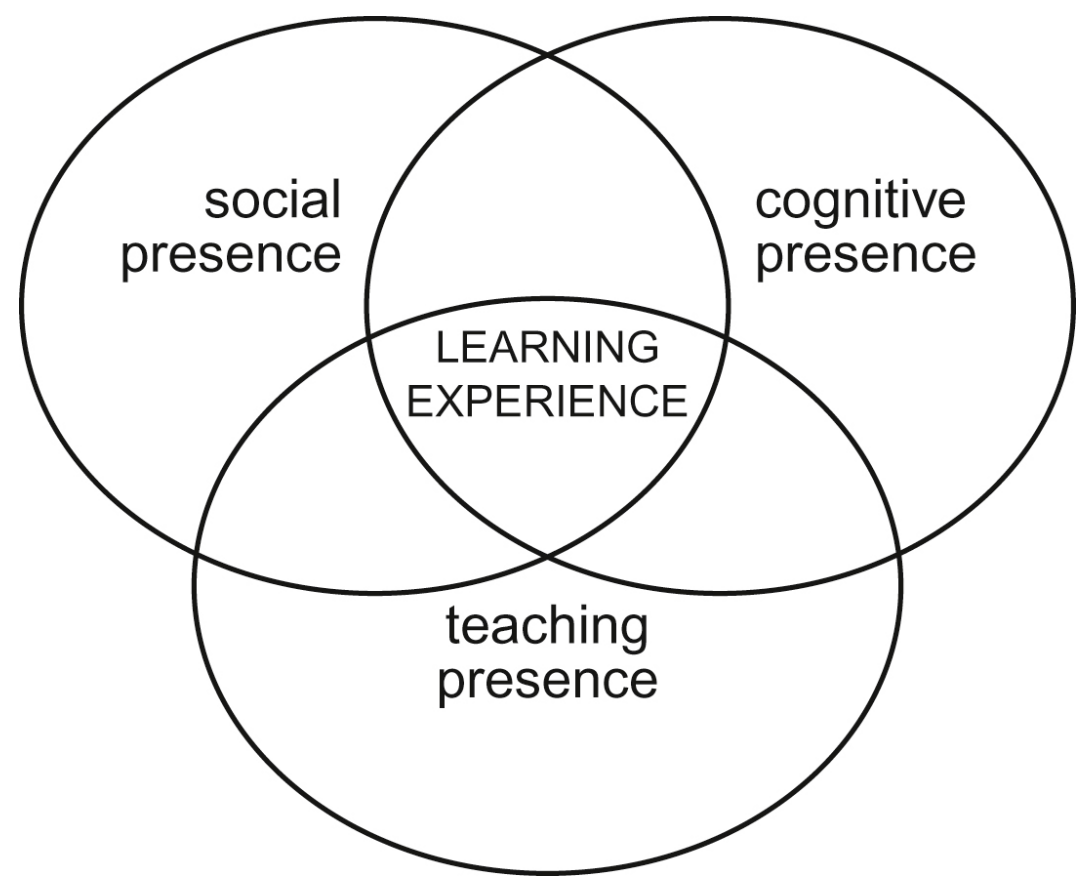

Figure 1. Adapted from Garrison, D.R., Anderson, T.R., \& Archer, W. (2000). Critical inquiry in a text-based environment: Computer conferencing in higher education. The Internet and Higher Education, 2(2-3), 87105. Used with permission of the author.

Social presence refers to the degree to which learners feel socially and emotionally connected with others in an online environment. Cognitive presence is the extent to which learners are able to construct and confirm meaning through sustained reflection and discourse in a critical community of inquiry. Teaching presence brings all the elements of a community of inquiry together in a balanced and functional learning experience congruent with the intended outcomes of design and facilitation with the needs and capabilities of the learners. As the CoI model proposes, and the research demonstrates, an undeniable relationship exists between social, cognitive, and teaching presence.

In examining research on the CoI framework, the occurrence of these elements of the CoI model in an online course appears to predict learner satisfaction in online education, thus contributing to learner success in asynchronous online courses. This 
relationship is evidenced in multiple studies of community colleges. It also presents a need for online course instructors to use multiple tools to communicate with students and meet their varying needs. To better assist in examining the occurrence of the presences in courses, researchers created a survey known as the Community of Inquiry (CoI) instrument (Arbaugh et al., 2008; see Appendix A). Since the instrument's validation in 2008, community college researchers have utilized it multiple times in conducting studies on social, teaching, and cognitive presence (Capra, 2012; Hampton, 2010; McWhorter, 2013; Morris, 2010).

Emerging web technologies in the form of asynchronous communication tools are being utilized in online classrooms for a variety of reasons, one of which is to improve communication and student satisfaction in online courses. As a component of social and teaching presence in the Community of Inquiry model proposed by Garrison and Anderson (2003), these tools emerge as essential elements of online classroom communication between instructors and students. A gap exists, though, in discovering which asynchronous communication tools enable teaching presence, along with social and cognitive presence, to become more apparent to students. This study proposed looking at the use of five tools (email, discussion boards or forums, blogs/web logs, wikis, and podcasting) in online classrooms to examine their impact on student perceptions of satisfaction with social, teaching, and cognitive presence at a community college.

\section{Statement of Problem}

Several researchers have studied the elements of presence in an online class by looking at one particular tool, such as the discussion board or forum (Hampton, 2010; Jahnke, 2010; Morris, 2010; Parker, 2012). Limited research exists, though, on community 
college student perceptions of online courses involving more than one asynchronous communication tool in relationship to the Community of Inquiry (CoI) framework. The purpose of this study was to determine the relationship between community college student perceptions of satisfaction with asynchronous communication tools and community college student perceptions of satisfaction with social, teaching, and cognitive presence in online courses in a Region V community college. The study also considered which demographics have an effect on satisfaction with asynchronous communication tools in online courses in a Region V community college.

The specific population that was studied is a Region V community college that is accredited to offer baccalaureate degrees. For the spring 2014 semester, enrollment at this community college was 2,946 students, with 1,405 students enrolled in at least one online course (R. Tracy, personal communication, January 21, 2014; J. Starkey, personal communication, January 14,2014 ). This college was one of only 34 public institutions in the country classified as a Baccalaureate/Associate's College by the Carnegie Foundation for the Advancement of Teaching (2013). This classification allowed this community college to offer more than 40 programs of study and, thus, more online offerings to students. It has four completely online degree programs approved by the Higher Learning Commission. It offered online availability for many courses, including general education courses, for a variety of students. This specific community college continues to increase its online offerings.

According to the most recent Request for Institutional Change sent to the Higher Learning Commission (HLC) on behalf of the institution, online learning is a vital element in the community college's vision to be "the regional college of choice as a student-centered, 
accessible learning community, dedicated to excellence in teaching and service" (Tracy, 2008, p. 2). This particular request, which the HLC granted, allowed the community college to offer some degrees completely online. The college administration asked for this educational offering in an effort to make the courses more accessible to regional citizens who live in remote areas and to those who have employment, financial, family, or transportation issues that make it difficult to attend class on campus. "By providing online degrees, economically challenged traditional and adult students will have the opportunity to complete degrees without added transportation expenses and lost work time" (Tracy, 2008, p. 2).

The institution continued to expand its online program offerings, even utilizing that as a benchmarked goal in the current five-year strategic plan. While the college's plans focused on growth of the program, the administration sought measures by which to assess students' perceptions of satisfaction with online courses. More research on online learning was needed at this particular teaching institution. The institution did employ researchers to study the topic. What limited information that was collected by means of student perceptions of satisfaction with online courses was done in end-of-semester evaluations when students who chose to complete the surveys also chose to leave comments in the open-ended section. The comment section sometimes shared pros or cons of online learning since the evaluation, itself, focused on satisfaction with the instructor and course content, not necessarily describing the online course specifically or the tools inside the course. This provided very little satisfactory data to assess the online programs at the institution (J. Starkey, personal communication, October 15, 2013). 
The study population in the Spring 2014 semester was the 1,363 currently enrolled students who were still taking at least one online course at this community college at the time the survey was conducted in mid semester (31.5\% completion rate). These individuals were surveyed because of their participation in online courses and the insight they could share about their perceptions of satisfaction with community college online courses in relation to areas of social, teaching, and cognitive presence, and asynchronous communication tools.

\section{Research Questions}

The study sought to answer the following research questions:

1.a. What are community college student perceptions of satisfaction with the use of asynchronous communication tools in a Region $\mathrm{V}$ community college?

1.b. Are community college students more satisfied with the use of one or more asynchronous communication tools than others in online courses in a Region V community college?

1.c. Which demographics have an effect on satisfaction with asynchronous communication tools in online courses in a Region V community college?

2.a. What are community college student perceptions of satisfaction of social, teaching, and cognitive presence in a Region V community college?

2.b. Are community college students more satisfied with the use of one or more of social, teaching, and cognitive presence in online courses in a Region $\mathrm{V}$ community college?

2.c. Which demographics have an effect on satisfaction with social, teaching, and cognitive presence in online courses in a Region V community college? 
3.a. What is the relationship between community college student perceptions of satisfaction of the use of asynchronous communication tools and community college student perceptions of satisfaction of social, teaching, and cognitive presence?

3.b. How does the relationship between community college student satisfaction with asynchronous communication tools and social, teaching, and cognitive presence vary depending on the different demographics?

\section{Research Design}

Data collected from participants in this study were categorized into three areas: demographic background variables, Community of Inquiry, and asynchronous communication tool usage. Two instruments were used in this research. The Community of Inquiry (CoI) instrument, developed by Arbaugh, Cleveland-Innes, Diaz, Garrison, Ice, Richardson, and Swan (2008), was utilized to measure social, teaching, and cognitive presence in the online classroom environment (see Appendix A). A survey based on the literature review was developed to gather the perceptions of students' satisfaction with the use of asynchronous communication tools in the online classroom. Known as an Asynchronous Communication Questionnaire, the developed survey specifically examined the satisfaction and use of e-mail, discussions or forums, blogs or web logs, wikis, and podcasting. Demographic information regarding student program of study, age, gender, GPA, and prior online experience also was gathered in an Asynchronous Communication Questionnaire (see Appendix B) developed by the researcher.

This study intended to determine the correlation between the use of specific asynchronous communication tools and student perceptions of student satisfaction with 
cognitive, social, and teaching presence. Mean scores and standard deviations were calculated for each of the survey items to determine community college student perceptions of student satisfaction with asynchronous communication tools and the correlating relationship to community college student perceptions of satisfaction of social, teaching, and cognitive presence. The survey instrument utilized a Likert rating scale that enabled respondents to span the spectrum from "strongly disagree" to "strongly agree." The researcher administered tests of frequency and Chi Square to the demographic questions of the Asynchronous Communication Questionnaire.

An analysis of variance (ANOVA) test was used to determine if significant differences in student perceptions of asynchronous communication tools exist. If this ANOVA produced a statistically significant result, a multiple comparisons test was conducted. An analysis of variance (ANOVA) test was used to determine if significant differences in student perceptions of social, teaching, and cognitive presence exist. If this ANOVA produced a statistically significant result, a multiple comparisons test was conducted. Pearson Correlation tests were used to determine whether the outcomes of the CoI variables (social, teaching, or cognitive presence) correlated with student perceptions of the use of asynchronous communication tools (e-mail, discussions or forums, blogs/weblogs, wikis, or podcasting) in the online class. T-independent tests and one-way ANOVA tests were used to assess if specific demographics emerged as significant in the study.

\section{Significance of the Study}

As a commonplace medium for instructional content in community colleges, the use of online courses is prevalent in higher education and is expected to continue to grow. 
While online classes offer a number of benefits to students, drawbacks of online education also exist. Because participants in an online classroom are not physically present together, they rely on communication tools to allow for interaction and collaboration. Much research can be found on the examination of interaction in the form of social, teaching, and cognitive presence in the online classroom (Garrison, Anderson, \& Archer, 2001; Garrison, ClevelandInnes, \& Fung, 2010; Shea \& Bidjerano, 2009; Swan, 2001; Tabar-Gaul, 2008). A gap exists, though, in discovering which asynchronous communication tools enable those presences to become more apparent to community college students.

This study added to research on social, teaching, and cognitive presence and explored student perceptions of student satisfaction with the use of various asynchronous communication tools. This study contributed to the literature in online learning by filling gaps that existed in online learning research in community colleges. A search of the Proquest Dissertations and Theses database using the subject "asynchronous communication tools" and descriptors of "online learning" and "teaching presence" yielded 41 studies published between 2004 and 2013. Of those studies, none contained all three elements. Little attention has been given to the use of multiple tools utilized in an online classroom in reference to the three components of the Community of Inquiry framework. Additional searches using other descriptors identified literature that was relevant and contributed to this study. Studies that focus on the Community of Inquiry framework and were referenced in this research include the works of Garrison, Anderson, and Archer $(2000,2001,2003)$. Research that focused on student satisfaction in online classes included studies by Arbaugh (2001); Jackson, Jones, and Rodriquez (2010); Jones (2012); and Shea, Fredericksen, Pickett, and Pelz (2004). 
One dissertation by Salloum (2011) addressed the use of multiple computermediated communication (CMC) tools. Using descriptive and inferential statistical analyses, Salloum evaluated mean differences for different combinations of CMC tool usage and for possible relationships between tool helpfulness and social or teaching presence. The only tools in common with Salloum's study and this study are email and discussion forums. Salloum's dissertation research was conducted with only seven graduate level teachertraining courses in the disciplines of special and gifted education at one large public university in the Southeastern region of the United States. The narrow scope of research available further presents a gap in research and a need to better understand the relationship between the Community of Inquiry framework and student perceptions of student satisfaction with asynchronous communication tools.

In looking at community college research, varying studies also were prevalent on specific tools, such as e-mail (Aragon \& Johnson, 2008; Arnold, 2005; Lea, 2007; Liu, 2007; Robinson \& Hullinger, 2008; Yang \& Cornelius, 2004), discussion boards or forums (Cvetko, 2002; Hampton, 2010; Hardin, 2004; Illowsky, 2007; Jahnke, 2010; Morris, 2010; Parker, 2012), blogs or web logs (Brownson, 2009; Dickey, 2004; Kerwalla et al., 2008; Perschbach, 2006; Rhode, 2008; Safer et al., 2005), wikis (Brownson, 2009; Cole, 2009; Martin, 2012; Nakamaru, 2012; Soules, 2008; Whitehouse, 2011), and podcasts (Brown \& Green, 2007; Brown et al., 2009; Crawford, 2007; Lombardo, 2011; Parker, 2012; Parson, Reddy, Wood, \& Senior, 2009). Few of these studies, however, examined more than one or two tools, nor do they look at the use of tools in correlation to the CoI model. As previously stated, this study seeks to determine student perceptions of student satisfaction with the use of 
asynchronous communication tools and with the existence of social, teaching, and cognitive presence in online courses in a Region V community college.

Anderson, Rourke, Archer, and Garrison (2001) delineate three critical roles of a teacher in going beyond the role of a facilitator to create effective teaching presence, asserting instructional design is the foremost role of an instructor in developing and presenting an online course that has effective teacher presence. Identifying student satisfaction with the use of asynchronous communication tools in community college online courses can be used to inform online course design that maximizes communication in the community college environment. Identifying student satisfaction of the use of these asynchronous communication tools (e-mail, discussion boards or forums, blogs/web logs, wikis, and podcasting) in correlation to student perceptions of social, teaching, and cognitive presence can be used to aid in the design of online courses that improve communication, and thus satisfaction, of students taking online courses at community colleges.

The results of this study may assist community college instructors who seek to assess student satisfaction in online courses. The results may also help educators better understand best practices of the use of asynchronous communication tools in assisting interaction in an online classroom. Improved understanding of student perceptions of student satisfaction through the lens of social, teaching, and cognitive presence in relation to the availability and use of asynchronous communication tools can help guide future development of online courses and serve as an assessment tool for student satisfaction with online courses. 


\section{Limitations}

This study examined the use of student perceptions of student satisfaction with cognitive, social, and teaching presence at only one community college in Region $\mathrm{V}$ as determined by the AACC. The community college used in this study is unique in that it is a hybrid institution. It is one of only 34 public institutions in the country classified as a Baccalaureate/Associate's College (Carnegie, 2013). Another possible limitation to this proposed study is that student participation in the survey was voluntary; non-responders to the survey may have different characteristics from those of responders.

\section{Definition of Terms}

Asynchronous online course - A class taught using technology tools and offered in an online format, such as a course management system. Instructors and students in the course communicate and collaborate over a period of time through a different time-different place mode.

Blogs/weblogs - a website that contains an online personal journal with reflections, comments and often hyperlinks provided by the writer.

Cognitive presence - "The extent to which learners are able to construct and confirm meaning through sustained reflection and discourse in a critical community of inquiry" (Garrison, Anderson, \& Archer, 2001, p. 11). At the base is critical and reflective thinking. Community college - a college without residential facilities that is often government funded, offering associate degrees from a curriculum fitted to the needs of the community. Community of Inquiry framework - a dynamic process model designed to define, describe, and measure elements supporting the development of online learning 
communities. The three principle elements identified by the CoI model are social presence, cognitive presence, and teaching presence (Swan \& Ice, 2010).

Discussion boards/forums - known by a variety of names such as discussion boards, discussion forums, message boards; a general term for any online bulletin board where one can leave and expect to see responses to messages he or she has left.

E-mail - short for electronic mail, is an electronic message that a user types on a screen and sends to one or more recipients.

Online asynchronous communication tools - communication tools used in an online course that allow students to learn at a different time and in a different place; common examples include email, discussion boards/forums, blogs/weblogs, wikis, and podcasting. These tools allow people to connect together at each person's own convenience and own schedule.

Online course - a course that is completely offered via means of the Internet with no traditional class meetings.

Podcast - a broadcast of audio or video files over the Internet using syndication feeds for playback on mobile devices and personal computers.

Social presence - "The ability of participants in a community of inquiry to project themselves socially and emotionally, as 'real' people (i.e., their full personality), through the medium of communication being used" (Garrison, Anderson, \& Archer, 2000, p. 94). It refers to the degree to which learners feel socially and emotionally connected with others in an online environment.

Student satisfaction - Elliott and Shin (2002) describe student satisfaction as the favorability of a student's subjective evaluation of the various outcomes and experiences 
associated with education. Student satisfaction is being shaped continually by repeated experiences in campus life.

Teaching presence - "The design, facilitation, and direction of cognitive and social processes for the purpose of realizing personally meaningful and educationally worthwhile learning outcomes" (Anderson et al., 2001, p. 5). Teaching presence brings all the elements of a community of inquiry together in a balanced and functional relationship congruent with the intended outcomes and the needs and capabilities of the learners.

Wikis - a web-based tool that allows for many authors to work on projects together with shared editing capabilities of the digital document.

\section{Summary and Organization}

Online courses offer accessibility and diversity for community college students whose work schedules or life commitments present a need for more flexibility in the classroom. As a result, students at $41 \%$ of public community colleges can earn a degree completely online (AACC Fact Sheet, 2013). The classes allow for access to course material any time and anywhere, providing opportunities that some community college students otherwise would not be able to access. While online classes offer some advantages to community college students, drawbacks of online education also exist. Some of the most commonly expressed disadvantages throughout many varying studies include little or no in-person contact and feelings of isolation. Because participants in an online classroom are not physically present together, they rely on communication tools to allow for interaction and collaboration.

Garrison and Anderson (2003) suggested an online classroom based on the idea of a community of learners as they developed the widely accepted Community of Inquiry 
model. The CoI model represents a process of creating a deep and meaningful learning experience through the development of three interdependent elements: social presence, teaching presence, and cognitive presence. These presences in an online course are noted to predict learner satisfaction in online education, thus contributing to learner success in asynchronous online courses. This relationship is evidenced in multiple studies of community colleges. Limited research exists, though, on community college student perceptions of online courses involving more than one asynchronous communication tool in relationship to the CoI framework. The purpose of this study was to determine the relationship between community college student perceptions of satisfaction with asynchronous communication tools and community college student perceptions of satisfaction with social, teaching, and cognitive presence in online courses in a Region V community college.

This introduction is followed by Chapter Two, a literature review of prior research related to the key elements of the current study. Chapter Three describes the research design, population and sampling plan, data collection tools and process, and data analysis methods. Chapter Four presents the results and the key findings of the data analysis with respect to the research questions and hypotheses. Chapter Five includes a discussion and interpretation of results, draws conclusions regarding the research questions, and suggests implications of the study for further research and practice in online learning. 


\section{Chapter 2}

\section{Review of the Literature}

\section{Introduction}

Chapter Two presents a review of relevant research on the Community of Inquiry framework and the use of asynchronous communication tools in online courses at community colleges. This study sought to determine the relationship between community college student perceptions of satisfaction with asynchronous communication tools and community college student perceptions of satisfaction with social, teaching, and cognitive presence in online courses in a Region V community college. Topics included in this chapter are a history of distance education, growth of online learning, advantages and disadvantages of online learning, related research in this study area, and asynchronous communication tools utilized in online courses. As part of the related research, this chapter includes a review of Chickering and Gamson's (1987) Seven Principles of Good Undergraduate Instruction and its relation to the Community of Inquiry theory. Finally, the chapter provides information on research conducted on various asynchronous communication tools and their relationship to student perceptions of satisfaction in online courses.

\section{History of Distance Education}

Current online course offerings via the Internet have evolved from what began as distance education courses. Distance education, synonymous with correspondence or adult education or distance learning, refers to education when an instructor and students are separated by geographic distance or by time, and communication technologies are used to bridge the resulting instructional gap (Moore \& Kearsley, 2005). The purpose of distance 
education is to provide accessibility to students who either cannot attend traditional courses due to occupational, family, or social responsibilities, or are unwilling to attend traditional courses. Through these offerings, college courses are accessed wherever the students are and provide an opportunity for them to pursue degrees without the inconvenience of traveling to campus (Beard \& Harper, 2002). These courses are especially appealing to community college students because they do not reside on campus, are of varying ages, or have scheduling conflicts with work and family responsibilities (Tung, 2007). Today's distance learning courses have changed greatly in their interaction capabilities since the origins of distance learning, namely correspondence courses. Moore and Kearsley (2005) explain the evolution of distance education through five generations: correspondence, broadcast radio and television, open universities, teleconferencing, and the Internet.

The origins of distance education began with the advent of postal delivery in the mid-1880s when Sir Issac Pitman developed the first correspondence course to teach shorthand (Moore \& Kearsley, 2005). Several correspondence courses in many countries followed. In 1892 William Rainey Harper, a professor of Hebrew who is known as the father of correspondence instruction, established an extension division at the University of Chicago to deliver courses by mail. It is noted as the world's first formal distance education program. In a correspondence course, instructors sent readings, study guides, and other printed material to students who completed the assignments and returned them through the mail. In 1915 the creation of the National University Extension Association broadened the focus to the necessity of pedagogical models and national level guidelines for the 
growing number of correspondence courses. Correspondence courses eventually became known as independent study courses.

The first educational radio station began in 1921. The instructional delivery medium became unsuccessful by 1940 when only one college-level credit course was offered and it failed to attract enrollments (Nasseh, 1997). It did, however, become a harbinger for educational television. In the early 1950s correspondence study struggled to gain acceptance and was seen as suspect by academics (Moore \& Kearsley, 2005). The Ford Foundation began to play a role in developing support of studies in correspondence education. In 1956 research by Gale Childs on the application of television instruction, in combination with correspondence study, found that television instruction was not a method. Instead, television was an instrument by which instruction could be transmitted from one place to another (Childs, 1971).

Open universities were the next generation of distance education, taking shape in the 1960s and 1970s. In an open university, teaching is mainly conducted by means of broadcasting, correspondence, or summer school. The first was Britain's Open University, which remains as a leader in large-scale application of technology to facilitate distance learning. The first open university in the United States was New York State's Empire State College, which commenced in 1971. One of the main purposes of the university in New York was to make higher education degrees more accessible to learners unable to attend campus-based, traditional programs.

In the 1980s teleconferencing emerged as the primary technology for distance education. The application of audio and video conferencing changed the mode of instructor-student interaction, allowing for synchronous communication to occur. The 
Internet became the common delivery medium in the 1990s via use of computers. With many opportunities for interaction between the instructor and the student, the growth of online courses, online programs, and even online colleges began rapidly. Online universities such as University of Phoenix originated with virtual education in 1980, followed by the presentation of online curriculum through CALCampus founded in 1982.

On a community college level, Foothill College in California became one of the first community colleges to offer online classes in the early 1990s. Foothill later developed a course management system for online degree programs, and then adopted an open course platform for an online teaching environment. In 1996 the Michigan Community College Association began a project known as the Michigan Community College Virtual Learning Collaborative. It allowed Michigan community college students to take online courses from any member colleges, providing expanded opportunities to access online courses. A year later in 1997 Kansas City Kansas Community College offered its first online courses. Community colleges across the nation soon began to follow suit.

\section{Growth of Online Learning}

Online learning is ubiquitous in today's higher education systems. In this section, the growth of online learning will be examined with statistics illustrating the growth of online learning, reasons why community colleges find online courses to be useful for students, support mechanisms community colleges have established for online growth, reasons why online courses are growing in community colleges specifically, and predictions for future online learning growth in community colleges.

Statistics illustrate the growth of online learning. What began with just a few courses at a few colleges is now immense. More than 7.1 million students were taking at 
least one online course during the Fall 2012 term, an increase of 411,757 students over the previous year. Thirty-three percent of higher education students now take at least one course online, an all-time high (Allen \& Seaman, 2014). Some universities are built on webbased courses alone, but those that were established for traditional courses are placing more emphasis on the online component. Studies tracking community colleges specifically report significant growth in both online courses and programs in that sector as well.

The reasons why community colleges find online courses to be useful for students begin with the community college mission. Community colleges are founded with a broad mission to provide access to postsecondary educational programs and services that lead to stronger, more vital communities. That mission is shaped by specific commitments: 1) serve all segments of society through an open-access admissions policy that offers equal and fair treatment to all students, 2) provide a comprehensive educational program, 3) serve the community as a community-based institution of higher education, 4) teach and learn, and 5) foster lifelong learning (Vaughan, 2000).

As a service of its mission, a typical community college offers three levels of education: associate degrees, certifications, and continued education. Associate degrees can be obtained for a career goal or as a transfer degree to a four-year college. Certifications, founded in vocational training, are in career-training paths and take less time to complete. The continued education programs offer updated knowledge and enhanced skills for adult learners. In all three levels of community college education, online course options are utilized to meet the demands and mission of community colleges. An option for online courses increases the accessibility of courses to students. Community 
college students often choose that option of online learning due to the demands of work and family (NCES, 2011).

In an examination of higher education, Trow (2010) describes community colleges as "relatively inexpensive, open access, full of mostly part-time, older students who have full- or part-time jobs; they are heavily vocational, and yet offer academic courses at both the advanced secondary and postsecondary levels" (p. 262). Trow (2010) notes that these types of colleges in the United States, these community colleges, are very much a part of high education:

They are included in its statistics of enrollment, and in its calculations of cost and expenditure. And they are linked in everyone's minds as part of a common if differentiated enterprise, and, most important, are so linked in the minds of politicians, civil servants, and laymen when broad plans for the reform or expansion of higher education are being discussed. (p. 263)

And these institutions have experienced great change throughout the years. Brint and Karabel (1989) describe the history of community colleges (originally junior colleges) as moving rapidly "from a position of marginality to one of prominence" (p. 23). From 1919 to 1939 , growth in these institutions rose from 8,102 students to 149,854 , Brint and Karabel noted from U.S. Office of Education statistics. "Thus, on the eve of World War II, an institution whose very survival had been in question just three decades earlier had become a key component of America's system of higher education" (p. 23). As decades progressed, so did the growth of the junior college. After World War II, many students had a desire to move beyond working and lower-middle class origins. Community colleges became a steppingstone to four-year colleges and universities and to the professional and managerial 
jobs that graduates of such institutions traditionally obtained. Brint and Karabel cite in 1946 that $17 \%$ of students entered higher education through a junior or community college. It was more than $40 \%$ by 1970 (p. 101).

One part of the original vision of the founders of the junior college movement had thus become a reality in the two and one-half decades after World War II: the twoyear college had spread to virtually every state in the union and, in so doing, had become an integral part of the system of higher education. (Brint \& Karabel, 1989, p. 101)

In the 1970s and 1980s, the transformation continued for community colleges as the traditional function of providing transfer programs took a back seat to an identity and curricular offerings began to revolve around occupational training. Brint and Karabel note in 1980 that $40 \%$ of undergraduates in higher education were found in community colleges, and more than half of all students entering higher education for the first time did so in a two-year institution rather than a four-year institution. "More than ever before, the American dream of upward mobility through education depended on the fate of the millions of students in the nation's community colleges" (Brint \& Karabel, 1989, p. 103). As Cohen noted in his examination of higher education's shaping, community colleges had an impact in changing not only education, but also society. As students found reduced barriers for individual advancement through education, this:

Tended to assist in creating a more just society because when individuals have equal opportunities to gain access to various avenues of employment and to participate more fully in the polity, the background from which they sprang becomes a weaker influence. (Cohen, 1998, p. 279) 
These changes, however, were not without growing pains. Burton Clark refers to many of these conditions as part of the "cooling-out" function of higher education. Clark discusses issues such as open-door admissions, the ideology of equal opportunity, the ethical and practical urges that encourage high school graduates to believe that college is a necessity and a right, the desire of elected officials for high admission numbers at community colleges, reorienting students who cannot excel in traditional coursework, and the accompanying retention issues of an open-admission policy. "The conflict between open-door admissions and performance of high quality often means a wide discrepancy between the hopes of entering students and the means of their realization" (Clark, 1960, p. 571). Junior or community colleges do not highlight a cooling-out process. It is instead routed through options like pre-entrance testing which leads some students directly into remedial coursework or an orientation to college course where counseling is available to students. Sometimes those students do excel and as Clark noted, "It is indeed a function of the open door to let hidden talent be uncovered" (p. 576).

Community colleges collaboratively use support mechanisms such as national organizations and committees for purposes of research and for advocating and sharing in areas of retention, course completion, development education, vocational resources, and other community-college specific challenges. The same is true for educational technologies and tools. Early support mechanisms for technologies and tools began in 1977 when a committee of the board of directors of the American Association of Community and Junior Colleges (now the American Association of Community Colleges, AACC) created the Task Force on the Uses of Mass Media for Learning. In 1993 the renamed Instructional Technology Council (ITC) became its own separate non-profit 501(c)(3) organization. ITC 
is an affiliated council of the AACC and represents nearly 400 institutions that offer distance education courses to their students in the United States, Canada, and around the world. The common theme for the ITC is growth of online courses. ITC reported a $22 \%$ online enrollment increase during Fall 2009 over the previous year (Mullins, 2013).

The reasons why online courses are growing in community colleges specifically focus on student demand. In a survey of community college presidents, Kenneth Green, founding director of The Campus Computing Project, confirmed that the primary catalyst for expanding online programs is student interest, not other options such as efforts to reduce instructional costs (Green, 2010a). The survey by The Campus Computing Project (Green, 2010b) was provided to community college presidents and district chancellors. The focus of the survey was enrollments and budgets. Community college presidents reported that budget cuts and hiring freezes cast a shadow over programs and services. However, the findings show that enrollment in community colleges continues to increase. In this survey, $91 \%$ of the 128 responding presidents and district chancellors reported that their campuses were offering more online classes in response to student interest and demand. Green determined from these survey results that community colleges would benefit from a strategy for online expansion, especially in terms of expectations of continued budget cuts. As Green summarized after the 2010 survey, the most significant of the strategies to cope with the changing environment of community college education is in increasing the number of online course offerings and expanding online programs.

The predictions for future online learning growth in community colleges coincide with Green's suggestions. Growth is predicted to continue, with a 9.3\% increase in online enrollments from 2010 to 2011, according to the Babson Survey Research Group's annual 
Survey of Online Learning. The survey results, which are the most recent available, show that while college enrollments are flattening with incremental improvements to the job market, online enrollments show no plateau. "While the growth rate fell to its lowest level in at least a decade, the survey shows that enrollment in distance courses and programs continues to be more than healthy" (Lederman, 2013, np). The survey actually discovered that online enrollments continue to make up an increasing proportion of all enrollments in higher education.

The Pearson Foundation Community College Student Survey supports Lederman's (2013) claim on a community college level as well. More than 7 in 10 public and for-profit colleges are now offering full academic programs online, instead of just freestanding courses. Nearly one-half of private nonprofit colleges are offering fully online courses, double the number doing so in 2002, which shows significant growth in just over a decade. Six in 10 community college students have taken college courses online, with $46 \%$ taking at least one course online in the Fall 2011 semester, according to the most recently available results of the Pearson Foundation Community College Student Survey (Pearson Foundation \& Harris Interactive, 2011). Thirty-nine percent of the students in that survey would actually like to take all of their courses online, with $13 \%$ of them already doing so.

\section{Advantages/Disadvantages of Online Learning}

With the growth of online learning, specific advantages and disadvantages of online classes emerge. In this section, the researcher will discuss both advantages and disadvantages of online learning for community college students. It is necessary to examine these pros and cons of online learning when considering the role of asynchronous 
communication tools and the role of social, teaching, and cognitive presence in influencing student perceptions of student satisfaction with the online community college classroom.

Advantages. Online programs offer opportunities for community college students who have other responsibilities. The classes allow for access to course material any time and anywhere, providing opportunities that some community college students otherwise would not be able to access. The advantages that will be discussed in this section include: the determination of time and place of learning by the student, greater control of the learning process, access to global resources, and the ability to track progress.

Community college students need the flexibility to determine time and place of learning because many are nontraditional students, those aged 25 and older. The reality for community college students is that they need to work: $84 \%$ of community college students work, and 60\% work more than 20 hours a week (NCES, 2011). Age becomes a critical factor to consider in community college research. The average age of a community college student is 29 (AACC, 2013). That falls into the non-traditional age category. Community colleges historically and today provide access to education for nontraditional students, such as adults who are working while enrolled. In the 2011-2012 academic year, approximately 3.3 million community college students were enrolled full-time, and approximately 4.8 million community college students were enrolled part-time (AACC, 2013). Many enroll with just a few courses because of other responsibilities in their lives. A president of Ivy Tech Community College explained the benefits of online learning for this group of students:

I strongly believe that the future of higher education lies with online learning. Increasingly, college and university students now find themselves with obligations 
beyond that of getting a degree. Jobs and family commitments make equal demands on their time. Having the option of taking online classes and studying on their own time is critically important. (Snyder, 2013, np)

His comments support the determination of time and place of learning by the student as an advantage of online learning. Others agree. "In many ways distance education makes education accessible and available to many people. In this manner, it is particularly well suited to the mission of community colleges" (Pecorino, 2004, np). Similarly, Frederick Community College (FCC) in Maryland highlights this advantage to online learning with the claim: "You can take distance education courses from your home or office using the Internet, cable TV, and other technologies. The advantage of distance learning is that it enables you to learn when it's convenient for you" (frederick.edu, np).

Greater control of the learning process is an advantage of online learning for community college students because it allows the student flexibility in learning. This advantage is highlighted in an online news article on the pros and cons of online learning:

As an online student, you have greater control over your learning experience. You can take courses from home or complete work in another quiet place, such as the library. Adult students enjoy the ability to complete coursework on their schedule to accommodate work and family responsibilities. You can also work at your own pace, as long as you complete projects, assignments and tests by the prescribed due dates. You also do not need to worry about showing up to class at a specific time each day. (Kokemuller, 2013a, np) 
Jaggars (2013) expressed similar sentiments in a review of research on online learning in community colleges in the last decade. "In particular, the flexibility of online coursework is a boon for students balancing work, family, and school responsibilities; and such students may create a loud clamor for the expansion of online learning options" (pp. 595-596).

Access to global resources is an advantage of online learning for community college students because online courses appeal to a more global market than traditional classes. Students enrolling in an online course are not limited by geographical distance to an institution. In a completely online program, students may never even go to the campus. They can live anywhere and still take the classes. The same is true of instructors. Community colleges can hire experts to teach a course regardless of where the instructor might reside. Thus, students can interact with classmates and instructors from a much broader region, possibly even from other countries.

The ability to track progress is an advantage of online learning for community college students because it keeps students well informed of their status in a course. As grades are posted in most course management systems, the grades are automatically sent to the students. This potential for a quick turnaround of grades after assignments are turned in could lead to more clarity in instruction. If a student receives quick feedback in the form of a grade on one assignment, it can assist him or her in completing the next assignment. Many systems also have tracking features. Newer course management systems, such as OpenClass from Pearson Publishing, include learner analytics - a section of the course where students can obtain data about their current grade in the course, the 
type of grade needed on the next assignment to reach their intended course grade, and more.

Disadvantages. While online classes offer a number of benefits to students, drawbacks of online education also exist. Some commonly expressed disadvantages that the researcher will discuss include: little or no in-person contact and feelings of isolation, problems with technology, and the need for a student to be actively involved in learning. In addition, students need to be self-regulated. The presence of these factors in an online course lead to reduced student satisfaction, which can lead to even greater problems such as completion or retention issues. The Community College Research Center (CCRC) at Columbia University's Teachers College provides multiple studies that evidence concern over lower completion rates for online students (Xu \& Jaggars, 2013). This work prompted another CCRC study by Bork and Rucks-Ahidiana (2013) on the misalignment between instructor and student expectations regarding each other's roles and associated behaviors in online courses. "While being an online instructor or student is similar in many ways to those same roles in a face-to-face course, the asynchronous nature of the interaction and pedagogy in online courses exacerbates the challenge of identifying and resolving misaligned expectations" (p. 1).

Little or no in-person contact is a disadvantage of online learning for community college students because it leads to the feelings of isolation some students experience in this educational medium. For that reason, limited social interaction is often listed as a disadvantage in online education. "While online students often engage peers in online discussions and interact with teachers via e-mail, this doesn't replicate the face-to-face experiences in a traditional classroom. The informal social interactions with peers before 
and after classes helps instill a sense of community and belonging" (Kokemuller, 2013b, np). In research conducted by Aragon and Johnson (2008) and by Bradley (2009), the findings revealed a need for interaction in the online classroom. Aragon and Johnson found that one of the main reasons for non-completion of a course was a problem with communication that led to those feelings of isolation. Students who did not feel involved with the course found it very easy to quit the course.

Problems with technology are a disadvantage of online learning for community college students because they make a student feel unprepared. Problems with technology and a learning curve in how to utilize the system have similar qualities in the area of technological preparedness. Bork and Rucks-Ahidiana (2013) call expectations about the level of technological skills that students should possess prior to enrolling in an online course an "area of stakeholder disagreement" (p. 9). In short, in their interviews of both instructors and students, they discovered that students felt as though they were prepared, but instructors felt that students were not prepared for online learning. Instructors noted a need for more technological proficiency. As one respondent to their survey said, "It surprises me that sometimes students just don't know how to copy and paste and do some of the basic, basic stuff" (p. 9). Others expressed concern about the need for some students to enroll in online courses and then ask for step-by-step directions on common tasks such as attaching files. “And some of them ... don't know how to put page numbers on the paper. And it's like 'Should you really be in an online class if you can't get the page numbers to go in?'” (p. 10).

Problems with technology are also a disadvantage of online learning for community college students in the area of technical difficulties. Technical problems are defined in 
Jaggars recent summary of online learning in community colleges as: "both unavoidable system-based problems and difficulties caused by the user's lack of familiarity with the system" (Jaggars, 2013, p. 602). In reviewing the research of others in the area of online learning at community colleges, Jaggars notes that a predominant reason for student withdrawal from an online course can be technical problems, computer-based learning issues, or other factors explicitly related to the online nature of a course. "To the extent that student technical difficulties spring from outdated at-home technology, they can also have an impact on the pedagogical quality of the course" (p. 602). Students who still utilize dialup Internet services, for example, often note technical difficulties in online courses as even minor tasks become tedious due to slow upload and download speeds.

The need for a student to be actively involved in learning is a disadvantage of online learning for community college students because some students are not prepared for this type of learning. Slevin (2008) called online learning a "process by which learners are encouraged to be responsible, autonomous and critical, and go beyond any information that they are given" (p. 119). In online learning, a need exists for students to be actively involved. "You must have discipline to schedule and complete your own work" (Kokemuller, 2013a, np). Online class work can be more challenging without a set time and place to acquire the information and complete assignments. A student must take an active role and responsibility in his/her own educational success.

Self-disciplined students can benefit from the flexibility and convenience of online classes, but the lack of formal structure can be a pitfall for undisciplined or unmotivated students. You don't have a standard meeting time, and you don't have a regular, direct interaction with teachers and peers who can remind you of 
assignments and push you to work harder. Online students who lack self-discipline can fall behind on assignments, fail to study adequately by test deadlines, and ultimately suffer because of a lack of initiative in engaging instructors via e-mail or phone. (Kokemuller, 2013b, np)

Jaggars (2013) also noted that in an overview of research of online learning at community colleges that most courses are asynchronous, allowing students to access course materials and work on assignments at times that are convenient to the student. "While this flexibility is a boon to some students, the relative lack of structure in online courses may lead others to get lost, procrastinate, or fall behind on assignments" (p. 601).

\section{Related Research}

The disadvantages of online learning demonstrate a concern among educators in the areas of student engagement, student/teacher interaction, and social presence. Jaggars completed recent research through the Community College Research Center that contends these disadvantages result in online courses becoming second choice for students in some subject areas, as Jaggars detailed in an interview with Inside Higher Education (Fain, 2013). The study found that community college students preferred face-to-face instruction in courses they considered difficult, interesting, or important. The qualitative research conducted by one-on-one interviews found the majority interviewed felt they did not learn course material as well in an online class, and reported the cause of that deficit to be less satisfaction with teacher explanation and interaction. Jaggars' study of online community college learning is part of an ongoing and larger research project. The sample size in this portion of the study was smaller, with 46 students from two Virginia community colleges who had taken both online and traditional courses as the sample population. Jaggars agrees 
the sample was small, but informed Inside Higher Education that it is a good snapshot of attitudes at community colleges (Fain, 2013). Jaggars' (2011) study suggests that while students appear to welcome the option of taking courses online, they may not welcome the continued expansion of online courses if it requires a concomitant decrease in face-to-face offerings.

Concepts like quality of learning (Anderson, 2004; Jaggars, 2011; Palloff \& Pratt, 2007), effective teaching (Salmon, 2011; Swan, 2003; Young, 2006), student learning (Swan, 2004), and student satisfaction (Arbaugh, 2001; Swan, Garrison, \& Richardson, 2009; Swan \& Ice, 2010) are many components of online learning that have been studied. The focus of this study looked at the relationship between community college student perceptions of satisfaction with the use of asynchronous communication tools in online courses at a Region V community college and possible correlations with social, teaching, and cognitive presence. As the review shows, several researchers have studied the elements of presence in an online class by looking at one particular tool, such as the discussion board or forum (Hampton, 2010; Jahnke, 2010; Morris, 2010; Parker, 2012). Limited research exists, though, on community college student perceptions of online courses involving more than one asynchronous communication tool in relationship to the Community of Inquiry (CoI) framework.

To better understand the importance of that connection between the asynchronous communication tools and the CoI framework, the researcher will examine some common themes of online learning. First, interaction will be discussed through the lens of Chickering and Gamson's (1987) Seven Principles of Good Undergraduate Instruction. Next, the lack of social presence in the online environment will be discussed through the lens of the CoI 
theory. Then, the CoI model will be presented as the framework for this proposed research in the areas of student perceptions of student satisfactions with online courses. A review of some recent research utilizing the CoI theory will be discussed. Finally, some examples of the use of CoI in community college specific research will be shared.

Interaction is a critical component in producing a successful online course. Students taking online courses want high-quality feedback and good communication from their instructors, thus interaction becomes a fundamental building block of a quality online course. Chickering and Gamson's (1987) Seven Principles of Good Undergraduate Instruction address a need for interaction. The literature is rich in studies that address faculty behaviors that lead to perceived student satisfaction in both the traditional and online environments. Much of this research is grounded in the work of Chickering and Gamson's Seven Principles of Effective Teaching.

Student satisfaction within the online classroom is directly affected by quantity and quality of interactions between the assigned faculty member and the enrolled online students. Jackson, Jones, and Rodriguez (2010) utilized the principles of good undergraduate instruction and the principles of effective teaching as a framework to clarify the relationship between student learning and student satisfaction in the online classroom. Their research found that plentiful and instructive interaction between faculty and students in the Internet-based classroom resulted in greater satisfaction and learning among enrolled online participants, while decreasing the level of interaction results in isolation and increasing levels of dissatisfaction.

A lack of social presence and community and a feeling of isolation or anonymity are common disadvantages that emerge in asynchronous online learning research. 
Asynchronous online learning promotes a collaborative learning environment to provide student satisfaction with the course. A review of the literature emphasizes the importance of forming a learning community in online education.

Community of Inquiry (CoI) Theory. The essential feature of online learning extends beyond its access to information and builds on its communicative and interactive features. Quality online learning blends diversity and cohesiveness into a dynamic and intellectually challenging 'learning ecology' (Garrison \& Anderson, 2003). “This interactivity goes far beyond the one-way transmission of content and extends our thinking regarding communications among human beings engaged in the educational process" (p. 3). These researchers equate that a quality educational experience is the dynamic integration of content and context created and facilitated by a discipline expert and pedagogically competent teacher. In developing the CoI theoretical framework, Garrison and Anderson demonstrated a facilitated approach to teaching based on the idea of a community of learners.

The CoI Model. The CoI model provides a comprehensive theoretical framework to inform both research on online learning and the practice of online instruction. It assumes that student satisfaction with online learning requires the development of a community that supports meaningful inquiry and deep learning. The CoI theoretical framework represents a process of creating a deep and meaningful learning experience through the development of three interdependent elements: social presence, teaching presence, and cognitive presence.

Social Presence. The role of social presence is described as "the ability of participants in a community of inquiry to project themselves socially and emotionally, as 'real' people 
(i.e., their full personality), through the medium of communication being used" (Garrison, Anderson, \& Archer, 2000, p. 94). It refers to the degree to which learners feel socially and emotionally connected with others in an online environment.

Teaching Presence. The role of teaching presence is described as "the design, facilitation, and direction of cognitive and social processes for the purpose of realizing personally meaningful and educationally worthwhile learning outcomes" (Anderson et al., 2001, p. 5). Teaching presence brings all the elements of a community of inquiry together in a balanced and functional relationship congruent with the intended outcomes and the needs and capabilities of the learners.

Cognitive Presence. The role of cognitive presence is described as "the extent to which learners are able to construct and confirm meaning through sustained reflection and discourse in a critical community of inquiry" (Garrison, Anderson, \& Archer, 2001, p. 11). At the base is critical and reflective thinking.

As the CoI model proposes, and the research demonstrates, an undeniable relationship exists among social, teaching, and cognitive presences. In examining research on the CoI framework, the occurrence of these elements of the CoI model in an online course appears to predict learner satisfaction in online education, thus contributing to learner success in asynchronous online courses. This relationship is evidenced in multiple studies of community colleges. It also presents a need for online course instructors to use multiple mediums to interact with students and meet their varying needs.

The CoI model suggests that the online learning experience unfolds in the interaction of three interdependent presences - social, teaching, and cognitive. A decade after the model was presented, a study by Shea and Bidjerano (2009) found complex 
interrelationships among the three presences. Garrison, Cleveland-Innes, and Fung (2010) explored the causal relationships among the presences. Their findings support the hypothesized fundamental role of teaching presence in the development of both social and cognitive presence, as well as social presence's role as a mediating variable in the development of the latter.

Garrison, Anderson, and Archer (2001) noted that social presence was shown to predict learner satisfaction in online education, and challenged the widely held assumption that face-to-face, non-verbal behaviors are necessary for establishing teacher and student rapport. A significant correlation abounds between students' perceived learning and satisfaction levels with their instructors (Fredericksen et al., 2000; Richardson \& Swan, 2000; Shea, Fredericksen, \& Pickett, 2002). Tabar-Gaul (2008) examined social presence, teaching presence, and cognitive presence through online interaction in a community college study of introductory-level computer courses. The study also explored online retention components. Tabar-Gaul concluded that teaching presence was the most significant component for successful online learning as perceived by both faculty and students in the study. Successful online learning in this research focused on completion of the course, interaction between the teacher and students, and the inclusion of course activities to aid in better course grades. Cognitive presence was the second most important component in an online learning environment. The researcher recognized the importance of effective online interactions and pedagogy as factors to increase online learning success and retention.

To better assist in examining the occurrence of the presences in courses, researchers created a survey known as the Community of Inquiry (CoI) instrument 
(Arbaugh et al., 2008). Researchers who validated the CoI instrument did so with a university student population. Many of the studies since that validation also focused on university student populations. However, the instrument is not specific to a certain student population and can be used by varying groups. Since the instrument's validation in 2008, community college researchers have utilized it multiple times in conducting studies on social, teaching, and cognitive presence (Capra, 2012; Hampton, 2010; McWhorter, 2013; Morris, 2010). The CoI instrument, a 34-item questionnaire, is proven to be an effective instrument in assessing social, teaching, and cognitive presence in the community college environment (see Appendix A).

The CoI instrument measures teaching presence by assessing perceptions about organization, facilitation, and direct instruction. The CoI instrument measures social presence by assessing perceptions about affective expression, open communication, and group cohesion. The CoI instrument measures cognitive presence by assessing perceptions about triggering events, exploration, integration, and resolution. It is expected that these perceptions are directly influenced by the interactions and communications that take place among students, between students, among the instructor and students, and between the instructor and students through asynchronous communication tools provided as part of the course.

Hampton (2010) researched student characteristics and student immediacy in the community college environment in regards to reducing perceived distance in online learning. Specifically, Hampton examined whether the student characteristics of age, gender, learning style, online communication competency, and online social presence affected student immediacy behaviors in the community college online learning 
environment. The researcher examined 2,522 discussion postings from 152 urban online community college students. She utilized both content analysis and a survey. Hampton found that the interaction effects of student age and gender did significantly affect immediacy behaviors. Hampton concluded "that reducing the psychological distance felt between online students is rooted in the ability of those students to get to know their online classmates through meaningful and authentic interaction" (Hampton, 2010, np).

In a study of online learning at a community college, Capra (2012) utilized the CoI model to examine social, teaching, and cognitive presence as critical components for the facilitation of a meaningful learning experience. The researcher used a qualitative inquiry for 15 community college students to examine facilitation of a meaningful learning experience. This study raised questions about pedagogical soundness of fully online courses for community college students. Capra's research found a very limited existence of the CoI elements, declaring that students, thus, did not achieve a meaningful learning experience.

Morris (2010) explored community college student perceptions of online learning using the CoI model as a construct. Morris surveyed 25 students in regard to their online educational experience. The researcher chose seven of those students who provided information-rich responses to interview. The researcher also conducted an artifact review of course syllabi. One of five results found in the data analysis centered on communication and interaction. The study results indicated that a major source of engagement for online students came from communication and interaction through discussion board participation. The study results further demonstrated that student individual 
characteristics, learning preferences, and learning goals influenced student perceptions of course satisfaction, beneficial course activities, and self-predicted success.

McWhorter (2013) examined the online course in terms of quality of interaction, noting a concern for higher attrition rates in online courses when compared to face-to-face (or traditional) classes. The CoI model served as the framework for McWhorter's research. Specifically, McWhorter studied the relationship between students' perceived community of inquiry and learning outcomes in regards to course retention, final grade, and students' perceived quality of learning. The researcher used a study population of 52 students in accounting courses (26 students in each section with one as a treatment group). The results of the study suggest that interaction is critical for student outcomes, especially with early involvement in the course activities. McWhorter calls for further research that focuses on the ability of educators to utilize technology to increase the amount of interaction in the online class.

This study differs from the aforementioned studies in both methodology and intent. Hampton (2010) examined only one asynchronous communication tool - discussion boards. Hampton also examined the postings specifically for content. Capra (2012) used a qualitative approach in researching the impact of online learning for 15 students and examined more of the teaching and learning process as opposed to student perceptions of satisfaction. Morris (2010) used a mixed-methods approach with a small survey population of 25 , from which the researcher chose seven for interviews. Morris only examined the discussion board as a communication tool in her study. McWhorter (2013) looked at a small demographic of students in one program of study and utilized a treatment group, examining types of assignments instead of the technology employed. 
As one of the founding fathers of the CoI framework, Anderson noted this is a challenge for instructors and course developers to construct an environment of learning that results in student satisfaction with the course. "There is no single, right medium of online learning, nor a formulaic specification that dictates the kind of interaction most conducive to learning in all domains with all learners. Rather, teachers must learn to develop their skills so that they can respond to student and curriculum needs by developing a set of online learning activities that are adaptable to diverse student needs" (Anderson, 2004, p. 54).

\section{Asynchronous Communication Tools}

Studies show that to improve student satisfaction, instructors must establish mechanisms for communicating with students in an online environment (Aragon \& Johnson, 2008; Bradley, 2009; Dixson, 2010; Gayton \& McEwen, 2007; Harrell, 2008; Robinson \& Hullinger, 2008; Yang \& Cornelius, 2004). A variety of emerging technologies exists inside online classrooms for instructors to utilize asynchronous communication tools - including e-mail, discussion boards/forums, blogs/web logs, wikis, and podcasting - to deliver information to students (teaching presence) and to allow for student/student communication (social presence) in the online course environment. The researcher examined five specific asynchronous communication tools by providing a commonly accepted definition of the tool, explaining common uses in online learning, discussing advantages and disadvantages of each tool, and sharing results of research on the tool, including community college specific research. Table 1 shows the asynchronous communication tools chosen and the supporting research. 
Table 1

Asynchronous Communication Tools and Corresponding Studies

\begin{tabular}{|c|c|}
\hline & Study \\
\hline E-mail & $\begin{array}{l}\text { Arnold (2005) } \\
\text { Liu (2007) } \\
\text { Yang \& Cornelius (2004) } \\
\text { Robinson \& Hullinger ( 2008) } \\
\text { Aragon \& Johnson (2008) } \\
\text { Lea (2007) }\end{array}$ \\
\hline Discussion boards/forums & $\begin{array}{l}\text { Jahnke (2010) } \\
\text { Parker (2012) } \\
\text { Hardin (2004) } \\
\text { Morris (2010) } \\
\text { Illowsky (2007) } \\
\text { Hampton (2010) } \\
\text { Cvetko (2002) }\end{array}$ \\
\hline Blogs/web logs & $\begin{array}{l}\text { Brownson (2009) } \\
\text { Safer et al. (2005) } \\
\text { Kerawalla et al. (2008) } \\
\text { Dickey (2004) } \\
\text { Perschbach (2006) } \\
\text { Rhode (2008) }\end{array}$ \\
\hline Wikis & $\begin{array}{l}\text { Soules (2008) } \\
\text { Brownson (2009) } \\
\text { Cole (2009) } \\
\text { Whitehouse (2011) } \\
\text { Nakamaru (2012) } \\
\text { Martin (2012) }\end{array}$ \\
\hline Podcast & $\begin{array}{l}\text { Brown \& Green (2007) } \\
\text { Parson et al. (2009) } \\
\text { Brown et al. (2009) } \\
\text { Lombardo (2011) } \\
\text { Crawford (2007) } \\
\text { Parker (2012) }\end{array}$ \\
\hline
\end{tabular}


E-mail. Known as e-mail, short for electronic mail, this is the oldest collaboration tool and most common method for communication in online learning. An e-mail is an electronic message that a user types on a screen and sends to one or more recipients. In online learning, common uses for e-mail include: announcements, due dates, schedule changes, modifications to an assignment, or addressing possible misconceptions. It can also be utilized as a private means of communication between the instructor and student or among students themselves.

Common advantages of e-mail are that it provides direct access to the instructor. It is a private area to address classroom concerns and assignment issues, or to answer student questions that are of a personal nature. E-mail requires minimal technical skills and can be used to attach files. Nearly all college students already have an e-mail account assigned to them when enrolling as a source of information and communication. It is expected that most college students will know how to send and receive e-mails prior to enrolling in an online course.

Common disadvantages of e-mail include no response, no checking on the account, and no understanding of how to use the communication tool properly. The greatest disadvantage of e-mail in online learning occurs when students simply don't check their accounts. When this happens, they miss important messages from the instructors on the way to proceed and progress in the course. Research by Arnold (2005) presented another concern for e-mail usage when the study found that some topics are difficult to discuss critically via e-mail. Another disadvantage is evident when some students cannot properly utilize the e-mail system, despite an institution's expectations for e-mail use with students. While e-mail requires only minimal technical skills, some students who enroll in online 
courses have not yet mastered how to send an e-mail, how to attach a document to the email, and how to download and upload files to and from an e-mail.

Many studies focus on the importance of online readiness for student success in online courses. As a result, many community colleges now offer online readiness assessments or tests for students considering taking online courses. These assessments, often with a customizable set of questions, explore facets such as personal attributes and learning style, technical knowledge, ability to read and retain information, and typing skills. The student receives results that lay out areas for improvement and areas of strength, learning style, and technical competency. Much research in this area (Aragon \& Johnson, 2008; Lea, 2007; Liu, 2007; Robinson \& Hullinger, 2008; Yang \& Cornelius, 2004) indicates that student readiness for online learning can lead to more student satisfaction in the courses and, thus, better retention.

Liu (2007) investigated factors predicting students' retention and final grades in a community college online course. The study utilized the Learner Autonomy Profile, the Online Technologies Self-Efficacy Scale, and the Social Presence and Privacy Questionnaire to determine student readiness. The study suggested that psychological readiness and social readiness were significant predictors of course retention and final grade in the online environment. The relationships between technological readiness and course retention and final grade were insignificant. Based on those findings, the study proposed actions to include early identification of at-risk students through means such as online readiness testing, as well as developing integrated social and learning communities.

As a result of current research on e-mail, and in examination of current advantages and disadvantages of the tool, e-mail emerged as the most common tool available. 
Instructors are expected to utilize e-mail in an online course. Research into this tool, therefore, often doesn't focus as much on the mechanisms of the tools as it does on specific areas such as feedback and writing skills. The following studies review aspects of research on e-mail in the online course, and specifically in online courses at community colleges.

Yang and Cornelius (2004) investigated student perceptions of quality education in online courses at two universities and a community college. The study group was students who were reluctant to take online courses because of past experiences. Researchers wanted to examine what resulted in negative online experiences. They discovered the following negative experiences: delayed feedback from the instructors, unavailable technical support, lack of self-regulation and self-motivation, sense of isolation, monotonous instructional methods, and poorly designed course content. The students expressed a desire and need to be able to email instructors and receive timely feedback. Yang and Cornelius suggested more research into the area of improving communication and utilizing other communication tools as enhancements to the educational experience in the online classroom in regards to both course content and social presence.

In a 2008 study, Robinson and Hullinger examined more than 200 undergraduate students in relation to Chickering and Gamson's Seven Principles of Good Practice in Undergraduate Education, underlined by Chickering and Erhmann's guidelines on how online education should be consistent with those principles. They discovered that e-mail was the primary source for student-faculty interaction, and that those interactions mostly revolved around grades and assignments.

Aragon and Johnson (2008) examined factors influencing completion and noncompletion of community college online courses. The purpose of the study was to 
investigate the differences in demographic, enrollment, academic, and self-directed learning characteristics between students who complete and those who do not complete online courses. They found no significant association for age, ethnicity, or financial aid eligibility. Gender showed $66 \%$ of females completing, compared to $52 \%$ of males. Number of hours enrolled in online courses emerged as a factor as course completers enrolled in more courses than noncompleters.

Aragon and Johnson further surveyed those reporting noncompletion as to why they did not finish. The responses of highest use were personal/time, course design and communication, technology/WebCTtutorial, and institutional issues. Of those responding about course design and confusion, students complained about being unable to get responses from instructors, noting delayed feedback through an e-mail system to be a source of frustration for students. The study produced two recommendations: 1) a responsibility of course developers to plan and design quality materials, and 2) for instructors to establish a mechanism for communicating with students. "Instructional designers need to look for innovative ways to facilitate quality teaching and learning recognizing that simply converting a face-to-face course to an online course does not accomplish this task" (p. 155).

Lea (2007) focused on the observation, collection, and analysis of texts that constitute a visible part of the students' online experiences. She examined e-mail messages and discussion forum comments. She concluded that writing emerges as a marker of power and authority as it is the means by which students are often assessed, especially in an online environment. 
Discussion boards or forums. Discussion boards are also known as discussion forums, threaded discussion, and electronic bulletin boards. This asynchronous collaboration tool is a key element in many learning management systems. In online learning, common uses of discussion boards or forums typically include an instructor posting a topic or question for discussion. Students then respond to the instructor, as well as to the postings of other students in the course.

Common advantages of discussion boards center on their ability to provide a social presence in an online course. This tool allows for student interaction with course content, with the instructor, and with other students. Discussion boards are noted to become a voice for students who normally wouldn't speak out in a traditional classroom setting. They also provide students opportunity for reflection and researched responses to engage in higher quality discussions.

Jahnke (2010) noted four themes emerging from research into discussion board use: interactivity, group construction of knowledge, ability to revisit recorded thinking, and awareness of online identity. Students reported it very beneficial to ask questions, get feedback and help others, referring to such learning as "collective intelligence" (p. 30). Students also found it useful to be able to interact with others and information sources at the same time. They were able to pool together knowledge collectively to reach a common goal.

Sharing ideas in a virtual space and understanding collective intelligence had a "powerful influence on learning," according to one participant (p. 30). She liked the idea of a sense of building group understanding of requirements of the project to be completed. Students noted their discussions in an online forum were enhanced over those comments 
given in a classroom where a lack of time exists to formulate ideas, contribute, and reflect. The ability to go back to the discussions in an online forum is another advantage noted by students who try to recall something said in a classroom discussion but cannot. Despite the fact that they couldn't be face-to-face with other students, they knew that their representation of themselves online had implications on how others perceived them. Representation also became an important issue since discussions could be permanently recorded in an online environment.

While discussion boards are known to have several advantages, research such as that conducted by Parker (2012) shares common disadvantages of discussion boards. Parker noted the improper use of discussion boards in online courses can come from communication-related barriers such as a lack of community interaction, delayed responses from instructors, and an inhuman feel to the online experience. Overuses of discussion boards without much direction from an instructor are reported to be a common disadvantage, with some course requirements of up to 20 posts per week on a similar topic in a course. Writing skills also become more important in a discussion posted online as opposed to speaking comments during a discussion in a traditional classroom. Hardin (2004) explained how students have to represent themselves by their writing skills in an online discussion environment, which increases the significance of writing skills. The better the skills, the more favorable the perception of the person often becomes. For those with poor writing skills, it can be seen as a disadvantage since the online publishing remains on record for weeks.

As a result of current research on discussion boards, and in examination of current advantages and disadvantages of the tool, discussion boards emerge as a common tool to 
enhance interactivity in an online course. Instructors often utilize discussion boards or forums in an online course. Research into this tool, therefore, is vast, often sharing how it enhances the social presence and sometimes highlighting the misuse of the tool. The following studies review aspects of research on discussion boards in the online course, and specifically in online courses at community colleges.

Morris (2010) explored community college student perceptions of online learning within the theoretical construct of the Community of Inquiry model, which describes the manner in which the elements of cognitive, social, and teaching presence interact to create an educational experience. The study results indicated that communication and interaction through discussion board participation were a major source of engagement for online students. The study further demonstrated that individual student characteristics, learning preferences, and learning goals influenced student perceptions of course satisfaction.

Illowsky (2007) studied the use of the effects of discussion postings in online elementary statistics in community college classes to understand more about which forms of interaction can lead to greater academic success and retention. Researchers of students in face-to-face sections have concluded that lack of interaction among community college students is a significant reason students do not succeed (Hoachlander, Sikora, \& Horn, 2003; Tinto, 2002; Tinto, Russon, \& Stephanie, 1994). The research is deficient, though, about which individual forms of online interaction may lead to greater academic success and retention in online courses at community colleges, or how these forms individually affect instructional design of courses. The study attempted to discover the effect of online discussion postings on retention, but was unable to produce statistically significant results. Illowsky proposes more research in this area. 
Hampton (2010) studied 2,522 discussion postings from 152 community college students to ascertain that reducing the psychological distance felt between online students is rooted in the ability of those students getting to know their online classmates through meaningful and authentic interaction. Earlier research by Cvetko (2002) investigated the student-to-student interactions that take place in an online community college course and how those interactions impact an online learning community. Data were collected from discussion boards, emails, group papers, and interviews to understand the impact of the teaching/learning environment on student interaction. In this study, the environment impacted the way students interacted, collaborated, and socialized with peers. It changed the way participants interacted within the learning community and impacted how the students interpreted meaning and perceived time.

Parker (2012) examined the application of the asynchronous communication tools of email and discussions, as well as posting of class notes, to determine how community college students perceived communication in their online classes. The survey results revealed participants did not perceive the effectiveness of their online communication to be as effective as communication in traditional classes. Parker found that instructors could not decrease the feeling of distance in an online course if they did not effectively utilize communication tools to create meaningful interactions. Results of this study show a strong correlation between communication and satisfaction levels of students regarding online classes. Students indicated more satisfaction toward online classes when effective communication maintained a strong presence. Effective communication also emerged as a major factor in the motivation of students to complete an online class. Students in this study, however, lacked exposure to other asynchronous communication tools, such as 
blogs, wikis, and podcasts. Parker proposes that online instructors need to employ a variety of communication tools to produce more engaged and active learning experiences and to accommodate all learning styles.

Blogs/web logs. Online journals that can be either public or private, and which communicate ideas in a continuous flow, are known as blogs or a web logs. Some media outlets use blogs to serve as information sites or for self-expression. Blogs often have the inclusion of a home page, an archive of postings, and a specific author. In online learning, common uses of blogs include allowing students the web-based communication tool as a means to create an online portfolio, post reflections, and receive feedback.

Common advantages of blogs include: the ability to allow for multiple participants, the mechanisms of its presentation style, and the creation of content at a higher thinking level. With blogs, material is presented in reverse chronological postings, with the most current information readily accessible. Blogs can promote collaboration and allow for an invitation to those outside of the classroom to participate and review student work. Blogging can be a process that students return to throughout a course and continue to expand. In research by Brownson (2009), meaning developed at a higher level with the content, as students felt empowered by blogging and expressed an increased social interaction. That correlates with research from Safer et al. (2005) where blogs were found to reduce the feeling of distance in online courses.

Common disadvantages of blogs include: the need for technical and writing skills, as well as the motivation to complete the assignments. A variety of resources are available for bloggers, but it requires more technical skills than some earlier asynchronous communication tools. Another great disadvantage to blogging is that in some research, like 
Brownson (2009), students simply skipped that step of the assignment since it was not outlined in the course syllabus and not provided a grade. Brownson also found that instructors sometimes failed to understand the technology of blogging and wikis; thus they were unable to connect those tools to the content of the online course. Kerawalla et al. (2008) found a similar problem. Students either felt that blogging was not worth the effort or they did not have anything to contribute to the discussion.

As a result of current research on blogs, and in examination of current advantages and disadvantages of the tool, blogs emerge as a new tool available for online educators. Many instructors, however, are unfamiliar with blogs and do not fully utilize them in their online courses. Research into this tool, therefore, focuses on the uses of blogs, and how those uses relate to increased interaction or reflection in online courses. The following studies review aspects of research on blogs in the online course, and specifically in online courses at community colleges.

An overall feeling of reduced isolation and sense of an online community emerged from the analysis of blogs as noted in a survey by Dickey (2004). Other asynchronous communication tools, including discussions and emails, had been used prior to this study that focused on web logs in small groups. Dickey found that web logs in small groups resulted in the most significant causal relationships due to the increase in social activity and the integration of content materials into the conversations.

To foster reflection in learning, Perschbach (2006) examined how instructors utilized blogs in a study of computer science students at a community college. Students were required to read both course and peer blogs, and to contribute to a personal reflective blog. The goal of the research was to explore evidence of critical thinking and reflection 
through the blogs. Perschbach used elements of Garrison's research on collaboration or community in an online course, and Bloom's taxonomy (1956) as the standard for measuring individual critical thought. The results of the study indicated that blogging effectively recorded critical thinking for students, as well as providing a personal voice to create a sense of ownership of ideas, active participation in personal learning, and a contribution to a collaborative learning effort.

Rhode (2008) used a mixed-methods study to explore the dynamics of interaction within a self-paced online learning environment looking at both traditional and asynchronous communication tools. The goal was to determine what forms of interaction learners in a self-paced online course value most, as well as what impact they perceive interaction to have on their overall learning experience. Participants in the study reported the activity of blogging as being equally valued and, in some ways, superior to instructordirected asynchronous discussion via a discussion board.

Wikis. A wiki document is an editable website created incrementally by visitors working collaboratively. Wikis allow for the generation and sharing of large amounts of complex knowledge. This web-based tool allows for many authors to work on projects together with editing capabilities of the digital document. Users can create information together, allowing for a learner-centered perspective. Wikis can incorporate sound, images, and text. In online learning, typical uses of wikis include: brainstorming, group projects, meeting support, making lists, social bookmarking for a collection of links, building a group portfolio, and writing a collective letter, position statement, or web response.

Common advantages of wikis focus on active construction of course content, higher quality work by participants, cooperation among users, and the ability to store and modify 
large amounts of information collectively. In consideration of a paradigm shift in higher education towards student-centered learning, a focus on individual and peer learning is often utilized under the constructivist model of learning, of which a key tenet is that people learn best by actively constructing their learning. A wiki affords students the opportunity to construct their own course content. The ideal goal of multiple users in an online document is that content continually improves as others with expertise add to ideas to create a knowledge repository. Thus, a wiki becomes a hypertext system for storing and modifying information. Soules (2008) found that wikis led to a higher quality of work compared to traditional ways of completing projects. The cooperation factor expands social interaction in courses using wikis, thus resulting in more student satisfaction with the course (Brownson, 2009).

Common disadvantages of wikis are a lack of proper use, the ability to change course content, and the appearance of the document. The most famous wiki document is the online encyclopedia, Wikipedia. With a collaborative effort in construction, concerns can arise as to content. To prevent undesired modifications, wikis record individual changes and keep extensive page histories. If inaccurate or unsuitable material is posted, a wiki can roll back to a previous version. Some view this system, though, as unreliable. Cole (2009) reports a failed experiment to use wiki technology to enhance student engagement. In this study, however, students had problems with the technology and didn't want to use it or share posts with their peers. They viewed a wiki as having no real gain and lacking the appearance of fun.

As a result of current research on wikis, and in examination of current advantages and disadvantages of the tool, wikis emerge as a very new and often underused tool. Many 
instructors are unfamiliar with this web-based tool, and how to use it properly to engage students in course content. Research into this tool, therefore, is relatively new and limited. The following studies review aspects of research on wikis in the online course, and specifically in online courses at community colleges.

Globaloria, a project in elementary schools, high schools, community colleges, and universities, utilizes social networks by means of blogging and a wiki as a learning environment for educational game design. Students receive and post all assignments inside the wiki that is shared by all participants nationwide. Educators have a teaching wiki. Students have a shared wiki. Individual schools have smaller wikis within the larger one. Research conducted by Whitehouse (2011) on this project reveals that educators believe the experience makes them better teachers. They use a wiki that is self-led, collaborative, peer-to-peer, and expert-guided. Often, the experience of using a wiki and a blog in the instruction of a Globaloria course becomes something teachers are willing to replicate in other courses they teach, Whitehouse found.

Nakamaru (2012) studied the extent to which students in a community college remedial English as a second language course engaged with a class wiki. The study examined the relationship between the students' patterns of engagement over time and success in exiting remediation. While the engagement in the wiki outside of the classroom helped students avoid further remediation, the average level of engagement with the asynchronous communication tool was low. The researcher concluded that technologymediated learning activities do not necessarily lead to increased engagement.

Martin (2012) conducted an action research study to examine the use of a wiki to encourage critical thinking and digital literacy in a community college history class. The 
wiki was the source of an online textbook that students had created over many semesters and continually revised. The history professor used the student textbook instead of one from a book publisher in an effort to empower students to create knowledge and to consider bias in historical writing. The findings raise concerns for trust and identity, and note a need for balance between freedom of discovery using the wiki system and organizational structure.

Podcasting. The recording and dissemination of sound is known as podcasting. The "casting" part comes from broadcasting, while the "pod" comes from the iPod, which was the device via which podcasts were first intended to be heard. A podcast is a broadcast of audio or video files over the Internet using syndication feeds for playback on mobile devices and personal computers. Podcasting is defined as the technology of distributing digital files, either audio or video, to users who subscribe to receive those files (Brown \& Green, 2007). In online learning, common uses of podcasts include those defined by research groups such as Parson et al. (2009). The researchers used coding of individual group members and e-mail sent during course work to identify seven instructional strategies that podcasting can facilitate in an online course: lecture, demonstration, elaboration/clarification, feedback, interview, instruction/assignment, and social presence. Lectures, the delivery of content through speech, are common in higher education. Instructors utilize lecture to provide instructions to students, to introduce a topic, to state facts and opinions about a subject, and to arouse interest in a subject.

Common advantages of podcasts are that the tool allows students to feel a connection to an instructor, and it removes isolation between instructors and students by providing a communication method that goes beyond text-only interaction, as cited by 
Brown et al. (2009). Student perceptions of satisfaction with podcasts in Brown et al.'s research expressed enjoyment with the use of podcasts and hearing an actual voice in an asynchronous online course. Some cited feeling like the instructor was with them, while others said the use of the podcast made them feel as if the instructor was more of a real person. "It is the increase in the sense of social presence that creates a strong argument for making use of podcasting technology to provide through voice and image a more intimate, human experience for distance learners" (p. 370).

Common disadvantages of podcasts center on technological problems with the use of the tool. Students must be able to open and listen to podcasts. In courses where students must respond to a prompt by creating a podcast, the process of creation can become a hindrance to student perceptions of satisfaction with the asynchronous communication tool. Creation of the podcasts is also a disadvantage for faculty. Lombardo (2011) interviewed community college faculty on the use of podcasts. The study found that the participants were interested in using new technologies in their teaching, but time, training, and support were lacking, which may have contributed to a low adoption rate.

As a result of current research on podcasts, and in examination of current advantages and disadvantages of the tool, podcasts emerge as a tool that is likely to grow in use. Instructors can utilize podcasts in a myriad of instructional strategies in an online class. Research into this tool often focuses on which specific areas of the course podcasts are being utilized to enhance. The following studies review aspects of research on podcasts in the online course, and specifically in online courses at community colleges.

Technologies such as podcasting offer an enhanced virtual social context for learning. Early research in this area began at Duke University (Belanger, 2005; Earp, 
Belanger, \& O’Brien, 2006) with a study spanning several years. Students received iPods to download and listen to lectures from traditional courses. A great concern in doing this project was that students would skip class and just utilize the downloaded lectures. It was discovered, though, that students still found class useful and utilized the lectures for revision, understanding, and course enhancement. Goldberg and McKhann (2000) later required students to listen to a podcast lecture before attending class to enhance course discussion. Students reported learning more. Frydenberg (2006) included students in podcast development to create "bite-sized" podcasts to clarify main points of lectures.

Brown et al.'s (2009) research of faculty members at a southeastern university examined the use of podcasting as a teaching strategy instead of traditional text-based media in a year-long cooperative study. The 11 faculty members who participated, having varying backgrounds in the technology itself, discovered the emergence of four distinct podcasting technologies. "The faculty members involved in this study concur with the notion accepted among educators, that the current, most popular method of delivering online distance instruction that relies primarily on text is not satisfactory" (p. 353). The faculty members believe that computer mediated communication can encourage collaboration and learning online together, and that technologies to improve it might increase student satisfaction, thus increasing motivation and learning.

The study focused on the cooperative inquiry model, enabling the participants to conduct research with one another rather than on one another. They held regular meetings, kept journals, and prepared reports for one another. Four primary podcast types were used: audio, video, screencast, and slideshow. Instructional uses included: lecture, demonstration, instructions, elaboration/clarification, feedback, interview, assignment, 
and social presence. Demonstrations were most commonly used with screencasts to explain how to perform specific tasks using software, and were approximately three minutes each. Lecture podcasts were one to six minutes.

Student response to the use of podcasts for assignments was positive. They noted the elaboration/clarification podcasts to be helpful in clearing up misunderstandings. One faculty member sent all feedback to students in audio files. As a result, the students' quality of work noticeably improved from enhanced feedback. Comments from students included enjoying the podcasts, hearing an actual voice, feeling like the instructors were there with them, and feeling as if the instructor was more of a "real" person. "It is the increase in the sense of social presence that creates a strong argument for making use of podcasting technology to provide through voice and image a more intimate, human experience for distance learners" (p. 370). Brown et al. (2009) called for more research in the area, noting a need to identify possible technological and pedagogical applications of podcasting as part of online course delivery.

Crawford (2007) studied integrating multimedia components into web-enhanced and online learning environments to support higher order thinking skills, specifically analysis, synthesis, and evaluation. She studied podcasting, video blogging (often referred to as vlogs), and instructional gaming. While a podcast is a digital audio file that can be downloaded for listening, a vlog can be viewed as a video podcast, or a vodcast. Video is the primary content and is accompanied by supporting texts, images, or meta data to provide context. Educational games are similar to video games but are designed to teach about a certain subject or help players learn a specific skill. Such can also be referred to as edutainment, as it combines both education and entertainment. Crawford encourages 
more interaction in online courses with these types of learning tools. She proposes a Distance Delivery Hierarchy of Needs: technological (computer) needs, digital literacy needs, self-regulation needs, social interactive needs, and self-actualization (fulfillment) needs. "While the instructors/facilitators focus upon designing and developing the learning environment, it is imperative to maintain a focus upon the appropriate and successful enhancement of the learning environment through technological means, in an suitably ubiquitous manner" (Crawford, 2007, p. 46).

Parson et al. (2009) used broadcast material, namely podcasts and vodcasts, to gather opinions on course enhancement. Students were in favor of extra online teaching resources. The majority of the students (77\%) felt that vodcasts and podcasts should be made available in courses on a more regular basis. Only 5.5\% felt slide presentations alone were sufficient. The students noted that the most beneficial aspect was a vodcast or podcast that accompanied the lecture slides. Students reported finding such material easy to use and understand, calling such an important source of information useful in terms of revisions and assessment. This research supports the idea that incorporating audio and video into a course enhances learning. It appears much of the research is done as an ancillary to a traditional-format lecture course. It also appears that research on podcast use in an online course in a community college is very limited and almost nonexistent.

\section{Summary}

Current online course offerings via the Internet have evolved from what began as distance education courses. Distance education refers to education when an instructor and students are separated by geographic distance or by time, and communication technologies are used to bridge the resulting instructional gap (Moore \& Kearsley, 2005). The purpose of 
distance education is to provide accessibility to students who either cannot attend traditional courses due to occupational, family, or social responsibilities or are unwilling to attend traditional courses. Through these offerings, college courses are accessed wherever the students are and provide an opportunity for them to pursue degrees without the inconvenience of traveling to campus (Beard \& Harper, 2002). These courses are especially appealing to community college students who don't reside on campus, are of varying ages, or have scheduling conflicts with work and family responsibilities (Tung, 2007).

Online learning is ubiquitous in today's higher education systems. What began with just a few courses at a few colleges is now immense. Thirty-three percent of higher education students now take at least one course online, an all-time high (Allen \& Seaman, 2014). Some universities are built on web-based courses alone, but those that were established for traditional courses are placing more emphasis on the online component. Studies tracking community colleges specifically report significant growth in both online courses and programs in that sector as well. For community college presidents, student demand is the number one reason for increasing online offerings (Green, 2010a).

While demand is increasing, the online class has both advantages and disadvantages, as discussed in this chapter. As a result of those disadvantages, concepts like quality of learning, effective teaching, and student satisfaction are many components of online learning that have been studied. In this chapter, interaction was discussed through the lens of Chickering and Gamson's (1987) Seven Principles of Good Undergraduate Instruction. The lack of social presence in the online environment was discussed through the lens of the CoI theory. The Community of Inquiry (CoI) framework provides a comprehensive theoretical model to inform both research on online learning and the 
practice of online instruction. It assumes that student satisfaction with online learning requires the development of a community that supports meaningful inquiry and deep learning. The CoI theoretical framework represents a process of creating a deep and meaningful learning experience through the development of three interdependent elements: social presence, teaching presence, and cognitive presence.

Several researchers have studied the elements of presence in an online class by looking at one particular asynchronous communication tool. Limited research exists, though, on community college student perceptions of online courses involving more than one asynchronous communication tool in relationship to the CoI framework. This study filled a gap in the research by examining student perceptions of student satisfaction with the use of asynchronous communication tools and with the existence of social, teaching, and cognitive presence in online courses in a Region V community college. 


\section{Chapter 3}

\section{Research Design}

\section{Introduction}

Chapter Three addresses the methods used to determine the relationship between community college student perceptions of satisfaction with asynchronous communication tools and community college student perceptions of satisfaction with social, teaching, and cognitive presence in online courses in a Region V community college. This chapter contains the research rationale, the research theoretic, and a description of the study population. The chapter also contains a description of the research procedures used, including a review of the survey selected and survey development. Finally, the chapter describes the specific manner in which data was analyzed.

The study sought to answer the following research questions:

1.a. What are community college student perceptions of satisfaction with the use of asynchronous communication tools in a Region $\mathrm{V}$ community college?

1.b. Are community college students more satisfied with the use of one or more asynchronous communication tools than others in online courses in a Region V community college?

1.c. Which demographics have an effect on satisfaction with asynchronous communication tools in online courses in a Region V community college?

2.a. What are community college student perceptions of satisfaction of social, teaching, and cognitive presence in a Region $\mathrm{V}$ community college? 
2.b. Are community college students more satisfied with the use of one or more of social, teaching, and cognitive presence in online courses in a Region $\mathrm{V}$ community college?

2.c. Which demographics have an effect on satisfaction with social, teaching, and cognitive presence in online courses in a Region V community college?

3.a. What is the relationship between community college student perceptions of satisfaction of the use of asynchronous communication tools and community college student perceptions of satisfaction of social, teaching, and cognitive presence?

3.b. How does the relationship between community college student satisfaction with asynchronous communication tools and social, teaching, and cognitive presence vary depending on the different demographics?

The researcher utilized two instruments in this research. The Community of Inquiry (CoI) instrument (see Appendix A) was used to measure social, teaching, and cognitive presence in the online classroom environment. In tests for the CoI instrument (Arbaugh et al., 2008), it was determined both reliable and valid for use in studies that examine the CoI elements as predictor variables of course outcomes and as criterion variables in studies examining the extent to which the course characteristics encourage or inhibit the development of social, teaching, and/or cognitive presence. (See Appendices C and D for an e-mail requesting permission to use the instrument and for an e-mail granting permission to use the instrument.)

A survey based on the literature review was developed to gather the perceptions of students' satisfaction with the use of asynchronous communication tools in the online 
classroom (see Appendix B). Specifically, the survey examined the satisfaction and use of email, discussions or forums, blogs or web logs, wikis, and podcasting. Demographic information regarding student program of study, age, gender, GPA, and prior online experience also were gathered in an Asynchronous Communication Questionnaire developed by the researcher.

\section{Research Rationale}

This section addresses two areas of research design. It first addresses the characteristics of quantitative research and provides justification as to why this study was best conducted in this manner. It also provides information about the specific study population, including the criteria for selecting these individuals. Finally, the section examines recent studies that target the same demographics to be considered in this study to show whether or not those demographics prove to be important independent variables to consider in this research.

Research Theoretic. Philosophically, researchers make claims about what knowledge is, how it is known, the values that go into it, how it is to be written, and the processes for studying it (Creswell, 2003). The researcher collected information on instruments based on measures. "Data, evidence, and rational considerations shape knowledge" (Creswell, 2003, p. 7).

Two basic types of research are used in educational studies: quantitative research and qualitative research. Quantitative methods are employed "to describe current conditions, investigate relationships, and study cause-effect phenomena" (Gay, Mills, \& Airasian, 2006, p. 10). Quantitative research gathers data in numerical form that can be grouped in categories or by other means such as asking participants to complete rating 
scales or answer closed questions on a questionnaire. It utilizes the objective measurement and statistical analysis to explain phenomena (Mustafa, 2011). Qualitative methods seek to "understand situations in their uniqueness as part of a particular context and the interactions there ... to understand the nature of that setting" (Patton, 1985, p. 1). Qualitative research differs as it produces descriptive data collected by the researcher through interviews, observations, or open-ended questions. As the primary source of data collection, the researcher often immerses him- or herself into the environment to gain an understanding of "what it means for participants to be in that setting, what their lives are like, what's going on for them, what their meanings are" (Patton, 1985, p. 1).

The researcher used a quantitative descriptive design for this study. Descriptive research is concerned with assessing attitudes and perceptions of respondents (Gay, Mills, \& Airasian, 2006). Descriptive studies report data such as measures of central tendency, including the mean, median, mode, deviance from the mean, variation, percentage, and correlation between variables. Aside from the type of measurement, descriptive research uses statistics in order to draw inferences (AECT, 2001).

Descriptive statistics utilize data collection and analysis techniques that yield reports concerning the measures of central tendency, variation, and correlation. The combination of its characteristic summary and correlational statistics, along with its focus on specific types of research questions, methods, and outcomes, is what distinguishes descriptive research from other research types. (p. 3)

The intent of this descriptive research was to produce statistical information about aspects of education that interest educators. The researcher utilized a quantitative design employing strategies of inquiry such as surveys to collect information on predetermined 
instruments that yield statistical data. Data for this study were collected through two surveys of students taking online courses at a community college. An assumption of these data was that the factors associated with student perceptions of student satisfaction of the use of asynchronous communication tools will likely affect student perceptions of student satisfaction of social, teaching, and cognitive presence at a community college offering online courses.

Study Population. The specific population studied was a community college that offers both baccalaureate and associate degrees in the Mid-Ohio Valley of West Virginia. To determine the study population, the researcher examined previous overall enrollment numbers at the institution, as well as specifically in online courses, to determine if the semester to be studied was typical of the college's normal enrollment patterns.

This particular student body attends a Region V community college that is accredited to offer baccalaureate degrees. It is one of only 34 public institutions in the country classified as a Baccalaureate/Associate's College. This classification allows this community college to offer more than 40 programs of study and, thus, more online offerings to students. It currently has four completely online degree programs approved by the Higher Learning Commission. It does offer online availabilities for many courses, including general education courses, for a variety of students.

Online courses also continue to increase despite a decrease in enrollment at the institution. The 2011 student enrollment at this specific community college was 4,234 students, with $42.3 \%$ being of a non-traditional age defined by the institution as age 25 or older, and with 2,656 full-time students and 1,578 part-time students. Of course this enrollment reflects an area referred to as a bubble enrollment by college administration. It 
was a higher than usual enrollment due to an economic decline. For community colleges, times of economic upheaval often result in increased enrollment as more people return to college to retrain or enhance their skills until the job market improves. As shown in Table 2 , the community college continues to have significant numbers in its online offerings. Table 2

Online Courses Offered and Student Enrollment Per Term

\begin{tabular}{lcc}
\hline \multicolumn{1}{c}{ Semester } & $\begin{array}{c}\text { Number of Online } \\
\text { Courses Offered }\end{array}$ & $\begin{array}{c}\text { Number of Students } \\
\text { Enrolled in Online Courses }\end{array}$ \\
\hline Spring 2013 & 164 & 1,616 \\
Fall 2013 & 136 & 1,384 \\
Spring 2014 & 130 & 1,405 \\
\hline Total & 430 & 4,405 \\
\hline
\end{tabular}

In the Spring 2013 semester, 164 courses were offered online. The definition of online courses at this community college is that the course is offered completely online through the course management system (J. Wass, personal communication, November 7, 2013). In the Fall 2013 semester, 136 courses were offered online during a semester in which several online instructors piloted a new course management system. In the Spring 2014 semester, the college completely transitioned to a new course management system. A total of 130 courses were offered online. This total is less than administrators had planned due to a decision to expand fewer course offerings to online in the Spring 2014 semester to ensure a more smooth transition process from one system to another as the test groups found many concerns with the new course management system. Still, the total number of students taking online courses continues to grow at the institution. The total number of 
students enrolled in online courses at the beginning of Spring 2014 was 1,405 students, a slight increase over Fall 2013 (J. Starkey, personal communication, January 14, 2014).

For the Spring 2014 semester, enrollment at this community college was 2,946 students, with 1,405 students enrolled in at least one online course at the beginning of the semester (R. Tracy, personal communication, January 21, 2014; J. Starkey, personal communication, January 14, 2014). By mid-semester when the researcher conducted the survey, the total enrollment dropped to 1,363 students. The study population was the 1,363 currently enrolled students in the Spring 2014 semester who were taking at least one online course at this community college when the survey was administered. These individuals were surveyed because of their participation in online courses and the insight they could share about their perceptions of satisfaction with community college online courses in relation to areas of social presence, teaching presence, cognitive presence, and asynchronous communication tools. A return rate of at least $20 \%$ with a $5 \%$ margin of error was the minimum goal of this research.

Demographic Studies. In this study, the researcher wanted to examine whether community college student perceptions of the online course varies across these named student demographic statistics and academic subject areas. Following this review of specific demographic variables utilized in studies of online learning at community colleges, certain characteristics emerged as areas to include in the demographic assessment of this proposed study. Table 3 shows the demographic variables chosen and the supporting research. 
Table 3

Demographic Variables and Corresponding Studies

\begin{tabular}{ll}
\hline & \multicolumn{1}{c}{ Study } \\
\cline { 2 - 2 } Program of study & Xu \& Jaggars (2013) \\
& Lander (2009) \\
& Hamilton (2011) \\
& Scism ( 2006) \\
& Xu \& Jaggars (2013) \\
Dolan (2011) & York (2003) \\
& Colorado \& Eberle (2010) \\
& Hampton (2010) \\
& Xu \& Jaggars (2013) \\
& Payn (2009) \\
& McSporran \& Young (2001) \\
& Xu \& Jaggars (2013) \\
Gender & Thomas (2005) \\
& Beavers (2009) \\
GPA & Kennedy (2001) \\
& Aviat (2011) \\
Prior online experience & BroadbandUSA (2013) \\
Speedmatters.org (2013) \\
Pew Research Internet Project (2013) \\
Zickuhr \& Smith (2013) \\
\end{tabular}

In examining student perceptions of satisfaction with the use of asynchronous communication tools, and in examining student perceptions of satisfaction with the CoI elements of social, teaching, and cognitive presence, the following variables were considered: program of study, age, gender, GPA, prior online course experience, and 
Internet access at home. One study by Xu and Jaggars (2013) supported the majority of the demographics in this study, specifically looking at four of the six proposed areas.

Program of Study. Four studies supported the use of program of study as being a statistically significant demographic to consider in studying community college students. Program of study is defined as a sequence of career education courses in a given career cluster or pathway that prepares students for continued education or entry into a career. $\mathrm{Xu}$ and Jaggars (2013) examined student adaptability to online learning by comparing performance in online courses to performance in face-to-face courses in a study of nearly 500,000 online and face-to-face courses taken by more than 40,000 degree-seeking students enrolled in one of 34 community and technical colleges in Washington State. The study examined specific student characteristics believed to have an impact on online learning performance, focusing on students' gender, age, and prior academic performance (GPA). The researchers found statistically significant relationships in all three areas, as well as in adaptability to online learning by academic subject, noting that online courses might be more engaging or effective in some subject areas than in others. Online courses that tended to be more popular were in the arts and humanities subjects, and less popular in natural science areas. Yet, students were relatively better able to adapt to online learning in the subjects of computer science, applied professions, and natural science.

Lander (2009) looked at a variety of demographics, including age, gender, field of study, and previous experience online, as independent variables to investigate the relationships among online community college students' characteristics and instructional delivery model preferences. Only program of study emerged as having a significant relationship in regards to online students' individual preferences, interactive learning 
preferences, social presence (not the same type of social presence as defined by the Community of Inquiry framework) preferences, and environmental preferences. Online students in health programs tended to have higher scores in individual preferences, while math and science and engineering and computer science online students tended to have lower scores in interactive learning preferences, social presence preferences, and environmental preferences compared to humanities, social science, and education online students.

In 2011, Hamilton examined predictor variables in a community college study of persistence in six health-related programs of study. Of the many demographic variables that Hamilton studied, the findings revealed a statistically significant difference in only program of study in relation to persistence rates among the specific health-related programs. In a descriptive analysis, Scism (2006) looked at the association between online course completion in a metropolitan community college and noted student characteristics. Scism examined specific variables that included gender, age, and program of study. A univariate analysis found the highest percentage of online course completion for females, and those students aged 40 to 55 years. Scism also found that online health courses had the highest percentage of completion.

Age. Five studies supported the use of age as being a statistically significant demographic to consider in studying community college students. Age is defined as the length of time during which a human being has existed; measured by years from birth. As Scism (2006) found, Xu and Jaggars (2013) cite that many studies support the notion that, in community colleges, older students are more likely to complete online courses than their younger counterparts. Colorado and Eberle (2010) argued that older students' success in 
online learning may be due to increases with age in levels of rehearsal, elaboration, critical thinking, and metacognitive self-regulation - each of which may contribute to success in online coursework. To explain the stronger performance of non-traditional students within their study of online courses, as well as student retention, York (2003) examined age. The researcher discovered that with the variable of age, a statistically significant relationship existed between student performance and attrition. Older students (aged 24 and older) performed at higher levels and withdrew less often than younger students (aged 18-23) in online courses.

Dolan (2011) examined student engagement in online community college classes in relation to asynchronous reflective discussions. The researcher found a statistically significant difference in engagement scores for those aged 26 to 34 as compared to a younger group of 18- to 25-year olds, with the engagement scores of the older group being significantly higher. Dolan cited this as no surprise to community college instructors who often see students in this age group beginning college or returning to college with more life experiences and more responsibilities. “Those attributes, along with a general settling down, tended to make the students in this age group more serious about their studies and more likely to be engaged in the class" (p. 52). Hampton (2010) shared a similar sentiment when researching student characteristics and student immediacy in the community college environment in regards to reducing distance in online learning. Hampton found that the interaction effects of student age and gender did significantly influence affective immediacy behaviors. Hampton concluded "that reducing the psychological distance felt between online students is rooted in the ability of those students to get to know their online classmates through meaningful and authentic interaction" (Hampton, 2010, np). 
As Xu and Jaggars approached the student characteristic of age, they utilized the notion founded in research "that older students may perform more successfully than younger students in online courses is intriguing, given that older college students tend to have poorer academic outcomes overall" (Xu \& Jaggars, 2013, p. 3). The researchers found that while both older and younger students show significant negative coefficients for online learning, the estimates for older students were significantly weaker than those for younger students for both course persistence and course grade. “... it appears that older students' superior adaptability to online learning lends them a slight advantage in online courses in comparison with their younger counterparts" (Xu \& Jaggars, 2013, p. 17).

Gender. Three studies supported the use of gender as a statistically significant demographic to consider in studying community college students. Gender is defined as all the members of one sex; the state of being male or female. Xu and Jaggars (2013) confirmed that many studies show no differences between males and females in terms of their learning outcomes in online courses. Others, though, have found that women perform significantly better than men (McSporran \& Young, 2001; Payn, 2009).

To explain the stronger performance of women within their study of online courses, McSporran and Young (2001) used a mixed-methods approach of course observation and student survey data. They concluded that women in their sample were more motivated, more adept at communicating online, and more effective in scheduling their learning. Male students, in contrast, accessed fewer discussion forum posts and course website pages, had poorer time management skills, and tended to be overconfident in terms of their ability to complete learning tasks and assignments. In a much different approach to a gender study, Payn (2009) explored the learning needs of women learners in community college online 
environments. Learning styles were conceptualized through epistemological strategies and stages according to the learner's life phase. Payne concluded that gender-related reasoning patterns were evident in the mixed-method research study, with $90 \%$ of those in the survey and $83 \%$ of those interviewed reflecting language that expressed an alignment with their gender-related reasoning patterns.

As Xu and Jaggars (2013) approached the student characteristic of gender, they utilized the notion founded in research that women may perform more strongly than men in online courses. They posed questions such as "Do women more easily adapt to online courses than men? Put another way, is the gap between male and female performance wider or narrower within the online context than within the face-to-face classroom context?" (Xu \& Jaggars, 2013, p. 2). After completing the research, Xu and Jaggars reported that men had stronger negative coefficients for online learning compared to women in terms of both course persistence and course grade. The researchers interpreted that “(1) men had more difficulty adapting to online learning than did women; and (2) while females outperformed their male counterparts on average across all courses, the gender performance gap was stronger in the online context than in the face-to-face context" (Xu \& Jaggars, 2013, p. 17).

GPA. Two studies supported the use of GPA as a statistically significant demographic to consider in studying community college students. GPA is defined as an indication of a student's academic achievement at a college or university, calculated as a total number of grade points received over a given period divided by the total number of credits awarded. A recent Community College Research Study (CCRS) found that while all online community college students show a decrease in performance in fully online courses, some 
students show a deeper decline than others, including males and students with lower prior GPAs. This study conducted for the CCRS by Xu and Jaggars (2013) noted that performance gaps that exist among these subgroups of gender and GPA in face-to-face courses become more pronounced in fully online courses. Specifically in regards to GPA as a student characteristic in online courses, the researchers found that lower performing students $(<3.02 \mathrm{GPA})$ were $2 \%$ more likely to drop out of face-to-face courses than higher performing students (>3.02 GPA). In online courses, lower performing students were 4\% more likely to drop out. The results in regards to GPA indicated that students with stronger academic capacity tended to be less negatively affected by online courses. That proved an assumption of the research that low-GPA students would have more difficulty adapting to the online context than high-GPA students:

... students with weaker academic preparation may also have insufficient time management and self-directed learning skills, both of which are thought to be critical to success in online and distance education. Thus, while one would expect students with lower levels of academic preparation to fare more poorly in any course compared to their better prepared peers, one might expect that performance gap to be even wider in the online context. (Xu \& Jaggars, 2013, p. 4)

The CCRS study found GPA to be a predictive analytic to consider in retention. Thomas' research (2005) found GPA to be a characteristic of course completion as well. While Thomas measured student responses according to traditional versus nontraditional ages, GPA emerged as a significant variable in the study examining which support services met the needs of online community college students in regards to completion. When looking at course completers, Thomas found that with traditionally-aged respondents, few 
had dependents, they earned higher GPAs, and they rated themselves both more confident of mastering the class and more satisfied with understanding the course content. In the non-traditional completer category, Thomas found that respondents in the younger age bracket of that older group had more confidence in completing the course, they were enrolled for more credit hours, and that they had significantly fewer dependents in their households.

Online Course Experience. Two studies supported the use of online course experience as being a statistically significant demographic to consider in studying community college students. Online course experience is defined as the number of online courses a student completes in the course of his/her educational studies. Kennedy (2001) examined previous experiences with online learning. In Kennedy's qualitative study, previous experience in a learning context that focused on online communication and asynchronous instruction emerged as a significant factor. When looking at students who did not complete online courses, Kennedy found little previous experience with online technology and asynchronous instruction directly related to non-completion of the course. Beavers (2009) completed a case study of community college students' perceptions regarding faculty's practice of online course delivery at a Virginia community college. The findings of the study indicated that as the number of online courses that a student successfully completed increased, so did the student's preference of distance learning over the traditional classroom environment.

Internet Access. Four sources and one study supported the use of Internet access at home as being a statistically significant demographic to consider in studying community college students. Internet access at home is defined as the type of Internet service provided 
in the respondent's home. Problems with technology are a noted disadvantage in online learning. This disadvantage encompasses a concern for adequate Internet access at the home. At the time the survey was conducted, it was unknown how many students in the study population would have adequate Internet access as no known studies existed. In recent years the State of West Virginia developed a goal for its Broadband Deployment Council: "Promote deployment of low-cost, innovative, and affordable broadband access to all its citizens" (Aviat, 2011). A chance for funding became available in 2009 with the debut of the federal stimulus programs for broadband in underserved and unserved areas. West Virginia pursued this chance for funding and developed an overarching vision of universally available broadband communications. The state planned for its Internet providers to collaborate on the project instead of competing.

The West Virginia Statewide Broadband Infrastructure Project planned to bring high-speed Internet access to all parts of the state by increasing the state's existing microwave public safety network and add 2,400 miles of fiber, the means by which the high-speed or broadband access is delivered. The expanded statewide network proposed to directly connect more than 1,000 anchor institutions, including public safety agencies, public libraries, schools, government offices, and other critical community facilities at speeds up to $45 \mathrm{Mbps}$ (BroadbandUSA, 2013). As a result of the project, every K-12 school in the state will have high-speed Internet connection. In addition, access to healthcare, distance learning opportunities, and broadband and video applications for emergency first responders will be increased. The project goal was to make affordable broadband service available to more than 700,000 households, 110,000 businesses, and 1,500 anchor institutions (including 55 county courthouses, 344 police stations, 447 fire departments, 
471 schools, 34 jails, and 176 public libraries) by allowing the local Internet service providers to connect to this open network.

An expectation of the broadband project for West Virginia was to raise the state's ranking for per capita access to one of the highest among all 50 states. The state received a grant of more than $\$ 126$ million to complete this project. As of a report filed on November 22,2013 , the project is 92 percent completed with a total of 17 new towers and 494 new wireless links installed (BroadbandUSA, 2013). According to Speedmatters.org, broadband access increased from 72 percent to 91 percent in West Virginia in the last four years (speedmatters.org, 2013). The Federal Communications Commission defines basic broadband or high-speed Internet at speeds greater than 4 mbps download and 1 mbps upload. The West Virginia Statewide Broadband Infrastructure Project is allowing for more access and higher speeds of Internet.

The reality, though, is that not all West Virginians are using broadband even if it is available. "Because West Virginia has a low-income population, the percentage actually using broadband is considerably less — only about 60 percent" (speedmatters.org, 2013). In looking at trends in home broadband adoption, the Pew Research Internet Project (2013) analyzed the nationwide availability of broadband Internet connections in homes. As of May 2013, 70\% of American adults aged 18 and older had a high-speed broadband connection to the Internet at home (Zickuhr \& Smith, 2013). "The demographic factors most correlated with home broadband adoption continue to be educational attainment, age, and household income" (Zickuhr \& Smith, 2013, p. 1). It is more common for college graduates to have high-speed Internet (90\%), and far less common for those who did not graduate high school to have high-speed Internet access (37\%). Other demographics of 
importance in determining whether those who have access to broadband actually utilize it are age and income. Adults under the age of 50 are more likely to have broadband at home, and those living in households earning at least $\$ 50,000$ per year are more likely to have broadband access at home.

\section{Research Procedures}

This section includes the validity and reliability of both the survey selected and the survey developed. For the survey developed, this section also includes information on the panel of experts utilized to validate the survey instrument and how its reliability will be established. Finally, the section examines the proposed data collection and data analysis methods for this particular study.

Validity and reliability are often used to describe the quality of quantitative studies. The relationship between the two aspects of research is that both are desired. At best, a study can have a measure that has both high validity and high reliability. It yields consistent results in repeated application and is an accurate reflection of what the researcher intended to measure.

Validity is the extent to which a survey or test measures what it is supposed to measure. A valid survey should satisfy four criteria: face validity, content validity, criterion-related validity, and construct validity (Kimberlin \& Winterstein, 2008). Face validity is the extent to which the measurement method appears on its face to measure the construct of interest. Content validity is the extent to which the measurement method covers the entire range of relevant behaviors, thoughts, and feelings that define the construct being measured. Criterion-related validity is the extent to which respondents' scores are correlated with criteria that reflect the same construct. Construct validity is 
determined by a series of validation studies that can include content and criterion-related approaches to determine whether the construct underlying a variable is actually being measured. Validity is the most important characteristic a survey or test can have. Without validity, the interpretations of the data have inappropriate (or no) meaning (Gay, Mills, \& Airasian, 2006).

The most commonly used measure of validity is a correlation coefficient. Correlation coefficients range in absolute value from 0 to 1.00. A correlation of 1.00 indicates two measures are perfectly related. This is particularly helpful in making predictions from ratings. A correlation of 0 indicates two measures are unrelated. In practice, validity coefficients for a single test rarely exceed .50 . A validity coefficient of .30 or higher is generally considered useful for most circumstances (Biddle, 2005).

Reliability is the extent to which results are consistent over time and are an accurate representation of the total population. A reliable study is one which can be reproduced under a similar methodology. A reliable study should exhibit test-retest reliability, interitem reliability, and, if applicable, inter-observer reliability. Reliability coefficients range from 0.00 to 1.00 , with higher coefficients indicating higher levels of reliability. Reliability refers to the level of confidence a researcher can place in a study.

Cronbach's alpha is a widely used measure of determining internal consistency reliability. It is a function of the average intercorrelations of items and the number of items in the scale. It is used for summated scales. The greater the number of items in a summated scale, the higher Cronbach's alpha tends to be, with major gains being in additional items. "This is one reason why the use of a single item to measure a construct is not optimal. Having multiple items to measure a construct aids in the determination of the reliability of 
measurement and, in general, improves the reliability or precision of the measurement" (Kimberlin \& Winterstein, 2008, p. 2277). Cronbach's alpha will be used in this study to measure reliability. Cronbach's alpha is calculated following the collection of data. The formula for Cronbach's alpha is:

$$
\alpha=\frac{N \cdot \bar{c}}{\bar{v}+(N-1) \cdot \bar{C}}
$$

In the formula, $\mathrm{N}$ is equal to the number of survey items, c-bar is the average inter-item covariance among the items, and v-bar equals the average variance of the survey items.

CoI Instrument. This section examines the already developed Community of Inquiry (CoI) instrument (Arbaugh et al., 2008). Researchers who validated the CoI instrument did so with a university student population. Many of the studies since that validation also focused on university student populations. However, the instrument is not specific to a certain student population and can be used by varying groups. Since the instrument's validation in 2008, community college researchers have utilized it multiple times in conducting studies on social, teaching, and cognitive presence (Capra, 2012; Hampton, 2010; McWhorter, 2013; Morris, 2010). It has proven to be an effective instrument in assessing social, teaching, and cognitive presence in the community college environment.

The Community of Inquiry (CoI) instrument, a 34-item questionnaire (see Appendix A), was utilized to assess social, teaching, and cognitive presence in the online classroom environment. The CoI instrument utilizes a five-point Likert scale ( 1 = strongly disagree; 2 = disagree; 3 = neutral; 4 = agree; 5 = strongly agree). Use of a "neutral" or "don't know" response column is an area of debate. "It depends on whether it's appropriate to force your 
respondents to agree or disagree" (Suskie, 1996, p. 34). Suskie also cites the original proposal for the Likert scale from 1932 by Rensis Likert that had the categories of strongly approve, approve, undecided, disapprove, and strongly disapprove. Over the years, the most common headings of Likert rating scales changed and mirror those utilized in the CoI instrument. Likert scales span a spectrum from one extreme to the other. The advantages of this type of rating are a) the format is familiar and easy to complete, b) the scales are efficient in being able to provide much information quickly and compactly, and c) the scales are successfully used to measure attitudes and opinions more than factual information. The challenge for survey creators is to write Likert scale questions that are unambiguous and those that do not yield biased results "because people are generally more inclined to agree than disagree with a statement" (Suskie, 1996, p. 33). Researchers have disputed the assessment of Likert scales through either non-parametric statistics for ordered data or parametric data. It is argued that many parametric data analyses for scaled data are sufficiently robust to be used with Likert data. "'Robust' means that, while these statistical analyses assume that the data are scaled, using interval data will probably not change the results significantly" (Suskie, 1996, p. 35).

The CoI instrument measures teaching presence by assessing perceptions about organization, facilitation, and direct instruction. The CoI instrument measures social presence by assessing perceptions about affective expression, open communication, and group cohesion. The CoI instrument measures cognitive presence by assessing perceptions about triggering events, exploration, integration, and resolution. It was expected that these perceptions were directly influenced by the interactions and communications that take place among students, between students, among the instructor and students, and between 
the instructor and students through asynchronous communication tools provided as part of the course.

Due to the structure of each of the presences and their inter-relationships, the researchers used a lens of construct validity to create a "psychometrically sound survey instrument with the potential to expand the study of online and blended learning" (Arbaugh et. al., 2008, p. 134). A Principal Components Analysis of the data from the test of the CoI instrument supported the construct validity of social presence, teaching presence, and cognitive presence measured by the instrument. Construct validity concerns the extent to which a measure is related to, or correlates with, theory or previous research. The results of the CoI instrument study found it met requirements of construct validity, deeming the survey as a valid measure of social presence, teaching presence, and cognitive presence.

In particular Arbaugh et al., (2008) noted correlation to demonstrate an overlap of the three presences, thus further denoting construct validity of the instrument: ... construct validity is highly dependent on the context in which measurement occurs. For example, were these Teaching Presence items administered to respondents independent of the remaining items for Social and Cognitive Presence, respondents' perceptions may be markedly different. In attempting to merge three separate constructs into one instrument, investigators assume the risk of unintentionally creating new and complex phenomena resulting from interactions among the three constructs. In fact, the results of this study suggest there is such an overlap, as evidenced by the correlation among factors. (p. 136) 
In regards to construct validity, researchers also found the $\mathrm{CoI}$ instrument supported the original definition for cognitive presence, thus another affirmation of the measure being valid. In tests for the CoI instrument (Arbaugh et al., 2008), researchers determined it to be both reliable and valid for uses "in studies that examine the CoI elements as predictor variables of course outcomes and as criterion variables in studies examining the extent to which the course characteristics encourage or inhibit the development of social, teaching, and/or cognitive presence" (p. 136). A predictor variable is one that can be used to predict the value of another variable, such as those used in statistical regressions. The criterion variable is the quality or attribute used to measure the effect of an independent variable, and is sometimes referred to as the dependent variable.

A team of seven researchers at four institutions used the CoI instrument with students in graduate business and education courses (Arbaugh et al., 2008; Swan et al., 2008). Participating institutions were located in the United States and Canada. In the summer of 2007, 287 students volunteered to complete the survey, yielding a response rate of $43 \%$. Cronbach's alpha, a statistical procedure used to assess the reliability of scores, yielded internal consistencies of 0.94 for teaching presence, 0.91 for social presence, and 0.95 for cognitive presence. This is well above the recommended level of 0.7 for each accepted scale (Kimberlin \& Winterstein, 2008).

Since the CoI instrument validation, many researchers have utilized the tool in their studies to break new ground in online and blended learning research and practice at a variety of institutions of higher education. Shea et al. (2010), a well-known researcher for large-scale, quantitative explorations of the development of communities of inquiry in general and teaching presence in particular, looked deeply into interrelationships among 
the presences by analyzing all discourse in two business management courses that had the same instructional design template, but two different instructors. Shea et al.'s research team also examined the efficacy of social network analysis for understanding the dynamics of online learning within a CoI framework. The researchers found complex relationships exist among the three presences. This study resulted in a call for future research that would examine more aspects of online courses, not just discussion posts, for evidence of social, teaching, and cognitive presences.

Diaz et al. (2010) analyzed the usefulness of the CoI instrument in investigating student perceptions of the survey items. The group worked with 413 students from multiple institutions to rate their courses and then how important they perceived each of the items to be. In a summation of the work with Diaz et al. (Swan \& Ice, 2010), the fellow researchers noted special interest in relation to social presence. "Though frequently given the least attention in comprehensive research, this analysis found the highest degree of parity between what students considered important and their perceptions of effective implementation in this area" (Swan \& Ice, 2010, p. 3).

In a final study examined, Garrison, Cleveland-Innes, and Fung (2010) used the CoI instrument to investigate relationships among the three presences in the perceptions of 205 students enrolled in fourteen courses by two masters level programs. Arbaugh, Bangert, and Cleveland-Innes (2010) conducted a study to examine disciplinary differences in the perceptions of social, teaching, and cognitive presences in more than 1,500 students at two institutions. They looked specifically at cognitive presence in relation to the students' program of study. 
Survey Development. An applicable pre-existing survey for the study of asynchronous communication tools could not be found. It became necessary for the researcher to develop a survey to address this portion of the research questions to gather the perceptions of students' satisfaction with the use of asynchronous communication tools in the online classroom. Specifically, the survey examined the use of e-mail, discussion boards or forums, blogs or weblogs, wikis, and podcasting. Demographic information regarding student program of study, age, gender, GPA, prior online experience, and Internet access also were gathered in the questionnaire.

The survey method is useful in investigating a variety of educational problems and issues. "The primary reason for using surveys as data collection tools for improving courses, programs, and instruction is to obtain students' opinions, attitudes, or beliefs" (Shank, 2010, p. 11). A researcher would choose a survey format over personalized interviewing of respondents if the study examines a general trend in people's opinions, experiences, and behaviors, if the goal is to learn general patterns from many people. "Surveys are particularly useful to find small amounts of information from a wider selection of people in the hopes of making a general claim" (Driscoll, 2011, p. 163).

Survey development should be based on the principles of accuracy and relevancy (Suskie, 1996). Suskie provides a list of goals for a researcher to consider when crafting a survey. Those include writing items that a) convey the meaning of the inquiry exactly as the research is intended, b) ensuring items avoid broad generalizations about attitudes or opinions, as well as avoidance of biased, loaded, leading or offensive questions, and c) minimizing the time burden on respondents. "The respondent should easily understand how to decide on an answer and how to record it. A simple answer format requiring only a 
few checks is better than a complicated scoring key" (Suskie, 1996, p. 48). Questions should be based on the objectives of the survey and the information to be collected. Survey authors must develop items that accurately provide the desired information by constructing survey items derived from objectives of the research. Suskie (1996) suggests that those questions be posed as brief, objective, simple, and specific.

The review of literature about asynchronous communication tools provided information that was used in the development of survey items. The review of literature identified five categories as asynchronous communication tools. The survey item on asynchronous communication tools included "none of these used" as a responsive choice, as not all students utilize all tools. The Asynchronous Communication Questionnaire (see Appendix B) developed by the researcher for this study focuses on student perceptions of satisfaction with e-mail, discussions or forums, blogs/weblogs, wikis, and podcasting. As a Likert rating scale is used for the CoI instrument, the same approach was utilized in measuring student satisfaction with the use of asynchronous communication tools in the online course.

Validity and Reliability in this Study. In review, validity and reliability are often used to describe the quality of quantitative studies. The relationship between the two aspects of research is that both are desired. At best, a study can have a measure that has both high validity and high reliability. It yields consistent results in repeated application and is an accurate reflection of what the researcher intended to measure.

Validity of the Asynchronous Communication Questionnaire was established by inviting a panel of experts to review the survey instrument before it was administered (Suskie, 1996). Cronbach's alpha, a coefficient of the internal consistency of a test, was 
utilized to measure the reliability of the research. The next section of the chapter describes these research procedures.

Panel of Experts. A review by a panel of experts is an effective means of providing validity to a survey instrument. Asking experts to review a survey before it is administered reveals if the items are clear and easily understood, and determines the survey's relationship with the study's research questions (Suskie, 1996). Individuals selected to evaluate a survey should include those possessing familiarity with the proposed field of study, as well as experience in survey design.

The researcher selected a panel of four individuals (as well as an alternate) to review and provide feedback on the survey. Two of the individuals are nationally-known experts in the field of the Community of Inquiry framework. One helped develop the original framework, and the other helped to validate the CoI survey instrument, as well as being an authority on asynchronous learning networks. The third expert is a nationallyknown expert in community college studies, completing work on the national level for the Community College Research Center on topics such as online education and instructional technology. The fourth is an expert on emerging technologies in online courses.

Panel members who reviewed the survey are: Dr. D. Randy Garrison, Director of the Teaching \& Learning Centre and a Professor in the Faculty of Education at the University of Calgary; Dr. Karen Swan, Professor of Educational Leadership at the University of Illinois Springfield and Co-Chair of the Sloan-Consortium Research Symposia Series; Dr. Shanna Smith Jaggars, Assistant Director of the Community College Research Center, Teachers College, Columbia University; and Dr. Ke Zhang, Associate Professor of Instructional Technology for Wayne State University College of Education. 
The researcher invited panel members to participate in the survey review via an email that briefly described the nature of the study (see Appendix E). Upon acceptance of the invitation, the researcher sent a second email containing a draft copy of the survey (see Appendix F), as well as reviewer instructions and a response form (see Appendix G). The researcher will incorporate suggestions from the panel of experts into the survey prior to its distribution to the study population.

The researcher asked the panel to review the survey and provide feedback on the following questions (Suskie, 1996):

- Is each survey item clear and easily understood?

- Is each survey item related to the study's topic and goals?

- Are there survey items that should be deleted? If so, which one(s)?

- Are there survey items that should be modified? If so, which one(s)?

- Are there additional survey items you would recommend? If so, please describe the item(s) and provide a rationale.

- Are the instructions to the respondents clear and easily understood?

- Do respondents have adequate assurance of confidentiality and anonymity?

- Is there an unreasonable cost or burden to the respondent population?

Responses from the panel helped revise the final survey to make it more clear to participants. The comments from experts noted they were glad to see more research being conducted in this area. They felt the survey was mostly clear and felt it would be a valid way to measure the intended goals of the survey. They did offer suggestions on making the survey even more clear. Changes that occurred as a result of their comments included: 1 ) adding another category to the question regarding GPA to allow for those with no GPA in 
their first semester to also respond, 2) reducing the options for number of online courses taken to just two options of "one or two" or "three or more," 3) including the definition of an online course to the question asking how many students had taken, 4) the use of words such as dial-up and broadband were removed from the Internet access question and replaced with descriptive words that were easier for survey participants to understand; 5) the definition of wikis was modified on the survey to be "a web-based tool that allows many authors to edit the same document at the same time, and see each other's edits," 6) the definition of podcasts was modified on the survey to be "a broadcast of audio or video files over the Internet, which you can play back on your mobile device or personal computer," 7) the question about tool satisfaction was altered to include a description of "it helps me to make meaningful connections with the instructor and other students, and to deeply engage with the course content."

Data Collection. The sequence of collecting data included the following steps:

Step 1: The study population was sent an e-mail to participate in the survey. The e-mail described the purpose of the research and explained that participation was voluntary and included the right to omit items that an individual did not want to answer. The e-mail ensured anonymity and confidentiality of information; no data reflecting responses from specific online courses were released. Last, the e-mail contained the researcher's contact information and informed participants of the opportunity to provide contact information voluntarily if they wished to participate in a drawing for gasoline cards given in appreciation for completing the surveys. Respondents 
could also provide contact information if they wished to receive a copy of the study's results upon completion.

Step 2: A reminder e-mail was sent out two days after the first message.

Step 3: After two weeks the survey was closed, and data analysis began.

Data Analysis. Mean scores and standard deviations were calculated for each of the survey items to determine community college student perceptions of student satisfaction with asynchronous communication tools and the correlating relationship to community college student perceptions of satisfaction of social, teaching, and cognitive presence. The survey instrument utilized a Likert rating scale that enabled respondents to span the spectrum from "strongly disagree" to "strongly agree." Scores ranged between 1 (strongly disagree) and 5 (strongly agree). In the CoI instrument, respondents also had the opportunity to select "neutral" as a response to all survey items. With the CoI instrument, those items with a 4 or 5 were viewed as factors that show a strong indication of the corresponding presence (social, teaching, or cognitive) in the course, and those items with a 1 or 2 were viewed as factors that show a weak indication of the corresponding presence (social, teaching, or cognitive) in the course. In the Asynchronous Communication Questionnaire developed by the researcher, those items with a 4 or 5 were viewed as factors demonstrating how those specific tools (e-mail, discussions or forums, blogs/weblogs, wikis, or podcasting) show satisfaction with communication in the course, and those items with a 1 or 2 were viewed as factors demonstrating how those specific tools (e-mail, discussions or forums, blogs/weblogs, wikis, or podcasting) show dissatisfaction with communication in the course. 
The researcher administered tests of frequency to the demographic questions of the Asynchronous Communication Questionnaire. A frequency distribution is the arrangement of values that one or more variables take in a sample. Each entry in the table contains the frequency or count of the occurrences of values within a particular group or interval. The table summarizes the distribution of values in the sample. A frequency distribution shows a summarized grouping of data divided into mutually exclusive classes and the number of occurrences in a class. An analysis of variance (ANOVA) is a statistical technique used to compare groups on possible differences in the mean of a quantitative study.

The researcher administered tests of significance ( $t$-independent tests) to determine if differences exist in community college student perceptions of satisfaction with asynchronous communication tools and the correlating relationship to community college student perceptions of satisfaction of social, teaching, and cognitive presence. Other posthoc tests that the researcher performed included Mauchly's Test of Sphericity, GreenhouseGeisser correction, and the Bonferroni correction. Data from the one-way ANOVA with repeated measures were analyzed using a within subjects effect. Mauchly's Test of Sphericity indicated that the assumption of sphericity had been violated $(p=0.000)$. Therefore degrees of freedom were corrected using Greenhouse-Geisser estimates of sphericity. A t-test is a statistical process to assess the probability that a particular characteristic of two groups is different. Statistical analysis was using Statistical Package for Social Sciences (SPSS).

The specific method of data analysis for each research question was as follows: 
Question 1.a: What are community college student perceptions of satisfaction with the use of asynchronous communication tools in an online course in a Region V community college?

Responses from the community college students surveyed with the Asynchronous Communication Questionnaire were used to calculate the mean score (to describe the results) for each tool in the survey. The mean scores for the items were grouped according to the specific categories of tools they measure. These mean scores were used to determine which (if any) of the five asynchronous communication tool categories were perceived as showing satisfaction with the online course for students. Those items rated 4 or 5 indicated satisfaction with the use of the tool in the course, and those tools rated 1 or 2 indicated dissatisfaction with the use of the tool.

Question 1.b: Are community college students more satisfied with the use of one or more asynchronous communication tools than others in online courses in a Region $\mathrm{V}$ community college?

A repeated measure analysis of variance (ANOVA) test was used to determine if significant differences in student perceptions of asynchronous communication tools exist among the sample population. The researcher administered the Bonferroni correction to determine how community college student perceptions of satisfaction differ with the various asynchronous communication tools. In completing this analysis each tool was compared with the other tools (e.g., e-mail with discussions or forums, e-mail with blogs/weblogs, e-mail with wikis, e-mail with podcasting, discussions or forums with blogs/weblogs, discussions or forums with wikis, discussions or forums with podcasting, blogs/weblogs with wikis, blogs/weblogs with podcasting, and wikis with podcasting). 
Question 1.c: Which demographics have an effect on satisfaction with asynchronous communication tools in online courses in a Region V community college?

The researcher administered tests of significance ( $\mathrm{t}$-independent tests) to determine how community college student perceptions of satisfaction differ with the various asynchronous communication tools depending on the responses to the demographic questions asked as part of the Asynchronous Communication Questionnaire. In completing this analysis each demographic was compared with each tool. Did age A versus B differ on their rating of e-mail, on their rating of discussions or forums, on their rating of blogs/weblogs, on their rating of wikis, and on their rating of podcasting? Then the same analysis for gender M versus $\mathrm{F}$, and so on for online course experience, and program of study. A one-way analysis of variance (ANOVA) test was used to determine if significant differences exist for GPA and Internet access at home. Statistical significance was defined at the $p<.05$ level.

Question 2.a: What are community college student perceptions of satisfaction with social, teaching, and cognitive presence in an online course in a Region V community college?

Responses from the community college students surveyed were used to calculate the mean score (to describe the results) for each presence in the CoI survey. The mean scores for the items were grouped according to the specific categories of presence they measure. These mean scores were used to determine which (if any) of the three CoI presences are perceived as improving student satisfaction with the online course. Those items respondents rated with a 4 or 5 indicated a strong indication of the corresponding presence (social, teaching, or cognitive) in the course, and those items respondents rated 
with a 1 or 2 indicated a weak indication of the corresponding presence (social, teaching, or cognitive) in the course.

Question 2.b: Are community college students more satisfied with the use of one or more of social, teaching, and cognitive presence in online courses in a Region V community college?

A repeated measure analysis of variance (ANOVA) test was used to determine if significant differences in student perceptions of presence exist among the sample population. The researcher administered tests of significance (t-independent tests) to determine how community college student perceptions of satisfaction differ with the various presences. In completing this analysis each presence was compared with the other presences (e.g., social with teaching, social with cognitive, teaching with cognitive).

Question 2.c: Which demographics have an effect on satisfaction with social, teaching, and cognitive presence in online courses in a Region V community college?

The researcher administered tests of significance ( $t$-independent tests) to determine how community college student perceptions of satisfaction differ from the various presences depending on the responses to the demographic questions asked as part of the Asynchronous Communication Questionnaire. In completing this analysis each demographic was compared with each presence. Did age A versus B differ on their rating of social presence, on their rating of teaching presence, and on their rating of cognitive presence? Then the same analysis for gender M versus F, and so on for online course experience, and program of study. A one-way analysis of variance (ANOVA) test was used to determine if significant differences exist for GPA and Internet access at home. Statistical significance was defined at the $p<.05$ level. 
Question 3.a: What is the relationship between community college student perceptions of satisfaction with the use of asynchronous communication tools and community college student perceptions of satisfaction with social, teaching, and cognitive presence?

Pearson Correlation tests were used to determine whether the outcomes of the CoI variables (social, teaching, or cognitive presence) correlated with student perceptions of the use of asynchronous communication tools (e-mail, discussions or forums, blogs/weblogs, wikis, or podcasting) in the online class. Thus, each tool was correlated with each presence (e.g., e-mail with social presence, e-mail with teaching presence, e-mail with cognitive presence, discussions or forums with social presence, discussions or forums with teaching presence, and so on for a total of 15 correlational relationships).

Question 3.b: How does the relationship between community college student satisfaction with asynchronous communication tools and social, teaching, and cognitive presence vary depending on the different demographics?

The correlation test results from RQ3.a. were examined in relation to the ANOVA and T-test results from RQ1.c. and RQ2.c. to assess if the relationship between community college student satisfaction with asynchronous communication tools and social, teaching, and cognitive presence varied depending on the different demographics.

\section{Summary}

The purpose of this study was to answer the following research questions: 1.a. What are community college student perceptions of satisfaction with the use of asynchronous communication tools in a Region V community college? 1.b. Are community college students more satisfied with the use of one or more asynchronous communication 
tools than others in online courses in a Region V community college? 1.c. Which demographics have an effect on satisfaction with asynchronous communication tools in online courses in a Region V community college? 2.a. What are community college student perceptions of satisfaction of social, teaching, and cognitive presence in a Region $\mathrm{V}$ community college? 2.b. Are community college students more satisfied with the use of one or more of social, teaching, and cognitive presence in online courses in a Region $\mathrm{V}$ community college? 2.c. Which demographics have an effect on satisfaction with social, teaching, and cognitive presence in online courses in a Region V community college? 3.a. What is the relationship between community college student perceptions of satisfaction of the use of asynchronous communication tools and community college student perceptions of satisfaction of social, teaching, and cognitive presence? 3.b. How does the relationship between community college student satisfaction with asynchronous communication tools and social, teaching, and cognitive presence vary depending on the different demographics?

The researcher used two instruments in this research. The Community of Inquiry (CoI) instrument (see Appendix A) was utilized to measure social, teaching, and cognitive presence in the online classroom environment. In tests for the CoI instrument (Arbaugh et al., 2008), it was determined both reliable and valid for uses in studies that examine the CoI elements as predictor variables of course outcomes and as criterion variables in studies examining the extent to which the course characteristics encourage or inhibit the development of social, teaching, and/or cognitive presence.

The Asynchronous Communication Questionnaire (see Appendix B), which was developed based on the literature review, was used to gather the perceptions of students' satisfaction with the use of asynchronous communication tools in the online classroom. 
Specifically, the survey examined the satisfaction and use of e-mail, discussions or forums, blogs or weblogs, wikis, and podcasting. Demographic information regarding student program of study, age, gender, GPA, prior online experience, and Internet access also was gathered in an Asynchronous Communication Questionnaire developed by the researcher.

Data for this study were collected through the survey of students taking online courses at a community college. The student body chosen for this study attends a Region V community college that is accredited to offer baccalaureate degrees. It is one of only 34 public institutions in the country classified as a Baccalaureate/Associate's College. This classification allows this community college to offer more than 40 programs of study and, thus, more online offerings to students. It currently has four completely online degree programs approved by the Higher Learning Commission. It does offer online availabilities for many courses, including general education courses, for a variety of students. In the Spring $2014,1,363$ students were taking an online course at the institution (J. Starkey, personal communication, March 16, 2014).

Chapter 3 described the research procedures used for this study, as well as procedures for data analysis. The chapter concluded with a description of the specific manner in which data was analyzed. Statistical tests for mean, standard deviation, and frequency will be conducted, as well as specific tests such as an analysis of variance, multiple comparisons, and Pearson Correlation tests. The results of these tests allowed the researcher to use this study to explain if statistically significant differences in student perceptions with the use of asynchronous communication tools do exist in online courses in a community college. The results of these tests also allowed the researcher to use this study to explain if statistically significant differences in student perceptions with social, 
teaching, and cognitive presence do exist in online courses in a community college. Finally, the researcher used this study to determine any correlations between the CoI variables of social, teaching, or cognitive presence, with the use of asynchronous communication tools (e-mail, discussions or forums, blogs/weblogs, wikis, or podcasting) in the online class. 


\section{Chapter 4}

\section{Data Analysis and Interpretation}

\section{Introduction}

The purpose of this study was to determine the relationship between community college student perceptions of satisfaction with asynchronous communication tools and community college student perceptions of satisfaction with social, teaching, and cognitive presence in online courses in a Region V community college. The study also considered which demographics have an effect on satisfaction with asynchronous communication tools in online courses in a Region V community college. Responses were collected from online students enrolled in a Region V community college during March of 2014. The Community of Inquiry (CoI) instrument was utilized to measure social, teaching, and cognitive presence in the online classroom environment. A survey based on the literature review was developed to gather the perceptions of students' satisfaction with the use of asynchronous communication tools in the online classroom. Tools included e-mail, discussions or forums, blogs or weblogs, wikis, and podcasting.

Chapter 4 includes the return rate and demographic statistics, provides data that addresses each of the study's research questions, and concludes with a summary of findings.

\section{Return Rate}

Data for this study were collected through the survey of students taking online courses at a community college. The student body chosen for this study attended a Region V community college that is accredited to offer baccalaureate degrees. In the Spring 2014, the population for this study consisted of the 1,363 students who were taking at least one 
online course at a Region V community college (J. Starkey, personal communication, March $16,2014)$

Of the 1,363 students, 430 completed the survey. The overall return rate was $31.5 \%$. An acceptable return rate is calculated to be 300 for a population of 1,363 with a $5 \%$ margin of error (Checkmarket, 2014). The survey for this study was an online survey that was initiated by e-mail.

\section{Demographic Information}

Six of the questions in the survey involved demographic information. The first question asked "What is your age?" The second question asked "What is your gender?" The third question asked "What is your overall GPA?" The fourth question asked "Including this semester, how many online courses have you taken at this community college?" The fifth question asked "In what program of study are you enrolled?" The sixth question asked "What type of Internet access do you have at your home?"

Table 4 displays the survey results for the first demographic question.

Table 4

Age of Respondents

\begin{tabular}{lc}
\hline \multicolumn{1}{c}{ Age } & $\begin{array}{c}\text { No. (\%) of } \\
\text { Respondents } \\
(\mathrm{N}=430)\end{array}$ \\
\hline $18-24$ & $186(43.3 \%)$ \\
25 or older & $244(56.7 \%)$ \\
\hline Total & $430(100 \%)$ \\
\hline
\end{tabular}


The largest number of respondents was students of a non-traditional age, those 25 years of age or older (244 or $56.7 \%$ ). The least number of respondents were traditional-aged students, falling into the category of 18 to 24 years of age (186 or $43.3 \%$ ).

Table 5 displays the survey results for the second demographic question in regards to gender.

Table 5

Gender of Respondents

\begin{tabular}{lc}
\hline \multicolumn{1}{c}{ Gender } & No. (\%) of \\
& $\begin{array}{c}\text { Respondents } \\
(\mathrm{N}=423)\end{array}$ \\
\hline Male & $94(22.2 \%)$ \\
Female & $329(77.8 \%)$ \\
\hline Total & $423(100 \%)$ \\
\hline
\end{tabular}

The largest number of respondents was females (329 or $77.8 \%$ ). The least number of respondents was males (94 or $22.2 \%$ ).

Table 6 displays the survey results for the third demographic question in regards to overall GPA.

Table 6

Overall GPA of Respondents

\begin{tabular}{lc}
\hline \multicolumn{1}{c}{ Overall GPA } & No. (\%) of \\
& Respondents $(\mathrm{N}=426)$ \\
\hline Above 3.0 & $284(66.7 \%)$ \\
$2.0-2.9$ & $123(28.9 \%)$ \\
Below 1.9 & $4(1.0 \%)$ \\
In first semester, no GPA & $15(3.4 \%)$ \\
\hline Total & $426(100 \%)$ \\
\hline
\end{tabular}


The largest number of respondents was those students with an overall GPA of above 3.0

(284 or $66.7 \%$ ). The least number of respondents was those with an overall GPA below 1.9

( 4 or $1.0 \%$ ). This indicates the majority of respondents were those with a high overall GPA.

It also indicates that a small portion of respondents (15 or 3.4\%) were first-time students in college, thus taking their first online courses.

Table 7 displays the survey results for the fourth demographic question in regards to previous online course experience.

Table 7

Online Course Experience of Respondents

\begin{tabular}{lc}
\hline \multicolumn{1}{c}{ Online Course Experience } & $\begin{array}{c}\text { No. (\%) of } \\
\text { Respondents (N = 426) }\end{array}$ \\
\hline One or two & $146(34.1 \%)$ \\
Three or more & $282(65.9 \%)$ \\
\hline Total & $428(100 \%)$ \\
\hline
\end{tabular}

The largest number of respondents was those who had taken at least three or more online courses (282 or $65.9 \%)$. The least number of respondents was those who had only taken one or two online courses (146 or $34.1 \%)$. This indicates the majority of respondents had more experience in online courses, already taking at least their third course in the online classroom.

Table 8 displays the survey results for the fifth demographic question in regards to the programs of study being pursued by the respondents. 
Table 8

Program of Study of Respondents by Academic Division

\begin{tabular}{|c|c|c|}
\hline Academic Division & Program of Study & $\begin{array}{c}\text { No. of } \\
\text { Respondents }\end{array}$ \\
\hline \multirow[t]{9}{*}{ Business and Economics } & Business Administration & 68 \\
\hline & Accounting & 39 \\
\hline & Business Technology & 35 \\
\hline & Public Relations & 13 \\
\hline & Journalism & 10 \\
\hline & Management/Marketing & 10 \\
\hline & General Business & 9 \\
\hline & Financial Management & 8 \\
\hline & Total Business and Economics & 192 \\
\hline \multirow[t]{5}{*}{ Non-Traditional Programs } & Regents & 56 \\
\hline & Board of Governors & 45 \\
\hline & Technical Studies & 5 \\
\hline & Occupational Development & 4 \\
\hline & $\begin{array}{l}\text { Total Non-Traditional } \\
\text { Programs }\end{array}$ & 110 \\
\hline \multirow[t]{5}{*}{ Education and Humanities } & Elementary Education & 44 \\
\hline & Child Development & 16 \\
\hline & General Studies & 14 \\
\hline & Multi-Disciplinary Studies & 7 \\
\hline & $\begin{array}{l}\text { Total Education and } \\
\text { Humanities }\end{array}$ & 81 \\
\hline \multicolumn{3}{|l|}{ Social Sciences and } \\
\hline \multirow[t]{3}{*}{ Languages } & Criminal Justice & 47 \\
\hline & Legal Studies & 8 \\
\hline & $\begin{array}{l}\text { Total Social Sciences and } \\
\text { Languages }\end{array}$ & 55 \\
\hline \multirow[t]{3}{*}{ Health Sciences } & Nursing & 36 \\
\hline & Surgical Technology & 5 \\
\hline & Total Health Sciences & 41 \\
\hline
\end{tabular}




\begin{tabular}{clc}
\hline Academic Division & \multicolumn{1}{c}{ Program of Study } & $\begin{array}{c}\text { No. of } \\
\text { Respondents }\end{array}$ \\
\hline STEM & Computer and Information & 9 \\
Technology & 5 \\
& Information Security & 4 \\
& Network Engineering & 3 \\
& Computer Science & 2 \\
& Software Engineering & 1 \\
3-D Modeling/Simulation Design & 1 \\
& Diversified Agriculture & 1 \\
& Energy Assessment/Mgmnt & 1 \\
& Engineering Technology & 1 \\
& Solar Energy Technology & 0 \\
\hline & Culinary Arts & $\mathbf{2 8}$ \\
\cline { 2 - 3 } & Total STEM & \\
Workforce and & & 2 \\
& & 0 \\
& Multi-Craft Technology & 0 \\
\hline & Machining Technology & $\mathbf{2}$ \\
\cline { 2 - 3 } & Welding Technology & \\
\cline { 2 - 3 } & Total Workforce and & \\
& Community Education & \\
\hline
\end{tabular}

The total number of responses exceeded the total number surveyed because respondents were able to provide more than one answer since some students at the Region $\mathrm{V}$ community college are dual enrolled in both an associate and baccalaureate program.

The programs of study offered at this Region $\mathrm{V}$ community college can be categorized into seven academic divisions - 1) Science, Technology, Engineering, and Mathematics (STEM); 2) Business and Economics; 3) Social Sciences and Languages; 4) Education and Humanities; 5) Health Sciences; 6) Non-Traditional Programs; and 7) Workforce and Community Education. The largest number of respondents was from the Business and Economics Division (192 or 37.7\%). This division includes the following academic programs of study: accounting, business administration, business technology, 
financial management, general business, journalism, management/marketing, and public relations. The second largest number of respondents was from the Non-Traditional Programs Division (110 or $21.6 \%$ ). This division includes the following academic programs of study: board of governors, occupational development, regents, and technical studies.

The third largest number of respondents was from the Education and Humanities Division (81 or $15.9 \%$ ). This division includes the following academic programs of study: child development, elementary education, general studies, and multi-disciplinary studies. The fourth largest number of respondents was from the Social Sciences and Languages Division (55 or $10.8 \%$ ). This division includes the following academic programs of study: criminal justice and legal studies. The fifth largest number of respondents was from the Health Sciences Division (41 or 8.1\%). This division includes the following academic programs of study: nursing and surgical technology. The sixth largest number of respondents was from the STEM Division (28 or 5.5\%). This division includes the following academic programs of study: 3-D modeling and simulation design, computer and information technology, computer science, culinary arts, diversified agriculture, energy assessment and management, engineering technology, information security, network engineering, software engineering, and solar energy technology. The least number of respondents was from the Workforce and Community Education Division (2 or 0.39\%). This division includes the following academic programs of study: machining technology, multi-craft technology, and welding technology.

Table 9 displays the survey results for the sixth demographic question in regards to Internet access that the survey respondents have at their homes. 
Table 9

Type of Internet Access of Respondents at their Homes

\begin{tabular}{lc}
\hline \multicolumn{1}{c}{ Type of Internet Access } & $\begin{array}{c}\text { No. (\%) of } \\
\text { Respondents } \\
(\mathrm{N}=430)\end{array}$ \\
\hline Moderately Quick Internet Access & $198(46.0 \%)$ \\
Quick and Reliable Internet Access & $188(43.7 \%)$ \\
Slow Internet Access & $30(7.0 \%)$ \\
No Internet Access & $14(3.3 \%)$ \\
\hline Total & $430(100 \%)$ \\
\hline
\end{tabular}

The largest number of respondents was those with moderately quick Internet access (198 or $46.0 \%$ ). The second largest number of respondents was those students who had quick and reliable Internet access at home (188 or 43.7\%). The third largest number of respondents was those students noted slow Internet access at home (30 or 7.\%). The least number of respondents was those with no Internet access at their homes (14 or 3.3\%).

Therefore respondents to this online survey tended to be: aged 25 or older $(56.7 \%)$, female (77.8\%), with an overall GPA above 3.0 (66.7\%), those who had taken more than three online courses (65.9\%), and those with either moderately quick or quick and reliable Internet access $(89.7 \%)$.

\section{Research Question 1}

Question 1.a: What are community college student perceptions of satisfaction with the use of asynchronous communication tools in an online course in a Region V community college?

Responses from the community college students surveyed with the Asynchronous Communication Questionnaire were used to determine which (if any) of the five 
asynchronous communication tools were perceived as showing satisfaction with the online course for students. Those items rated 4 or 5 indicated satisfaction with the use of the tool in the course, and those tools rated 1 or 2 indicated dissatisfaction with the use of the tool. Appendix I, Table I.1. presents the frequencies of satisfaction with each of the tools.

Podcasts had the highest satisfaction with a combined number of 84 respondents expressing satisfaction with the tool. Discussions or forums had the second highest satisfaction with a combined number of 74 respondents expressing satisfaction with the tool. E-mail had the third highest satisfaction with a combined number of 73 respondents expressing satisfaction with the tool. Blogs or weblogs had the fourth highest satisfaction with a combined number of 18 respondents expressing satisfaction with the tool. Wikis had the lowest satisfaction with a combined number of 11 respondents expressing satisfaction with the tool.

Question 1.b: Are community college students more satisfied with the use of one or more asynchronous communication tools than others in online courses in a Region $\mathrm{V}$ community college?

Community college students are more satisfied with the use of some asynchronous communication tools than others in online courses in a Region V community college. A repeated measure analysis of variance (ANOVA) test, found in Appendix J, Table J.1., was used to determine if significant differences in student perceptions of asynchronous communication tools existed among the survey respondents. The one-way ANOVA with repeated measures revealed a significant difference $(p=0.042)$ among participants' reported satisfactions with the use of various asynchronous communication tools (e-mail, discussions or forums, blogs/weblogs, wikis, or podcasting). 
To assure validity of the ANOVA, the researcher conducted post-hoc tests to include: Mauchly's Test of Sphericity, Greenhouse-Geisser correction, and the Bonferroni correction. Data from the one-way ANOVA with repeated measures were analyzed using a within subjects effect. Mauchly's Test of Sphericity indicated that the assumption of sphericity had been violated $(p=0.000)$. Therefore degrees of freedom were corrected using Greenhouse-Geisser estimates of sphericity. When using an ANOVA with repeated measures with a Greenhouse-Geisser correction, the mean scores were $F(3.195,223.65)=$ 2.516, $p<0.055$, as found in Appendix J, Table J.1. This means that the repeated measure ANOVA was still significant when conducting a test that alters degrees of freedom and reduces error rates. The tests validate the results that a significant difference did exist with student satisfaction of tools in the online course.

To determine which tool resulted in the most satisfaction for students, post-hoc tests using the Bonferroni correction revealed that a statistically significant difference did exist in the use of podcasts as compared to discussions or forums ( $p=0.003)$, blogs/weblogs $(p=0.011)$, and wikis $(p=0.036)$, as found in Appendix J, Table J.2. This means that participants were more satisfied with the use of podcasts than with the use of discussions, blogs, and wikis.

The repeated measures ANOVA showed both blogs/weblogs and wikis had a lower mean than the other tools. An analysis of the frequency of responses in the Likert scale questions in regards to satisfaction of the tool use in the online classroom, wikis and blogs also ranked much lower. This means that participants were less satisfied with wikis and blogs compared to e-mail, discussions, and podcasts. 
Question 1.c: Which demographics have an effect on satisfaction with asynchronous communication tools in online courses in a Region V community college?

The researcher administered tests of significance (t-independent tests) to determine how community college student perceptions of satisfaction differ with the various asynchronous communication tools depending on the responses to the demographic questions asked as part of the Asynchronous Communication Questionnaire. In completing this analysis of the five demographics, each demographic was compared with each of the five tools. Did age A versus B differ on their rating of e-mail, on their rating of discussions or forums, on their rating of blogs/weblogs, on their rating of wikis, and on their rating of podcasting? Then the same analysis for gender M versus F, and so on for online course experience, and program of study. Appendix K presents the comparison of perceptions with the tools regarding age, gender, and number of online courses taken. A one-way analysis of variance (ANOVA) test was also used to determine if significant differences exist for GPA and Internet access at home. Statistical significance was defined at the $p<.05$ level. Appendix L presents the variance of perceptions regarding the demographics and the tools. Only two tools had a significant finding in relation to the demographic number of online courses taken.

Region V community college students taking online courses did not yield a significant finding in satisfaction of tool use based on student perceptions of e-mail and age for those aged 18 to $24(M=3.59, S D=1.32)$ and those aged 25 and older $(M=3.75, S D=$ 1.22), $t=-1.34, p=0.178$, as found in Appendix K, Table K.1. The two age categories used included those aged 18 to 24, which are considered of traditional age, and those aged 25 
and older, which are considered of non-traditional age. The non-significant statistic means that the two groups are equal and any difference is due to error/chance.

Region V community college students taking online courses did not yield a significant finding in satisfaction of tool use based on student perceptions of e-mail and gender for female $(M=3.68, S D=1.30)$ and male $(M=3.70, S D=1.19), t=-0.14, p=0.891$, as found in Appendix K, Table K.2. The non-significant statistic means that the two groups are equal and any difference is due to error/chance.

Region V community college students taking online courses yielded a significant finding in satisfaction of tool use based on student perceptions of e-mail and the number of online courses students have taken, either one or two courses $(M=3.46, S D=1.36)$ or three or more courses $(M=3.79, S D=1.20), t=-2.50, p=0.013$, as found in Appendix $\mathrm{K}$, Table K.3. Respondents using e-mail in an online course at the Region V community college who had the experience of three or more online courses ranked the tool higher. With the $p<0.05$ these data mean that student perceptions of satisfaction with the use of asynchronous communication, specifically e-mail, in an online course in a Region V community college differ according to the number of courses taken.

Region V community college students taking online courses did not yield a significant finding in satisfaction of tool use based on student perceptions of discussions or forums and age for those aged 18 to $24(M=3.48, S D=1.27)$ and those aged 25 and older $(M=3.55, S D=1.38), t=-0.62, p=0.534$, as found in Appendix K, Table K.4. The two age categories used included those aged 18 to 24, which are considered of traditional age, and those aged 25 and older, which are considered of non-traditional age. The non-significant statistic means that the two groups are equal and any difference is due to error/chance. 
Region V community college students taking online courses did not yield a significant finding in satisfaction of tool use based on student perceptions of discussions or forums and gender for female $(M=3.52, S D=1.33)$ and male $(M=3.53, S D=1.33), t=-$ $0.09, p=0.928$, as found in Appendix K, Table K.5. The non-significant statistic means that the two groups are equal and any difference is due to error/chance.

Region V community college students taking online courses yielded a significant finding in satisfaction of tool use based on student perceptions of discussions or forums and the number of online courses students have taken, either one or two courses $(M=3.30$, $S D=1.45)$ or three or more courses $(M=3.62, S D=1.24), t=-2.35, p=0.019$, as found in Appendix K, Table K.6. Respondents using discussions or forums in an online course at the Region V community college who had the experience of three or more online courses ranked the tool higher. With the $p<0.05$ these data mean that student perceptions of satisfaction with the use of asynchronous communication, specifically discussions or forums, in an online course in a Region $\mathrm{V}$ community college differ according to the number of courses taken.

Region V community college students taking online courses did not yield a significant finding in satisfaction of tool use based on student perceptions of blogs/weblogs and age for those aged 18 to $24(M=2.97, S D=1.24)$ and those aged 25 and older $(M=$ 3.35, $S D=1.51), t=-1.51, p=0.134$, as found in Appendix K, Table K.7. The two age categories used included those aged 18 to 24, which are considered of traditional age, and those aged 25 and older, which are considered of non-traditional age. The non-significant statistic means that the two groups are equal and any difference is due to error/chance. 
Region V community college students taking online courses did not yield a significant finding in satisfaction of tool use based on student perceptions of blogs/weblogs and gender for female $(M=3.10, S D=1.42)$ and male $(M=3.42, S D=1.47), t=-1.09, p=$ 0.280, as found in Appendix K, Table K.8. The non-significant statistic means that the two groups are equal and any difference is due to error/chance.

Region V community college students taking online courses did not yield a significant finding in satisfaction of tool use based on student perceptions of blogs/weblogs and the number of online courses students have taken, either one or two courses $(M=3.11$, $S D=1.58)$ or three or more courses $(M=3.26, S D=1.28), t=0.54, p=0.591$, as found in Appendix K, Table K.9. The non-significant statistic means that the two groups are equal and any difference is due to error/chance.

Region V community college students taking online courses did not yield a significant finding in satisfaction of tool use based on student perceptions of wikis and age for those aged 18 to $24(M=3.09, S D=0.85)$ and those aged 25 and older $(M=3.11, S D=$ 1.18), $t=-0.08, p=0.934$, as found in Appendix K, Table K.10. The two age categories used included those aged 18 to 24, which are considered of traditional age, and those aged 25 and older, which are considered of non-traditional age. The non-significant statistic means that the two groups are equal and any difference is due to error/chance.

Region V community college students taking online courses did not yield a significant finding in satisfaction of tool use based on student perceptions of wikis and gender for female $(M=3.04, S D=1.02)$ and male $(M=3.25, S D=0.98), t$ $=-0.84, p=0.407$, as found in Appendix K, Table K.11. The non-significant statistic means that the two groups are equal and any difference is due to error/chance. 
Region V community college students taking online courses did not yield a significant finding in satisfaction of tool use based on student perceptions of wikis and the number of online courses students have taken, either one or two courses $(M=3.22, S D=$ 1.09) or three or more courses $(M=3.04, S D=0.98), t=-0.69, p=0.496$, as found in Appendix K, Table K.12. The non-significant statistic means that the two groups are equal and any difference is due to error/chance.

Region V community college students taking online courses did not yield a significant finding in satisfaction of tool use based on student perceptions of podcasts and age for those aged 18 to $24(M=3.58, S D=1.31)$ and those aged 25 and older $(M=3.71, S D$ $=1.09), t=-0.62, p=0.535$, as found in Appendix K, Table K.13. The two age categories used included those aged 18 to 24 , which are considered of traditional age, and those aged 25 and older, which are considered of non-traditional age. The non-significant statistic means that the two groups are equal and any difference is due to error/chance.

Region V community college students taking online courses did not yield a significant finding in satisfaction of tool use based on student perceptions of podcasts and gender for female $(M=3.78, S D=1.02)$ and male $(M=3.56, S D=1.47), t=0.95, p=0.349$, as found in Appendix K, Table K.14. The non-significant statistic means that the two groups are equal and any difference is due to error/chance.

Region V community college students taking online courses did not yield a significant finding in satisfaction of tool use based on student perceptions of podcasts and the number of online courses students have taken, either one or two courses $(M=3.47, S D$ $=1.17)$ or three or more courses $(M=3.78, S D=01.16), t=-1.45, p=0.154$, as in Appendix 
K, Table K.15. The non-significant statistic means that the two groups are equal and any difference is due to error/chance.

A one-way analysis of variance (ANOVA) test was used to determine if significant differences exist for GPA and Internet access at home. Statistical significance was defined at the $p<.05$ level. Appendix M presents the tables of analysis of variance for GPA and Internet access.

An analysis of variance showed that a significant difference did not exist in student perceptions of satisfaction with the use of asynchronous communication tools (e-mail, discussions or forums, blogs/weblogs, wikis, or podcasting) in an online course in a Region V community college for GPA at above a 3.0 GPA, between a 2.0 and 2.9 GPA, below a 2.9 GPA, and no GPA, $F(2.630)=1.996, p=0.114$, as found in Appendix L, Table L.1.

An analysis of variance showed that a significant difference did not exist in student perceptions of satisfaction with the use of asynchronous communication tools (e-mail, discussions or forums, blogs/weblogs, wikis, or podcasting) in an online course in a Region V community college for Internet access at no access, slow access, moderate access, and quick access, $F(2.630)=0.828, p=0.479$, as found in Appendix L, Table L.2.

Therefore respondents to this online survey tended to be more satisfied with the use of podcasts, discussions or forums, and e-mail as asynchronous communication tools in the online course. Students tended to be most satisfied with podcasts. Respondents tended to be less satisfied with blogs and wikis. Those students who had taken three or more online courses were more satisfied with some asynchronous communication tools in the online course. 


\section{Research Question 2}

Question 2.a: What are community college student perceptions of satisfaction with social, teaching, and cognitive presence in an online course in a Region V community college?

Responses from the community college students surveyed with the CoI survey were used to determine which (if any) of the three CoI presences were perceived as present in the online course. The CoI instrument utilizes a five-point Likert scale $(1=$ strongly disagree; 2 = disagree; 3 = neutral; 4 = agree; 5 = strongly agree). According to Suskie (1996), the Likert scales are successfully used to measure attitudes and opinions. As a Likert scale, the CoI examined the extent to which the course characteristics encouraged or inhibited the development of social, teaching, and/or cognitive presence (Arbaugh et al., 2008).

The CoI was used to measure student perceptions of satisfaction by examining responses that either agreed or disagreed with the statements about each of the corresponding presences. Following the example by Salloum (2011), the mean for each presence was considered. The researcher also examined frequency of responses that were specifically in the categories of strong indication of satisfaction. Those items respondents rated with a 4 or 5 indicated a strong indication of the corresponding presence (social, teaching, or cognitive) in the course, and those items respondents rated with a 1 or 2 indicated a weak indication of the corresponding presence (social, teaching, or cognitive) in the course. Appendix M, Table M.1. presents the frequencies of satisfaction with each of the presences. 
The perceptions of student respondents show a strong indication of all three presences in the online course. Teaching presence $(M=3.62)$ had a strong indication of satisfaction with a total of 605 responses agreeing (by answering the survey with a rating of 4) with the CoI statements relating to teaching presence and 447 responses strongly agreeing (by answering the survey with a rating of 5) with the CoI statements. A combined total of 1,052 responses had a rating of 4 or 5 in the CoI relating to satisfaction with teaching presence (out of 1, 716 total responses for $61.3 \%$ showing satisfaction). Specifically, those questions addressed design and organization, facilitation, and direct instruction.

Social presence $(M=3.63)$ had a strong indication of satisfaction with a total of 457 responses agreeing (by answering the survey with a rating of 4) with the CoI statements relating to social presence and 236 responses strongly agreeing (by answering the survey with a rating of 5) with the CoI statements. A combined total of 693 responses had a rating of 4 or 5 in the CoI relating to satisfaction with social presence (out of 1, 175 total responses for $59.0 \%$ showing satisfaction). Specifically, those questions addressed affective expression, open communication, and group cohesion.

Cognitive presence $(M=3.64)$ had a strong indication of satisfaction with a total of 639 responses agreeing (by answering the survey with a rating of 4) with the CoI statements relating to cognitive presence and 301 responses strongly agreeing (by answering the survey with a rating of 5) with the CoI statements. A combined total of 940 responses had a rating of 4 or 5 in the CoI relating to satisfaction with cognitive presence (out of 1, 487 total responses for $63.2 \%$ showing satisfaction). Specifically, those questions addressed triggering events, exploration, integration, and resolution. 
Question 2.b: Are community college students more satisfied with the use of one or more of social, teaching, and cognitive presence in online courses in a Region V community college?

Community college students are not more satisfied with the use of one or more of social, teaching, and cognitive presence in online courses in a Region V community college. A repeated measure analysis of variance (ANOVA) test was used to determine if significant differences in student perceptions of presence exist among the survey respondents. The one-way with repeated measures ANOVA did not reveal a significant difference $(p=0.798)$ among participants' reported satisfactions with social, teaching, and cognitive presence in an online course at a Region V community college. Appendix N, Table N.1. presents the oneway ANOVA with repeated measures.

To assure validity of the ANOVA, the researcher conducted post-hoc tests to include: Mauchly's Test of Sphericity, and the Greenhouse-Geisser correction. Data from the oneway ANOVA with repeated measures were analyzed using a within subjects effect.

Mauchly's Test of Sphericity indicated that the assumption of sphericity had been violated $(p=0.000)$. Therefore degrees of freedom were corrected using Greenhouse-Geisser estimates of sphericity. When using an ANOVA with repeated measures with a GreenhouseGeisser correction, the mean scores were $F(1.413)=0.136, p<0.798$, as found in Appendix $\mathrm{N}$, Table N.1. This means that the repeated measure ANOVA was not significant when conducting a test that alters degrees of freedom and reduces error rates. The tests validate the results that a significant difference did not exist with student satisfaction of tools in the online course. This means that participants were not more satisfied with the use of one presence over the other presences. 
Question 2.c: Which demographics have an effect on satisfaction with social, teaching, and cognitive presence in online courses in a Region $\mathrm{V}$ community college?

The researcher administered tests of significance ( $\mathrm{t}$-independent tests) to determine how community college student perceptions of satisfaction differ from the various presences depending on the responses to the demographic questions asked as part of the Asynchronous Communication Questionnaire. In completing this analysis each of the five demographics was compared with each of the three presences. Did age A versus B differ on their rating of social presence, on their rating of teaching presence, and on their rating of cognitive presence? Then the same analysis for gender $\mathrm{M}$ versus $\mathrm{F}$, and so on for online course experience, and program of study. Appendix 0 presents the tables of comparison of perceptions with the presences regarding age, gender, and number of online courses taken. A one-way analysis of variance (ANOVA) test also was used to determine if significant differences exist for GPA and Internet access at home. Statistical significance was defined at the $p<.05$ level. Appendix P presents the variance of perceptions regarding the demographics and the presences. None of the six demographics had a significant effect on student satisfaction with social, teaching, and cognitive presences.

Region V community college students taking online courses did not yield a significant finding in satisfaction of presence based on student perceptions of social presence and age for those aged 18 to $24(M=3.82, S D=0.61)$ and those aged 25 and older $(M=3.53, S D=0.95), t=1.75, p=0.084$, as found in Appendix 0, Table 0.1. The two age categories used included those aged 18 to 24 , which are considered of traditional age, and those aged 25 and older, which are considered of non-traditional age. The non-significant statistic means that the two groups are equal and any difference is due to error/chance. 
Region V community college students taking online courses did not yield a significant finding in satisfaction of presence based on student perceptions of social presence and gender for female $(M=3.68, S D=0.82)$ and male $(M=3.52, S D=0.92), t=$ 0.806, $p=0.424$, as found in Appendix 0, Table 0.2. The non-significant statistic means that the two groups are equal and any difference is due to error/chance.

Region V community college students taking online courses did not yield a significant finding in satisfaction of presence based on student perceptions of social presence and the number of online courses students have taken, either one or two courses $(M=3.36, S D=0.77)$ or three or more courses $(M=3.70, S D=0.86)$, $t=-1.75, p=0.087$, as found in Appendix 0, Table 0.3. The non-significant statistic means that the two groups are equal and any difference is due to error/chance.

Region V community college students taking online courses did not yield a significant finding in satisfaction of presence based on student perceptions of teaching presence and age for those aged 18 to $24(M=3.83, S D=0.82)$ and those aged 25 and older $(M=3.54, S D=1.22), t=1.58, p=0.117$, as found in Appendix 0, Table 0.4. The two age categories used included those aged 18 to 24, which are considered of traditional age, and those aged 25 and older, which are considered of non-traditional age. The non-significant statistic means that the two groups are equal and any difference is due to error/chance.

Region V community college students taking online courses did not yield a significant finding in satisfaction of presence based on student perceptions of teaching presence and gender for female $(M=3.70, S D=1.00)$ and male $(M=3.54, S D=1.31), t=$ 0.687, $p=0.495$, as found in Appendix 0, Table 0.5. The non-significant statistic means that the two groups are equal and any difference is due to error/chance. 
Region V community college students taking online courses did not yield a significant finding in satisfaction of presence based on student perceptions of teaching presence and the number of online courses students have taken, either one or two courses $(M=3.34, S D=0.98)$ or three or more courses $(M=3.71, S D=1.13), t=-1.71, p=0.094$, as found in Appendix 0, Table 0.6. The non-significant statistic means that the two groups are equal and any difference is due to error/chance.

Region V community college students taking online courses did not yield a significant finding in satisfaction of presence based on student perceptions of cognitive presence and age for those aged 18 to $24(M=3.74, S D=0.67)$ and those aged 25 and older $(M=3.59, S D=0.98), t=0.89, p=0.377$, as found in Appendix 0, Table 0.7. The two age categories used included those aged 18 to 24, which are considered of traditional age, and those aged 25 and older, which are considered of non-traditional age. The non-significant statistic means that the two groups are equal and any difference is due to error/chance.

Region V community college students taking online courses did not yield a significant finding in satisfaction of presence based on student perceptions of cognitive presence and gender for female $(M=3.67, S D=0.84)$ and male $(M=3.62, S D=1.02), t=$ 0.23, $p=0.816$, as found in Appendix 0, Table 0.8. The non-significant statistic means that the two groups are equal and any difference is due to error/chance.

Region V community college students taking online courses did not yield a significant finding in satisfaction of presence based on student perceptions of cognitive presence and the number of online courses students have taken, either one or two courses $(M=3.36, S D=0.78)$ or three or more courses $(M=3.72, S D=0.90), t=-1.85, p=0.071$, as 
found in Appendix 0, Table 0.9. The non-significant statistic means that the two groups are equal and any difference is due to error/chance.

A one-way analysis of variance (ANOVA) test was used to determine if significant differences exist for GPA and Internet access at home. Statistical significance was defined at the $p<.05$ level. Appendix P presents the analysis of variance for GPA and Internet access.

An analysis of variance showed that a significant difference did not exist in student perceptions of satisfaction with the existence of presence (social, teaching, or cognitive) in an online course in a Region V community college for GPA at above a 3.0 GPA, between a 2.0 and $2.9 \mathrm{GPA}$, below a $2.9 \mathrm{GPA}$, and no GPA, $F(2.630)=1.996, p=0.114$, as found in Appendix P, Table P.1.

An analysis of variance showed that a significant difference did not exist in student perceptions of satisfaction with the existence of presence (social, teaching, or cognitive) in an online course in a Region $\mathrm{V}$ community college for Internet access at no access, slow access, moderate access, and quick access, $F(2.630)=0.828, p=0.479$, as found in Appendix P, Table P.2.

Therefore, perceptions of students in this survey show an indication of interdependency of all three presences. Survey respondents were not more satisfied with the use of one presence over the other presences. None of the six demographics had a significant effect on student satisfaction with social, teaching, and cognitive presence in online courses in a Region V community college. The demographics that did not have a significant effect were: age, gender, program of study, GPA, number of online courses taken, and Internet access. 


\section{Research Question 3}

Question 3.a: What is the relationship between community college student perceptions of satisfaction with the use of asynchronous communication tools and community college student perceptions of satisfaction with social, teaching, and cognitive presence?

Pearson Correlation tests were used to determine whether the CoI variables (social, teaching, or cognitive presence) correlated with student perceptions of the use of asynchronous communication tools. Pearson Correlation looks for a measure of the correlation that exists between the variables. Thus, each of the five tools were correlated with each presence (e.g., e-mail with social presence, e-mail with teaching presence, e-mail with cognitive presence, discussions or forums with social presence, discussions or forums with teaching presence, and so on for a total of 15 correlational relationships).

Table 10 presents the scale used to interpret the strength of the relationship indicated by the correlation coefficient.

Table 10

Relative Strengths of Correlation

\begin{tabular}{cc}
\hline $\begin{array}{c}\text { Number Value } \\
\text { If } \mathrm{r}=\end{array}$ & Description of Strength \\
& \\
+.70 or higher & Very Strong Positive Relationship \\
+.40 to +.69 & Strong Positive Relationship \\
+.30 to +.39 & Moderate Positive Relationship \\
+.20 to +.29 & Weak Positive Relationship \\
+.01 to +.19 & None or Negligible Relationship \\
-.01 to -.19 & None or Negligible Relationship \\
-.20 to -.29 & Weak Negative Relationship \\
-.30 to -.39 & Moderate Negative Relationship \\
-.40 to -.69 & Strong Negative Relationship \\
-.70 or higher & Very Strong Negative Relationship \\
\hline
\end{tabular}

Table 10. Adapted from the Political Science Department at Quinnipiac University 
The strength of a correlation is measured by a correlation coefficient. The coefficient will fall within a range of +1.00 , which is a perfect positive relationship, and -1.00 , which is a perfect negative relationship. Table 11 displays the results of the relationship between the outcomes of the CoI variables (social, teaching, or cognitive presence) correlated with student perceptions of the use of asynchronous communication tools (e-mail, discussions or forums, blogs/weblogs, wikis, or podcasting). Data were calculated by factor for Pearson $r$ correlation for each combination of presence and asynchronous communication tool. This calculation is done by using the mean scores for each and then running a Pearson $r$ in SPSS to get the correlations.

Table 11

Correlations of Asynchronous Communication Tools with CoI Presences

\begin{tabular}{lcccc}
\hline Tool & $M$ & $\begin{array}{c}\text { Teaching } \\
\text { Presence }\end{array}$ & Social Presence & $\begin{array}{c}\text { Cognitive } \\
\text { Presence }\end{array}$ \\
\hline E-mail & 3.69 & 0.599 & 0.597 & 0.582 \\
Discussions & 3.52 & 0.614 & 0.661 & 0.624 \\
Blogs & 3.18 & 0.613 & 0.602 & 0.609 \\
Wikis & 3.10 & 0.445 & 0.600 & 0.554 \\
Podcasts & 3.70 & 0.584 & 0.503 & 0.541 \\
\hline
\end{tabular}

The correlation between e-mail and teaching presence is 0.599 . That is a strong positive relationship between these two groups and significant for (2-tailed) is 0.000 , which is significant at the 0.01 level. The correlation between e-mail and social presence is 0.597. That is a strong positive relationship between these two groups and significant for (2-tailed) is 0.000 , which is significant at the 0.01 level. The correlation between e-mail and cognitive presence is 0.582 . That is a strong positive relationship between these two groups and significant for (2-tailed) is 0.000 , which is significant at the 0.01 level. 
The correlation between discussions or forums and teaching presence is 0.614 . That is a strong positive relationship between these two groups and significant for (2-tailed) is 0.000, which is significant at the 0.01 level. The correlation between discussions or forums and social presence is 0.661 . That is a strong positive relationship between these two groups and significant for (2-tailed) is 0.000 , which is significant at the 0.01 level. The correlation between discussions or forums and cognitive presence is 0.624 . That is a strong positive relationship between these two groups and significant for ( 2 -tailed) is 0.000 , which is significant at the 0.01 level.

The correlation between blogs or weblogs and teaching presence is 0.613 . That is a strong positive relationship between these two groups and significant for (2-tailed) is 0.000, which is significant at the 0.01 level. The correlation between blogs or weblogs and social presence is 0.602 . That is a strong positive relationship between these two groups and significant for (2-tailed) is 0.000 , which is significant at the 0.01 level. The correlation between blogs or weblogs and cognitive presence is 0.609 . That is a strong positive relationship between these two groups and significant for (2-tailed) is 0.000 , which is significant at the 0.01 level.

The correlation between wikis and teaching presence is 0.445 . That is a strong positive relationship between these two groups and significant for (2-tailed) is 0.000 , which is significant at the 0.01 level. The correlation between wikis and social presence is 0.600. That is a strong positive relationship between these two groups and significant for (2-tailed) is 0.000 , which is significant at the 0.01 level. The correlation between wikis and cognitive presence is 0.554 . That is a strong positive relationship between these two groups and significant for (2-tailed) is 0.000 , which is significant at the 0.01 level. 
The correlation between podcasts and teaching presence is 0.584 . That is a strong positive relationship between these two groups and significant for (2-tailed) is 0.000 , which is significant at the 0.01 level. The correlation between podcasts and social presence is 0.503 . That is a strong positive relationship between these two groups and significant for (2-tailed) is 0.000 , which is significant at the 0.01 level. The correlation between podcasts and cognitive presence is 0.541 . That is a strong positive relationship between these two groups and significant for (2-tailed) is 0.000 , which is significant at the 0.01 level.

Every correlation shows a strong positive relationship and the 0.01 level is strong that these relationships exist. Anything below 0.05 is significant. SPSS reports the $p$-value for this test as being 0.000 , which indicates that there is strong evidence to believe a positive relationship exists between community college student perceptions of satisfaction with the use of asynchronous communication tools and community college student perceptions of satisfaction with social, teaching, and cognitive presence. There is a relationship between the three interdependent presences with each of the five examined asynchronous communication tools utilized in the online classroom.

Question 3.b: How does the relationship between community college student satisfaction with asynchronous communication tools and social, teaching, and cognitive presence vary depending on the different demographics?

The researcher examined the correlation test results, as found in Table 11, from RQ3.a. in relation to the t-independent test and one-way ANOVA results from RQ1.c., as found in Table K.1. to K.15 and Table L.1. and L.2., and RQ2.c., as found in Table 0.1. to 0.9. and Table P.1. and P.2., to assess if the relationship between community college student 
satisfaction with asynchronous communication tools and social, teaching, and cognitive presence varied depending on the five demographics.

The one demographic that emerged as having a statistically significant relationship among asynchronous communication tools was the amount of online courses taken.

Students who had taken three or more online courses in a Region V community college were more satisfied with the use of e-mail and discussions. The t-independent test and oneway ANOVA results did not reveal a significant difference among social, teaching, and cognitive presence.

\section{Summary of Findings}

This study addressed the relationship between community college student perceptions of satisfaction with asynchronous communication tools and community college student perceptions of satisfaction with social, teaching, and cognitive presence in online courses in a Region V community college. This study also addressed which demographics had an effect on satisfaction with asynchronous communication tools in online courses in a Region V community college.

- The largest group of respondents in the survey was female $(N=329)$.

- More students in the non-traditional age category of 25 years of age and older responded to the survey $(N=244)$ than the traditional age category of 18 to 24 years old $(N=186)$.

- The majority of students responding to the survey had an overall GPA above $3.0(N=$ 284 or $66.7 \%)$.

- The majority of students responding to the survey had taken three or more online classes $(N=282$ or $65.9 \%)$. 
- The two academic divisions with the highest percentage of students responding to the survey were from the Business and Economics Division $(N=192$ or $37.7 \%)$ and from the Non-Traditional Programs $(N=110$ or $21.6 \%)$.

- The majority of survey respondents ranked their Internet provider for their home as being moderately quick ( $N=198$ or $46.0 \%$ ) or quick and reliable $(N=188$ or $43.7 \%)$.

Research Question 1.a: What are community college student perceptions of satisfaction with the use of asynchronous communication tools in an online course in a Region V community college?

- Students in a Region V community college report satisfaction with the use of e-mail, discussions or forums, and podcasts as asynchronous communication tools in online courses. In examining the frequencies of satisfaction with each of the tools, podcasts had the highest satisfaction with a combined total of 84 respondents expressing satisfaction with the tool.

Research Question 1.b: Are community college students more satisfied with the use of one or more asynchronous communication tools than others in online courses in a Region V community college?

- The one-way ANOVA with repeated measures revealed a significant difference between the groups at the $p<.05$ level with $p=0.042$. Therefore a significant difference does exist in student perceptions of satisfaction with the use of asynchronous communication tools.

- Post-hoc tests using the Bonferroni correction revealed that a statistically significant difference did exist in the use of podcasts as compared to discussions or forums $(p=$ 
$0.003)$, blogs/weblogs $(p=0.011)$, and wikis $(p=0.036)$. This means that respondents were more satisfied with the use of podcasts than with the use of discussions, blogs, and wikis.

Research Question 1.c: Which demographics have an effect on satisfaction with asynchronous communication tools in online courses in a Region V community college?

- An analysis of variance showed that Region V community college students taking online courses yielded a significant finding in satisfaction of tool use based on student perceptions of e-mail and the number of online courses students have taken, either one or two courses $(M=3.46, S D=1.36)$ or three or more courses $(M=3.79$, $S D=1.20), t=-2.50, p=0.013$. Respondents using e-mail in an online course at the Region V community college who had the experience of three or more online courses rated the tool higher. With $p<0.05$ these data mean that student perceptions of satisfaction with the use of e-mail differ according to the number of courses taken.

- Region V community college students taking online courses yielded a significant finding in satisfaction of tool use based on student perceptions of discussions or forums and the number of online courses students have taken, either one or two courses $(M=3.30, S D=1.45)$ or three or more courses $(M=3.62, S D=1.24), t=$ $2.35, p=0.020$. Respondents using discussions or forums who had the experience of three or more online courses rated the tool higher. With $p<0.05$ these data mean that student perceptions of satisfaction with the use of discussions or forums differ according to the number of courses taken. 
Research Question 2.a: What are community college student perceptions of satisfaction with social, teaching, and cognitive presence in an online course in a Region $\mathrm{V}$ community college?

- An analysis of the frequency of responses of the CoI was used to determine which of the presences (social, teaching, or cognitive) were perceived as present in the online course. There was a strong indication that all three presences were present in online courses.

Research Question 2.b: Are community college students more satisfied with the use of one or more of social, teaching, and cognitive presence in online courses in a Region $\mathrm{V}$ community college?

- The one-way with repeated measures ANOVA did not reveal a significant difference between or within the groups at the $p<.05$ level with $p=0.798$. A significant difference did not exist in student perceptions of satisfaction with social, teaching, and cognitive presence in an online course a Region V community college.

Research Question 2.c: Which demographics have an effect on satisfaction with social, teaching, and cognitive presence in online courses in a Region V community college?

- An analysis of variance showed that a significant difference did not exist in regards to demographics and student perceptions of satisfaction with the existence of presence (social, teaching, or cognitive) in a Region V community college.

Research Question 3.a: What is the relationship between community college student perceptions of satisfaction with the use of asynchronous communication tools and community college student perceptions of satisfaction with social, teaching, and cognitive presence? 
- The Pearson Correlation showed a strong positive relationship at the 0.01 level. There is a strong positive relationship between community college student perceptions of satisfaction with the use of asynchronous communication tools and community college student perceptions of satisfaction with social, teaching, and cognitive presence.

Research Question 3.b: How does the relationship between community college student satisfaction with asynchronous communication tools and social, teaching, and cognitive presence vary depending on the different demographics?

- An analysis of variance showed that one demographic had a statistically significant relationship with asynchronous communication tools. Respondents who had taken three or more online courses were more satisfied with the use of e-mail and discussions.

- The t-independent test and one-way ANOVA results from RQ1.c. and RQ2.c. did not reveal a significant difference among social, teaching, and cognitive presence 


\section{Chapter 5}

\section{Summary, Conclusions, Discussion, and Recommendations}

This chapter includes a summary, study conclusions, discussion, and recommendations for practice and research. This chapter provides conclusions drawn from the data pertaining to the research questions presented in chapter four.

\section{Summary}

As a commonplace medium for instructional content in community colleges, the use of online courses is prevalent in higher education and is expected to continue to grow. While online classes offer a number of benefits to students, drawbacks of online education also exist. Because participants in an online classroom are not physically present together, they rely on communication tools to allow for interaction and collaboration. Garrison and Anderson (2003) suggested an online classroom based on the idea of a community of learners as they developed the widely accepted Community of Inquiry model. The CoI model provides a comprehensive theoretical framework to inform both research on online learning and the practice of online instruction. It assumes that student satisfaction with online learning requires the development of a community that supports meaningful inquiry and deep learning. The CoI theoretical framework represents a process of creating a deep and meaningful learning experience through the development of three interdependent elements: social presence, teaching presence, and cognitive presence.

This study examined the relationship between community college student perceptions of satisfaction with asynchronous communication tools and community college student perceptions of satisfaction with social, teaching, and cognitive presence in online courses in a Region V community college. This study also sought to determine which 
demographics have an effect on satisfaction with asynchronous communication tools in online courses in a Region V community college. Participants were invited to complete an online questionnaire to indicate their perceptions of survey items related to the three presences and five asynchronous communication tools, i.e., e-mail, discussions or forums, blogs/weblogs, wikis, and podcasts.

Three types of data were collected from participants in this study: demographic background variables, Community of Inquiry, and asynchronous communication tool usage. Two instruments were used in this research. The Community of Inquiry (CoI) instrument, developed by Arbaugh, Cleveland-Innes, Diaz, Garrison, Ice, Richardson, and Swan (2008), was utilized to measure social, teaching, and cognitive presence in the online classroom environment (see Appendix A). A survey based on the literature review was developed to gather the perceptions of students' satisfaction with the use of asynchronous communication tools in the online classroom. Known as the Asynchronous Communication Questionnaire, the researcher-developed survey specifically examined the satisfaction and use of e-mail, discussions or forums, blogs or web logs, wikis, and podcasting. Demographic information regarding student program of study, age, gender, GPA, prior online experience, and Internet access also was gathered in the Asynchronous Communication Questionnaire (see Appendix B).

The population for this study consisted of 1,363 students enrolled in at least one online course. This particular population attends a Region V community college that is accredited to offer baccalaureate degrees. Each student received an e-mail introducing the study, a brief overview of the instrument, and a request to participate in March 2014. The overall return rate was $31.5 \%$. 


\section{Conclusions}

This study contained three research questions in its examination of community college student perceptions of satisfaction with the use of asynchronous communication tools and community college student perceptions of satisfaction with social, teaching, and cognitive presence in online courses in a Region V community college.

This study found eight conclusions about community college student perceptions of satisfaction with the use of asynchronous communication tools and community college student perceptions of satisfaction with social, teaching, and cognitive presence in online courses in a Region V community college. They are as follows:

Research Question 1.a: What are community college student perceptions of satisfaction with the use of asynchronous communication tools in an online course in a Region V community college?

1. These community college students are more satisfied with the use of three asynchronous communication tools: e-mail, discussions or forums, and podcasts in online courses at a Region V community college. These community college students are less satisfied with the use of two asynchronous communication tools: wikis and blogs in online courses.

Research Question 1.b: Are community college students more satisfied with the use of one or more asynchronous communication tools than others in online courses in a Region V community college?

2. Yes, these community college students are more satisfied with the use of one particular asynchronous communication tool in comparison to the others in online courses at a Region V community college. The tool that emerged as 
providing the most satisfaction for these community college students was podcasts.

Research Question 1.c: Which demographics have an effect on satisfaction with asynchronous communication tools in online courses in a Region V community college?

3. Only one of the six demographics, number of online courses taken, had a significant effect on student satisfaction with asynchronous communication tools in online courses in a Region V community college for these community college students. Those students who had taken three or more online courses were more satisfied with asynchronous communication tools in online courses. The demographics that did not have a significant effect were: age, gender, program of study, GPA, and Internet access.

Research Question 2.a: What are community college student perceptions of satisfaction with social, teaching, and cognitive presence in an online course in a Region V community college?

4. These community college students indicate a strong positive correlation in regards to student satisfaction with social, teaching, and cognitive presence in online courses in a Region V community college.

Research Question 2.b: Are community college students more satisfied with the use of one or more of social, teaching, and cognitive presence in online courses in a Region V community college?

5. No, these community college students are not more satisfied with the use of one particular presence in comparison to the others in online courses at a Region $\mathrm{V}$ community college. 
Research Question 2.c: Which demographics have an effect on satisfaction with social, teaching, and cognitive presence in online courses in a Region V community college?

6. None of the six demographics had a significant effect on student satisfaction with social, teaching, and cognitive presence in online courses in a Region $\mathrm{V}$ community college for these community college students. The demographics that did not have a significant effect were: age, gender, program of study, GPA, number of online courses taken, and Internet access.

Research Question 3.a: What is the relationship between community college student perceptions of satisfaction with the use of asynchronous communication tools and community college student perceptions of satisfaction with social, teaching, and cognitive presence?

7. These community college students indicate a strong positive correlation between student satisfaction with the use of asynchronous communication tools and student satisfaction with social, teaching, and cognitive presence in online courses in a Region V community college.

Research Question 3.b: How does the relationship between community college student satisfaction with asynchronous communication tools and social, teaching, and cognitive presence vary depending on the different demographics?

8. The relationship between community college student satisfaction with asynchronous communication tools and student satisfaction with social, teaching, and cognitive presence in online courses in a Region V community college varies depending on the demographic. When these community college students took three or more online classes, they had a higher satisfaction with 
the use of e-mail and discussions. A statistically significant result did not emerge for these community college students with the other five demographics examined in this study: age, gender, program of study, GPA, and Internet access.

\section{Discussion}

This section provides information relevant to the study's conclusions. It begins with a review of the demographic information of the respondents. This section contains a discussion of findings related to community college student perceptions of satisfaction with the asynchronous communication tools and community college student perceptions of satisfaction with social, teaching, and cognitive presence in online courses in a Region $\mathrm{V}$ community college. The discussion of findings includes citations of relevant literature. This section also provides the researcher the opportunity to speculate about the implications of the data.

Demographics. Those in the study population were asked to indicate six demographics: age, gender, program of study, GPA, number of online courses taken, and Internet access. Only one of the six demographics, number of online courses taken, had a significant effect on student satisfaction with asynchronous communication tools in online courses in a Region V community college for these community college students.

The majority (66\%) of students responding to the survey had taken three or more online classes. Respondents using e-mail and discussions or forums in an online course at the Region V community college who had the experience of three or more online courses rated their satisfaction with those tools higher than those who had only taken one or two online courses. Kennedy (2001) supports this finding in research indicating that students with prior online course experience were more likely to complete a course than those 
without experience in online delivery of course material. Beavers (2009) also supported this finding with research indicating that as the number of online courses a student successfully completed increased, so did the student's preference for online courses. It seems to be the more students use the online system and its components, such as the asynchronous tools of e-mail and discussions, the more familiar and satisfied the students may become with the usage of those tools.

None of the six demographics had a significant effect on student satisfaction with social, teaching, and cognitive presence in online courses in a Region V community college for these community college students. One can speculate that the demographics did not emerge as significant because of the strong interdependent relationship of the three presences. This finding is supported in previous research by Arbaugh et al. (2008), who noted an overlap in the three presences as evidenced by correlation among factors. In defining the three presences, Garrison, Anderson, and Archer (2001) refer to social presence as the ability of participants to project themselves socially and emotionally through a medium of communication. Cognitive presence is described by the researchers as allowing learners to construct and confirm meaning. Teaching presence is described as bringing all the elements of social and cognitive presence together in a balanced and functional relationship congruent with intended outcomes.

\section{Community college student perceptions of satisfaction with the use of} asynchronous communication tools. Students rated their satisfaction with the use of three asynchronous communication tools - e-mail, discussions or forums, and podcasts with high satisfaction in this survey. Of the five asynchronous communication tools studied, podcasts had the highest satisfaction. Podcasts had a majority of respondents (85\%) 
expressing satisfaction with the communication tool's use in the course. Brown et al. (2009) supports this finding in their research, which found that students enjoy the use of podcasts and hearing an actual voice in an asynchronous online course. Respondents in Brown's study felt like the instructor was with them, or that the use of the podcast made them feel as if the instructor was more of a real person. Common advantages of podcasts are that the tool allows students to feel a connection to an instructor, and it removes isolation between instructors and students by providing a communication method that goes beyond text-only interaction, as cited by Brown et al. (2009).

As a result of current research on blogs and wikis, and in examination of current disadvantages of the tools, blogs and wikis emerge as new tools available for online educators. Many instructors, however, may be unfamiliar with blogs and wikis and may not fully utilize them in their online courses. In this study, use of blogs and wikis was very low in comparison to the other asynchronous communication tools. Only $6.7 \%$ of the study population noted the use of blogs in their online course, while only $4.9 \%$ of the study population noted the use of wikis in their online course. It seems logical that the more training that exists on a particular tool, the more comfortable the instructor becomes in using it and the more valuable the tool becomes to the student in improving the online course. One may speculate that the instructors at this community college surveyed may not have a full understanding or the technical skills to properly utilize blogs and wikis in the online course, thus contributing to the lower satisfaction ratings by students. Another speculation could be that blogs and wikis do not represent the preferred teaching style for those instructors at this community college, thus lowering the usage of the tools for this study population. 
Both blogs/weblogs and wikis had the lowest satisfaction when compared to other asynchronous communication tools in this study. Brownson (2009) supports this finding with research that found that instructors sometimes failed to understand the technology of blogs and wikis; thus they were unable to connect those tools to the content of the online course. Blogs are online journals that communicate ideas in a continuous flow. Blogs often include a home page, an archive of postings, and a specific author. Wikis are an editable website created incrementally by visitors working collaboratively. Thus content on the website can be changed or added easily by multiple users. A disadvantage of both tools is often a lack of training, which explains why instructors often fail to use these tools. Brownson noted other common disadvantages of blogs that include the need for technical and writing skills, as well as the motivation to complete the assignments. The researcher showed a variety of resources are available for bloggers, but it requires more technical skills than some older asynchronous communication tools like e-mail and discussions. Cole (2009), Nakamaru (2012) and Martin (2012) all support this finding in their research which all reported failed experiments to use wiki technology. Common disadvantages of wikis are a lack of proper use, the ability to change course content, and the appearance of the document. This web-based tool allows for many authors to work on projects together with editing capabilities of an often very large digital document. With a collaborative effort in construction, concerns can arise as to content. To prevent undesired modifications, wikis record individual changes and keep extensive page histories. If inaccurate information or unsuitable material is posted, a wiki can roll back to a previous version. Only in an environment where instructors received vast training on the use of wikis such as in the Globaloria project were positive experiences noted. Research 
conducted by Whitehouse (2011) on this project revealed that educators believed the experience made them better teachers. They used a wiki that was self-led, collaborative, peer-to-peer, and expert-guided.

\section{Community college student perceptions of satisfaction with social, teaching,} and cognitive presence. Students at this Region V community college indicate a strong positive correlation in regards to student satisfaction with social, teaching, and cognitive presence in online courses. These community college students were not more satisfied with the use of one particular presence in comparison to the others in online courses. This finding is supported in previous research by Arbaugh et al. (2008), who noted an overlap in the three presences as evidenced by correlation among factors. In defining the three presences, Garrison, Anderson, and Archer (2001) refer to social presence as the ability of participants to project themselves socially and emotionally through a medium of communication. Cognitive presence is described by the researchers as allowing learners to construct and confirm meaning. Teaching presence is described as bringing all the elements together in a balanced and functional relationship congruent with intended outcomes. Research by Shea and Bidjerano (2009) found complex interrelationships among the three presences. Their research identifies a relationship between learner understandings of teaching and social presence and its impact on their cognitive presence. It is difficult to examine only one presence without the mediating effects of the other presences because the instructional process ideally incorporates all three presences. Garrison, Cleveland-Innes, and Fung (2010) also support this complex relationship with their findings of the hypothesized fundamental role of teaching presence in the development of both social and cognitive presence. 
There seems to be an interdependent connection between the three presences. One may speculate that is why a specific presence did not emerge as more satisfying for students in this survey. This community college research supports the strong positive correlation among the factors of social, teaching, and cognitive presence as a result of communication in online courses.

Related findings. While a statistically significant result did not emerge for these community college students with the demographic categories Internet access and program of study, related findings do emerge in relation to prior research on these demographics.

At the time the survey was conducted, it was unknown how many students in the study population at this Region $\mathrm{V}$ community college would have adequate Internet access as no known studies existed. A small percentage of students (3\%) taking the online classes had no Internet access at home. The majority of survey respondents ranked their Internet provider for their home as being moderately quick (46\%) or quick and reliable (44\%). One can speculate that five years ago the results would have been very different and that fewer students would be able to take online courses from their homes. In recent years, the State of West Virginia committed to improving online access for a variety of reasons, including educational access for the state's residents. The West Virginia Statewide Broadband Infrastructure Project planned to bring high-speed Internet access to all parts of the state by increasing the state's existing microwave public safety network and add 2,400 miles of fiber, the means by which the high-speed or broadband access is delivered. The expanded statewide network proposed to directly connect more than 1,000 anchor institutions, including public safety agencies, public libraries, schools, government offices, and other critical community facilities at speeds up to $45 \mathrm{Mbps}$ (BroadbandUSA, 2013). It seems as 
though Internet service to the respondents of this survey is following suit with the state's improvement plans.

Considering prior research on program of study, one could have expected that the highest use in preference for online courses would emerge in a specific academic division at this Region V community college. For example, Hamilton (2011), Scism (2006), and Landers (2009) all found higher completion rates or student preferences for online learning in health-related fields. Xu and Jaggars (2013) found that online courses at community colleges tended to be more popular in the arts and humanities subjects, and less popular in the subjects of computer science, applied professions, and natural science. The respondents in this survey did not follow suit with those studies. The two academic divisions with the highest percentage of students responding to the survey were from the Business and Economics Division (38\%) and from the Non-Traditional Programs (22\%). The Education and Humanities Division had the third highest number of respondents (16\%). The Health Sciences Division had the fifth highest number of respondents (8\%). These data could be due to the areas of online course growth at the institution. The Business and Economics Division houses completely online degrees. The Non-Traditional Programs Division caters to many non-traditional students who choose online courses as an alternative delivery means. Part of the accessibility and diversity at community colleges is the offering of online courses to students whose work schedules present a need for more flexibility in the classroom (AACC, 2013).

\section{Recommendations for Practice}

1. Professional development opportunities specific to asynchronous communication tools in the online course should be provided for instructors teaching online courses at 
community colleges. It seems logical that the more training that exists on a particular tool, the more comfortable the instructor becomes in using it and the more valuable the tool becomes to the student in improving the online course.

2. Orientation programs specific to asynchronous communication tools should be provided for students taking online courses at community colleges. Students can be apprehensive about new tool use even after the instructor is effective in using the tool if they are not shown how to properly utilize the tool.

3. Conduct an annual survey with a tool such as the researcher-developed Asynchronous Communication Questionnaire to examine tool use and satisfaction with tool use in online courses. Faculty members teaching online courses need to know what tools result in higher or lower satisfaction ratings by students. Use of those tools producing higher satisfaction for students should be encouraged for faculty in all programs of study featuring online courses.

4. Students in their first online courses (less than three online courses) should also be given extra support services as they may be at risk for lower satisfaction with the course(s) as they may not have yet mastered the online course process. Examples of a support service could be an online tutoring service for how to navigate and be successful in an online course, or providing a $24 / 7$ help desk for online students encountering problems with the course management system. Another example of a support service would be to develop an early alert system for students in online courses so that faculty members who notice students having problems in the online course can report those students to a college retention officer. 
5. Faculty with experience in offering online courses should be teaching introductory level online courses that community college students likely would take as their first courses. Since the demographic of number of online courses emerged as significant for community college students in this study, it seems to be that the more students use the online system and its components, such as the asynchronous tools of email and discussions, the more familiar and satisfied the students become with the usage of those tools. Faculty seasoned in online instruction should be better equipped to assist students in those early courses. Experience in those first courses for online students often determine if students continue to take online courses. Kennedy (2001) found that students with prior online course experience were more likely to complete a course than those without that experience in online delivery of course material. Beavers (2009) indicated that as the number of online courses that a student successfully completed increased, so did the student's preference for online courses.

6. Internet access should be a demographic considered for community colleges that want to expand their online program offerings. In this study as few as 14 respondents did not have Internet access at home. This statistic is a realization of a statewide effort in West Virginia to bring high-speed Internet access to all parts of the state (BroadbandUSA, 2013). In areas not as fortunate to have a high-speed Internet expansion, availability of programs and especially download capacity for specific asynchronous communication tools should be considered.

\section{Recommendations for Future Research}

Online courses in community colleges need continual research to improve student satisfaction. An examination of specific asynchronous communication tools that were 
shown in this study to have low usage at this particular Region V community college should be further researched. For example, the uses of blogs and wikis in online courses and how those uses relate to increased interaction in online courses. Student satisfaction could also be examined as a result of specific uses of blogs and wikis in the online course.

Other asynchronous communication tools, such as the feedback comment blocks in the online course when returning grades, could be examined as a means of communication between students and instructors and in relation to its potential enhancement of satisfaction with social, teaching, and cognitive presence. Potential research questions for such a study could be: 1) What are community college student perceptions of satisfaction with the use of the grading feedback comments in an online course? 2) What is the relationship between community college student perceptions of satisfaction with the use of the grading feedback comments and community college student perceptions of satisfaction with social, teaching, and cognitive presence?

Another potential study could examine specific tools in relation to specific components of the CoI model. For example, does use of discussions have a direct effect on social presence or does it enhance teaching presence in the online course? Demographics that could be examined in such a study could include GPA, program of study, Internet access and number of online courses taken. It would also be interesting to see if community college student perceptions differed from university student perceptions in the use of specific asynchronous communication tools.

Types of online courses, whether be administered as either content or service courses, could be examined for their differences in online delivery. Types of instructors could also be considered to examine differences that may exist in courses delivered by full- 
time faculty versus courses delivered by adjunct (part-time) faculty. Location could be another area of study since some students are not taking online courses at home, are they still going to the community college to take these courses or do they utilize other public facilities or just other homes?

Since each tool has a different depth in capabilities and is much more vast than just the advantages and disadvantages note, a study could be completed to examine specific tools and their complicated understandings. For example, is a discussion board utilized in a classroom just to post comments or is it utilized to encourage conversation between students or even the instructor? Online instructors utilize different tools in different manners and some much more extensively. Therefore, looking at the use of the tool and the depth of its use may prove to be an enlightening topic to study.

Considering this study focused on one Region V community college, the same study could be similarly replicated at varying community colleges. Because new asynchronous communication tools are being developed and research on various tools when viewed collectively is limited, additional research should be conducted.

Also, considering this study focused on the use of asynchronous communication tools, a similar study could be replicated looking at the use of synchronous tools in the online course at varying community colleges. As with asynchronous communication tools, synchronous communication tools also are being developed and research on these various tools is limited, thus additional research should be conducted. 


\section{References}

Allen, I. E., \& Seaman, J. (2014). Grade change: Tracking online education in the United States. The Sloan Consortium. Babson Survey Research Group. Retrieved April 2, 2014, from http://www.onlinelearningsurvey.com/reports/gradechange.pdf

Allen, I. E., \& Seaman, J. (2013). Changing course: Ten years of tracking online education in the United States. The Sloan Consortium. Babson Survey Research Group. Retrieved February 11, 2013, from http://www.onlinelearningsurvey.com/reports/changingcourse.pdf

American Association of Community College (AACC). (2013). American Association of Community Colleges: Community college fact sheet. Washington, DC: AACC.

Anderson, T. (2003). Modes of interaction in distance education: Recent developments and research questions. In M. Moore \& G. Anderson (Eds.), Handbook of distance education (pp. 129-144). Mahwah, NJ: Erlbaum.

Anderson, T. (2004a). Teaching in an online learning context. In T. Anderson \& F. Elloumi (Eds.), Theory and practice of online learning (pp. 271-294). Athabasca, Canada: Athabasca University.

Anderson, T. (2004b). Toward a theory of online learning. In T. Anderson \& F. Elloumi (Eds.), Theory and practice of online learning (pp. 33-60). Athabasca, Canada: Athabasca University.

Anderson, T., Rourke, L., Archer, W., \& Garrison, R. (2001). Assessing teaching presence in computer conferencing transcripts. Journal of Asynchronous Learning Network, 5(2). Retrieved March 11, 2013, from http://auspace.athabascau.ca/bitstream/2149/725/1/assessing teaching presence . $\mathrm{pdf}$

Aragon, S. R. \& Johnson, E. S. (2008). Factors influencing completion and noncompletion of community college online courses. The American Journal of Distance Education, 22(1), 146-158.

Arbaugh, J. B. (2001). How instructor immediacy behavior affects student satisfaction and learning in web-based courses. Business Administration Quarterly, 64(4), 42-54.

Arbaugh, J. B., Bangert, A., \& Cleveland-Innes, M. (2010). Subject matter effects and the community of inquiry (CoI) framework: An exploratory study. Internet and Higher Education, 13(1-2), 37-44. 
Arbaugh, J.B., Cleveland-Innes, M., Diaz, S.R., Garrison, D.R., Ice, P., Richardson, J.C., \& Swan, K.P. (2008). Developing a community of inquiry instrument: Testing a measure of the Community of Inquiry framework using a multi-institutional sample. Internet and Higher Education, 11(3-4), 133-136.

Arnold, S. D. (2005). E-mail: Its contribution to the student/instructor learning and teaching relationship at colleges and universities (Doctoral dissertation). Retrieved from ProQuest Dissertations and Theses database (UMI No. 3178873)

Association for Educational Communications and Technology (AECT). (2001). What is descriptive research? Bloomington, IN: AECT. Available from http://learningen.org/ aust/EdTecheBooks/AECT HANDBOOK96/41/41-01/html

Aviat Networks Inc. (2011). Case study state of West Virginia: State of West Virginia says yes to the broadband internet. Retrieved from www.aviatnetworks.com

Balaji, M. S. (2010). Student interactions in online discussion forum: empirical research from 'media richness theory' perspective. Journal of Interactive Online Learning, 9(1), 1-22.

Bates, A., (1991). Interactivity as a criterion for media selection in distance education. Never Too Far, 16, 5-9.

Baum, S., \& Ma, J. (2011). Trends in college pricing (Trends in Higher Education Series). Washington, DC: College Board.

Beard, L., \& Harper, C. (2002) Student perceptions of online versus on campus instruction. Education, 122(4), 658-663.

Beavers, L.R. (2009). A case study of community college students' perceptions regarding faculty's practice of online course delivery: Virginia community college (Doctoral dissertation). Retrieved from ProQuest Dissertations and Theses database (UMI No. 3382265)

Belanger, Y. (2005). Duke University i-Pod first year experience: Final evaluation report. Durham: Center for Instructional Technology, Duke University.

Biddle, D. (2005). Adverse impact and test validation: A practitioner's guide to valid and defensible employment testing. Burlington, VT: Gower Publishing.

Bloom, B.S. (1956). Taxonomy of educational objectives, handbook I: The cognitive domain. New York: David McKay Co Inc.

Bork, R.H., \& Rucks-Ahidiana, Z. (2013). Role ambiguity in online courses: An analysis of student and instructor expectations (64). Community College Research Center: Columbia University, Teachers College. 
Bradley, J. (2009). Promoting and supporting authentic online conversations - which comes first - the tools or the instructional design? International Journal of Pedagogies and Learning, 5(3), 20-31.

Brint, S., \& Karabel, J. (1989). The diverted dream: Community colleges and the promise of educational opportunity in America, 1900-1985. New York, NY: Oxford University Press.

BroadbandUSA Connecting America's Communities. (2013). National Telecommunications and Information Administration: West Virginia statewide broadband infrastructure project. Retrieved from www.broadbandusa.gov

Brown, A., Brown, C., Fine, B., Luterbach, K., Sugar, W., \& Vinciguera, D. (2009). Instructional uses of podcasting in online learning environments: a cooperative inquiry study. Journal of Educational Technology Systems, 37(4), 351-371.

Brown, A., \& Green, T.D. (2007). Video podcasting in perspective: The history, technology, aesthetics, and instructional uses of a new medium. Journal of Educational Technology Systems, 36, 3-17. Doi:10.2190/ET.36.1.b

Brownson, S.M. (2009). A study of the integration of wikis and blogs into an online course on student interaction and satisfaction (Doctoral dissertation). Retrieved from ProQuest Dissertations and Theses database (UMI No. 3371718)

Burgess, L. A. (2003). WebCT as an e-learning tool: a study of technology students' perceptions. Journal of Technology Education, 15(1), 6-15.

Capra, T. (2012). A qualitative inquiry of online education from the perspective of community college students (Doctoral dissertation). Retrieved from ProQuest Dissertations and Theses database (UMI No. 3536337)

Carnegie Foundation for the Advancement of Teaching. (2013). Undergraduate instructional program classification. Carnegie Classifications. Carnegie Foundation for the Advancement of Teaching, n.d. Web. 10, Jan. 2013.

Checkmarket. (2014). Market research resources: Calculate a survey sample size. Retrieved from www.checkmarket.com

Chickering, A. W., \& Ehrmann, S. C. (1996). Implementing the seven principles: Technology as a lever. Retrieved December 6, 2012 from http://www.tltgroup.org/programs/seven.html.

Chickering, A. W., \& Gamson, Z. F. (1987). Seven principles for good practice in undergraduate education. AAHE Bulletin, March, 3-7. 
Childs, G. B. (1971). Recent research in correspondence instruction. In O. MacKenzie \& E.L. Christensen Ed.). The changing world of correspondence study. University Park: Pennsylvania State University.

Clark, B.R. (1960). The "cooling-out" function in higher education. The American Journal of Sociology, 65(6), 569-576.

Cole, M. (2009). Using wiki technology to support student engagement: Lessons from the trenches. Computers \& Education, 52, 141-146.

Colorado, J.T., \& Eberle, J. (2010). Student demographics and success in online learning environments. Emporia State Research Studies, 46(1), 4-10.

Crawford, C. M. (2007). Podcasting and video integration into the learning environment. International Journal of Learning, 13(9), 39-48.

Crawley, A. (2012). Supporting online students: A guide to planning, implementing, and evaluating services. San Francisco, CA: Jossey-Bass.

Creswell, J. W. (2003). Research design: Qualitative, quantitative, and mixed-methods approaches. ( $2^{\text {nd }}$ edition). Thousand Oaks: Sage.

Cvetko, M.G. (2002). Case study of the student-to-student interactions in an online course offered by a community college, and how the interactions impact learning community (Doctoral dissertation). Retrieved from ProQuest Dissertations and Theses database (UMI No. 3044324)

Dewey, J. (1916). Democracy and education. New York: Macmillan. Retrieved March 11, 2013, from the Institute for Learning Technologies Website: http://www.ilt.columbia.edu/publications/dewey.html

Diaz, S. R., Swan, K., Ice, P., \& Kupczynski, L. (2010). Student ratings of the importance of survey items, multiplicative factor analysis, and the validity of the community of inquiry survey. Internet and Higher Education, 13(1-2), 22-30.

Dickey, M. (2004). The impact of web-logs (blogs) on student perceptions of isolation and alienation in a web-based distance-learning environment. Open Learning, 19(3), 280-290.

Dixson, M.D. (2010). Creating effective student engagement in online courses: What do students find engaging? Journal of the Scholarship of Teaching and Learning, 10(2), $1-13$.

Dolan, D. M. (2011). Enhancing student engagement using online asynchronous, reflective discussions (Doctoral dissertation). Retrieved from ProQuest Dissertations and Theses database (UMI No. 3474276) 
Driscoll. D. L. (2011). Introduction to primary research: Observations, surveys, and interviews. In C. Low \& P. Zemliansky (Eds.), Writing spaces: Readings on writing (pp. 153-174). http://parlorpress.com/writingspaces

Earp, S., Belanger, Y., \& O’Brien, L. (2006). Duke digital initiative end of year report 2005-6. Washington: Duke University.

Ehrman, S. C. \& Gilbert, S. W. (2003). Better off with or without your CMS? 5 kinds of assessment that can really help. Campus Technology, 6, retrieved online http://campustechnology.com/Articles/2003/06/Better-Off-With-or-WithoutYour-CMS-5-Kinds-of-Assessment-That-Can-Really-Help.aspx.

Elliott, K. M. and Shin, D. (2002). Student satisfaction: An alternative approach to assessing this important concept. Journal of Higher Education Policy and Management , 24(2) 197-209.

Elloumi, F. (2004). Value chain analysis: A strategic approach to online learning. In T. Anderson \& F. Elloumi (Eds.), Theory and practice of online learning (pp. 61-96). Athabasca, Canada: Athabasca University.

Evans, N.J., Forney, D. S., \& Guido-DiBrito, F. (1998). Student development in college: Theory, research and practice. San Francisco: Jossey-Bass.

Fahy, P. (2004). Media characteristics and online learning technology. In T. Anderson \& F. Elloumi (Eds.), Theory and practice of online learning (pp. 137-174). Athabasca, Canada: Athabasca University.

Fain, P. (2013, April 26). Online courses are second choice for community college students in some subject areas. Inside Higher Ed. Retrieved from http://www.insidehighered.com

Frederick Community College. (September 10, 2013). Learning online. Retrieved from http://www.frederick.edu/courses and programs/distancelearning.aspx

Fredericksen, E., Pickett, A., Swan, K., Pelz, W., \& Shea, P. (2000). Student satisfaction and perceived learning with on-line courses: Principles and examples from the SUNY learning network. In Bourne, J. (Ed.), Online Education, Volume 1: Learning Effectiveness and Faculty Satisfaction. (pp. 7-36). Nashville, TN: Center for Asynchronous Learning Networks.

Frydenberg, M. (2006). Principles and pedagogy: The two P's of podcasting in the information technology classroom. Paper presented at the proceedings of ISECON 2006, November 4, in Dallas, USA.

Garrison, D.R., \& Anderson, T. (2003) E-learning in the $21^{\text {st }}$ century: A framework for research and practice. New York, NY: RoutledgeFalmer. 
Garrison, D.R., Anderson, T.R., \& Archer, W. (2000). Critical inquiry in a text-based environment: Computer conferencing in higher education. The Internet and Higher Education, 2(2-3), 87-105.

Garrison, D.R., Anderson, T.R., \& Archer, W. (2001). Critical thinking, cognitive presence, and computer conferencing in distance education. American Journal of Distance Education, 15(1), 7-23.

Garrison, D.R., \& Cleveland-Innes, M. (2005). Facilitating cognitive presence in online learning: Interaction is not enough. The American Journal of Distance Education, 15(1), 7-23.

Garrison, D.R., Cleveland-Innes, M., \& Fung, T. (2010). Exploring causal relationships among cognitive, social and teaching presence: Student perceptions of the community of inquiry framework. The Internet and Higher Education, 13(1-2), 31-36.

Gay, L. R., Mills, G. E., \& Airasian, P. (2006). Educational research: Competencies for analysis and applications. ( $8^{\text {th }}$ edition). New Jersey: Pearson.

Gayton, J., \& McEwen, B.C. (2007). Effective online instructional and assessment strategies. American Journal of Distance Education, 21(3), 117-132.

Doi:10.1080/08923640701341653

Goldberg, H.R., \& McKhann, G.M. (2000) Student test scores are improved in a virtual learning environment. Advances in Physiology Education, 23(1), 59-66.

Gorra, A. et al. (2010). Learning with technology: What do students want? Fifth International Conference on e-Learning. Penang, Malaysia, 126-133.

Green, K. C. (2010a). Survey of Community College Presidents. Encino, CA: The Campus Computing Project. Retrieved from http://www.campuscomputing.net/survey/community-colleges

Green, K. C. (2010b). The Campus Computing Survey. Encino, CA: The Campus Computing Project. Retrieved from http://www.campuscomputing.net/2010-campuscomputing-survey

Hamilton, A.R. (2011). A study of persistence in the northeast state community college healthrelated programs of study (Doctoral dissertation). Retrieved from ProQuest Dissertations and Theses database (UMI No. 3462045)

Hampton, M.M. (2010). Reducing distance in online learning: A study of student characteristics and student immediacy in the community college environment (Doctoral dissertation). Retrieved from ProQuest Dissertations and Theses database (UMI No. 3389874) 
Hardin, K. (2004). Teach them to fly: Strategies for encouraging active online learning. Turkish Online Journal of Distance Education, 5(2), 10-14.

Harrell, I. L. (2008). Increasing the success of online students. The Journal of the Virginia Community Colleges, 13(1), 36-44.

Helm, P., \& McClements, R. (1996). Multimedia business training: The big thing or the next big thing? In J. Frankl \& B. O’Reilly (Eds.). 1996 EDEN Conference: Lifelong learning, open learning, distance learning (pp. 134-137). Poitiers, France: European Distance Education Network.

Hillman, D. C., Willis, D. J. \& Gunawardena, C. N. (1994). Learner-interface interaction in distance education: An extension of contemporary models and strategies for practitioners. The American Journal of Distance Education, 8(2), 30-42.

Hoachlander, G., Sikora, A.C., \& Horn, L. (2003). Community college students: Goals, academic preparation, and outcomes (NCES 2003-164). Washington, DC: U.S. Department of Education, National Center for Education Statistics.

Illowsky, B. S. (2007). Effects of discussion postings in online elementary statistics community college classes (Doctoral dissertation). Retrieved from ProQuest Dissertations and Theses database (UMI No. 3249902)

Institute for Higher Education Policy. (2000). Quality on the line: Benchmarks for success in Internet-base distance education. Washington: DC: Institute for Higher Education Accreditation. Retrieved February 10, 2013, from http://www.ihep.org/Publications/publications-detail.cfm?id=69

Jackson, L. C., Jones, S. J., \& Rodriguez, R. C. (2010). Faculty actions that result in student satisfaction in online courses. Journal of Asynchronous Learning Networks, 14(4), 7896.

Jaggars, S.S. (2013). Online learning in Community Colleges. In M. G. Moore (Ed.), Handbook of Distance Education. Taylor and Francis, Hoboken.

Jaggars, S. S. (2011). Online Learning: Does It Help Low-Income and Underprepared Students (52). Community College Research Center: Columbia University, Teachers College.

Jahnke, J. (2010). Student perceptions of the impact of online discussion forum participation on learning outcomes. Journal of Learning Design, 3(2), 27-34.

Jonassen, D. (1991). Evaluating constructivistic learning. Educational Technology, 31(10), 28-33. 
Jones, S. (2012). Reading between the lines of online course evaluations: Identifiable actions that improve student perceptions of teaching effectiveness and course value. Journal of Asynchronous Learning Networks, 16(1), 49-58.

Keller, C., \& Cernerud, L. (2002). Students' perceptions of e-learning in university education. Journal of Educational Media, 27(1/2), 55-67. doi: 10.1080/0305498032000045458.

Kennedy, C. C. M. (2001). The experience of online learning at a community college in south Texas: A case study (Doctoral dissertation). Retrieved from ProQuest Dissertations and Theses database (UMI No. 3020061)

Kerawalla, L., Minocha, S., Kirkup, Gl, \& Conole, G. (2008) Characterising the different blogging behaviours of students in an online distance learning course. Learning, Media, and Technology, 33(1), 21-23.

Kilmurray, J. (2003). E-learning: It's more than automation. The Technology Source. Retrieved March 11, 2013, from http://technologysource.org/article/elearning/

Kimberlin, C. L., \& Winterstein, A. G. (2008). Validity and reliability of measurement instruments used in research. American Journal of Health-Systems Pharmacy, 65, 2276-2284. Doi:10.2146/ajhp070364

Kokemuller, N. (2013a). Pros and cons of online education. seattlepi.com. Retrieved from http://education.seattlepi.com/pros-cons-online-college-classes-1472.html

Kokemuller, N. (2013b). The advantages and disadvantages of online classes used in colleges. seattlepi.com. Retrieved from http://education.seattlepi.com/advantagesdisadvantages-online-classes-used-colleges-1020.html

Kupczynski, L., Ice, P., Wiesenmayer, R., \& McCluskey, F. (2010). Student perceptions of the relationship between indicators of teaching presence and success in online courses. Journal of Interactive Online Learning, 9(1), 23-43.

Lander, M.E. (2009). Investigation of the relationships among online community college students' characteristics and instructional delivery model preferences (Doctoral dissertation). Retrieved from ProQuest Dissertations and Theses database (UMI No. 3372071)

Langer, E. (1989) Mindfulness. Reading, MA: Addison-Wesley.

Lea, M. (2007). Emerging literacies in online learning. Journal of Applied Linguistics, 4(1), 79-100.

"Learning online." Frederick.edu, last modified September 10, 2013, http://www.frederick.edu/courses and programs/distancelearning.aspx 
Lederman, D. (2013, January 8). Survey finds online enrollments slow but continue to grow. Inside Higher Ed. Retrieved from http://www.insidehighered.com

Lipman, M. (1991). Thinking in education. Cambridge: Cambridge University Press.

Liu, S. Y. (2007). Community college online course retention and grade predictors (Doctoral dissertation). Retrieved from ProQuest Dissertations and Theses database (UMI No. 3260149)

Lombardo, T. (2011). Podcasting in a community college (Doctoral dissertation). Retrieved from ProQuest Dissertations and Theses database (UMI No. 3457794)

Martin, V.S. (2012). Using wikis to experience history (Doctoral dissertation). Retrieved from ProQuest Dissertations and Theses database (UMI No. 3479217)

McSporran, M., \& Young, S. (2001) Does gender matter in online learning? Retrieved from http://hyperdisc.unitec.ac.nz/research/ALTJpaper 9.pdf

McWhorter, R.R. (2013). An examination of how community of inquiry relates to student performance in an online community college course (Doctoral dissertation). Retrieved from ProQuest Dissertations and Theses database (UMI No. 3587936)

Moore, M. G. (1989). Three types of interaction. American Journal of Distance Education, 3(2), 1-6.

Moore, M. G., \& Kearsley, G. (2005). Distance education: a systems view (2nd ed.). Belmont, CA: Wadsworth.

Morris, T.A. (2010). Exploring community college student perceptions of online learning (Doctoral dissertation). Retrieved from ProQuest Dissertations and Theses database (UMI No. 3470458)

Mullin, C.M. (2012, February). Why access matters: The community college student body (AACC Policy Brief 2012-01PBL). Washington, DC: American Association of Community Colleges.

Mullins, C. (2013, April). 2012 distance education survey results: Trends in eLearning: Tracking the impact of eLearning at community colleges. Washington, DC: Instructional Technology Council.

Mustafa, R. F. (2011). The P.O.E.M.s of educational research: A beginners' concise guide. International Education Studies, 4(3), 23. 
Nagel, D. (2011). Online learning set for explosive growth as traditional classrooms decline. Campus Technology. Retrieved from http://campustechnology.com/articles/2011/01/26/online-learning-set-forexplosive-growth-as-traditional-classrooms-decline.aspx

Nakamaru, S. (2012). Investment and return: Wiki engagement in a "remedial" ESL writing course. Journal of Research on Technology in Education 44(4), 273-291. Retrieved from http://search.proquest.com.www.libproxy.wvu.edu/docview/1140132245/140E34 2C91F49767AE4/1?accountid=2837

Nasseh, B. (1997). A brief history of distance education. Adult Education in the News. Retrieved September 27, 2013 from http://www.seniornet.org/edu/art/history.html

National Center for Education Statistics (NCES). (2011). 2007-08 National Postsecondary Student Aid Study (NPSAS: 08) [Data file]. Washington, DC: U.S. Department of Education, Institute of Education Sciences. Available from http://nces.ed.gov/surveys/npsas/

Nunes, C. A. A., \& Gaible, E. (2002). Development of multimedia materials. In W. D. Haddad \& A. Draxler (Eds.), Technologies for education: Potentials, parameters, and prospects (pp. 95-117). Paris and Washington, DC: UN ESCO and Academy for Educational Development.

Palloff, R. M., \& Pratt, K. (2007). Building online learning communities: effective strategies for the virtual classroom. San Francisco, CA: Jossey-Bass.

Park, J. H. \& Choi, H. J. (2009). Factors influencing adult learners' decision to drop out or persist in online learning. Educational Technology \& Society, 12(4), 207-217.

Parker, D. A. H. (2012). Community college students' perceptions of effective communication in online learning (Doctoral dissertation). Retrieved from ProQuest Dissertations and Theses database (UMI No. 3514706)

Parson, V., Reddy, P., Wood, J., \& Senior, C. (2009). Educating an iPod generation: Undergraduate attitudes, experiences and understanding of vodcast and podcast use. Learning, Media and Technology, 34(3), 215-228.

Patton, M. Q. (1985). Quality in qualitative research: Methodological principles and recent developments. Invited address to Division (J) of the American Educational Research Association, Chicago.

Payn, L.S. (2009). Women's learning styles: Epistemological stages and online delivery (Doctoral dissertation). Retrieved from ProQuest Dissertations and Theses database (UMI No. 3359212) 
Pearson Foundation and Harris Interactive. (2011). Pearson Foundation Community College Student Survey [Summary of results]. Retrieved from http://www.pearsonfoundation.org/downloads/PF CC Survey 2011 Summary.pdf

Pecorino, P.A. (2004). Advantages and disadvantages of online learning. Retrieved from http://www.qcc.cuny.edu/SocialSciences/ppecorino/China-QCC-DE/AdvantagesDisadvantages-DE.html

Perschbach, J.W. (2006). Blogging: An inquiry into the efficacy of a web-based technology for student reflection in community college computer science programs (Doctoral dissertation). Retrieved from ProQuest Dissertations and Theses database (UMI No. 3206012)

Political Science Department at Quinnipiac University. (2009). Pearson's correlation coefficient: What does the correlation coefficient mean? Retrieved from http://www.statisticshowto.com/how-to-compute-pearsons-correlationcoefficients/

Ramsden, P. (2003). Learning to teach in higher education (2nd ed.). London: RoutledgeFalmer.

Rayla, M., \& Caperton, I.H. (Eds.). (2012). Globaloria: Invent, build, share: Students making game media for literacy and learning [Special section]. The Journal of Media Literacy, 59(1), 1-66.

Rhode, J.F. (2008). Interaction equivalency in self-paced online learning environments: An exploration of learner preferences (Doctoral dissertation). Retrieved from ProQuest Dissertations and Theses database (UMI No. 3291462)

Richardson, J., \& Swan, K. (2001). An examination of social presence in online learning: students' perceived learning and satisfaction. Seattle, WA: Paper presented the annual meeting of the American Educational Research Association.

Robinson, C.C. \& Hullinger, H. (2008). New benchmarks in higher education: student engagement in online learning. Journal of Education for Business, 84(2), 101-108.

Saeed, N., Yang, Y. \& Sinnappan, S. (2009). Emerging web technologies in higher education: A case of incorporating blogs, podcasts and social bookmarks in a web programming course based on students' learning styles and technology preferences. Educational Technology \& Society, 12(4), 98-109.

Safer, S., Farmer, F., Segalla, S., \& Elhoubi, E. (2005). Does the distance from teacher influence student evaluations. Educational Research Quarterly, 28(3), 28. 
Salloum, S. (2011). Student perceptions of computer-mediated communication tools in online learning: Helpfulness and effects on teaching, social, and cognitive presence (Doctoral dissertation). Retrieved from ProQuest Dissertations and Theses database (UMI No. 3491416)

Salmon, G. (2011). E-moderating: The key to online teaching and learning. New York, NY: Routledge.

Schrage, M. (1989). No more teams! Mastering the dynamics of creative collaboration. New York: Currency Doubleday.

Scism, B.R. (2006). Characteristics and patterns of enrollment and completion of first-time online students at midwest suburban college (Doctoral dissertation). Retrieved from ProQuest Dissertations and Theses database (UMI No. 3223713)

Shank, P. (2010). Online course quality assurance: Using evaluations and surveys to improve online teaching and learning. Faculty Focus Special Report. Madison: WI: Magna Publications.

Shea, P., \& Bidjerano, T. (2009). Community of inquiry as a theoretical framework to foster "epistemic engagement" and "cognitive presence" in online education. Computers \& Education 52(3), 543-553.

Shea, P. J., Fredericksen, E. E., \& Pickett, A. M. (2002). Student satisfaction and reported learning in the SUNY learning network. In J. Bourne \& J.C. Moore (Eds.), Elements of Quality Online Education, Volume 3. Olin and Babson Colleges: Sloan Center for Online Education.

Shea, P. J., Fredericksen, E. E., Pickett, A. M., \& Pelz, W. E. (2004). Faculty development, student satisfaction, and reported learning in the SUNY learning network. In T. M. Duffy \& J. R. Kirkley (Eds.), Learner-centered theory and practice in distance education (pp. 343-377). Mahwah, NJ: Lawrence Erlbaum Associates, Inc.

Shea, P., Hayes, S., Vickers, J., Gozza-Cohen, M., Uzuner, S., Mehta, R., Valchova, A., \& Rangan, P. (2010). A re-examination of the community of inquiry framework: Social network analysis. Internet and Higher Education, 13(1-2), 10-21.

Shea, P., Pickett, A. \& Sau Li, C. (2005). Increasing access to higher education: A study of the diffusion of online teaching among 913 college faculty. International Review of Research in Open and Distance Learning, 6(2). Retrieved from http://www.irrodl.org/content/v6.2/shea.html

Sims, R. (1999). Interactivity on stage: Strategies for learner-designer communication. Australian Journal of Educational Technology, 15(3), 257-272. 
Slevin, J. (2008). E-learning and the transformation of social interaction in higher education. Learning, Media and Technology, 33(2), 115-126.

Snyder, T. (2013, January, 30). The benefits of online learning. The Huffington Post. Retrieved from http://www.huffingtonpost.com/tom-snyder/the-benefits-ofonline-le b 2573991.html

Snyder, T.D., \& Dillow, S.A. (2011, April). Digest of education statistics: 2010 (NCES 2011015). Washington, DC: U.S. Department of Education, Institute of Education Sciences, National Center for Education Statistics.

Soules, A. (2008). Bridging the gap: Tools for elearning. Multimedia \& Internet @ Schools 15(2), 13-16.

Speedmatters.org. (2013). A project of Communication Workers of America: Affordable high speed internet for Americans. Retrieved from www.speedmatters.org/blog/archive/broadband-in-the-hills-and-hollows-of-westvirginia/

Suskie, L. A. (1996). Questionnaire survey research: What works ( $2^{\text {nd }}$ ed). Tallahassee, FL: Association for Institutional Research.

Swan, K. (2001). Virtual interaction: Design factors affecting student satisfaction and perceived learning in asynchronous online courses. Distance Education, 22(2), 306331.

Swan, K. (2003). Learning effectiveness: What the research tells us. In J. Bourne \& J.C. Moore (Eds) Elements of Quality Online Education, Practice and Direction. Needham, MA: Sloan Center for Online Education, 13-45.

Swan, K. (2004). Learning online: Current research on issues of interface, teaching presence and learner characteristics. In J. Bourne \& J. C. Moore (Eds.), Elements of quality online education, into the mainstream (pp. 63-79). Needham, MA: Sloan Center for Online Education.

Swan, K., Garrison, D.R., \& Richardson, J. (2009). A constructivist approach to online learning: The community of inquiry framework. In C.R. Payne (Ed.), Information technology and constructivism in higher education: Progressive learning frameworks (pp. 43-57). Hershey, PA: IGI Global.

Swan, K., \& Ice, P. (2010). The Community of Inquiry framework ten years later: Introduction to the special issue. Internet and Higher Education, 13(1-2), 1-4.

Swan, K., Richardson, J. C., Ice, P., Garrison, D. R., Cleveland-Innes, M., \& Arbaugh, J.B. (2008). Validating a measurement tool of presence in online communities of inquiry. e-mentor, 2(24), 1-12. Retrieved from http://www.e-mentor.edu.pl/eng 
Tabar-Gaul, L. (2008). A descriptive study of online interactions and learning effectiveness: Perspectives of online faculty and students (Doctoral dissertation). Retrieved from ProQuest Dissertations and Theses database (UMI No. 3338626)

Thomas, S. H. (2005). Student perceptions of support services designed to overcome barriers in the online learning environment of Illinois community colleges (Doctoral dissertation). Retrieved from ProQuest Dissertations and Theses database (UMI No. 3182395)

Tinto, V. (1987). Leaving college: Rethinking the causes and cures of student departure. Chicago: University of Chicago Press.

Tinto, V. (1993). Leaving college: Rethinking the causes and cures of student attrition $\left(^{\text {nd }}\right.$ ed). Chicago: The University of Chicago Press.

Tinto, V. (2002). Establishing conditions for student success. Address to the $11^{\text {th }}$ Annual Conference of the European Access Network, Monash University, Prato, Italy.

Tinto, V., Russon, P., \& Stephanie, K. (1994). Constructing educational communities: Increase retention in challenging circumstances. Community College Journal, 64(4), 18-22.

Tracy, R. (2008). West Virginia University at Parkersburg Request for Institutional Change: Online Delivery of Selected Existing Degree Programs. Retrieved from WVU Parkersburg website: http://legacy.wvup.edu/HLC Request 2008/index.htm

Trow, M. (2010). Twentieth-century higher education: Elite to mass to universal. Baltimore: The John Hopkins University Press.

Trowler, V. (2010) Student engagement literature review. York: Higher Education Academy.

Tung, C.K. (2007). Perceptions of students and instructors of online and web-enhanced course effectiveness in community colleges (Doctoral dissertation). Retrieved from ProQuest Dissertations and Theses database (UMI No. 3284232)

Valjataga, T., and Fiedler, S. (2009). Supporting students to self-direct intentional learning projects with social media. Educational Technology \& Society, 12(3), 58-69.

Vaughan, G. B. (2000). The community college story (2nd ed). Washington, DC: Community College Press.

Wang, L. C. \& Morgan, W. R. (2008). Student perceptions of using instant messaging software to facilitate synchronous online class interaction in a graduate teacher education course. Journal of Computing in Teacher Education, 25(1), 15-21. 
Webster, J. \& Hackley, P. (1997). Teaching effectiveness in technology-mediated distance education. The Academy of Management Journal, 40(6), 1282-1309.

Wenger, E. (2001). Supporting communities of practice: A survey of community-oriented technologies. (1.3 ed.) (Shareware). Retrieved March 11, 2013, from http://go.webassistant.com/4u/upload/users/u1000471/cop technology 2001.pdf

Whitehouse, P. (2011). Networked teacher professional development: The case of Globaloria. Journal of Interactive Learning Research, 22(1), 139-165.

Yang, Y. \& Cornelius, L. (2004). Students' perceptions towards the quality of online education: a qualitative approach. Report from 27th AECT: Association for Educational Communications and Technology. Chicago, IL.

York, D.L. (2003). Falling through the net: Implications of inherent characteristics in student retention and performance at a community college (Doctoral dissertation). Retrieved from ProQuest Dissertations and Theses database (UMI No. 3091987)

Young, S. (2006). Student views of effective online teaching in higher education. The American Journal of Distance Education, 20(2), 65-77.

Xu, D., \& Jaggars, S.S. (2013). Adaptability to online learning: Differences across types of students and academic subject areas. (CCRC Working Paper No. 54). New York: Columbia University, Teachers College, Community College Research Center.

Zickuhr, K. \& Smith, A. (2013). Home Broadband 2013. Pew Research Center's Internet and American Life Project. http://www.pewinternet.org/2013/08/26/homebroadband-2013/ 


\section{Appendix A}

Community of Inquiry Survey Instrument 


\section{Community of Inquiry Survey Instrument (draft v14)}

Design \& Organization

\section{Teaching Presence}

1. The instructor clearly communicated important course topics.

2. The instructor clearly communicated important course goals.

3. The instructor provided clear instructions on how to participate in course learning activities.

4. The instructor clearly communicated important due dates/time frames for learning activities.

Facilitation

5. The instructor was helpful in identifying areas of agreement and disagreement on course topics that helped me to learn.

6. The instructor was helpful in guiding the class towards understanding course topics in a way that helped me clarify my thinking.

7. The instructor helped to keep course participants engaged and participating in productive dialogue.

8. The instructor helped keep the course participants on task in a way that helped me to learn.

9. The instructor encouraged course participants to explore new concepts in this course.

10. Instructor actions reinforced the development of a sense of community among course participants.

Direct Instruction

11. The instructor helped to focus discussion on relevant issues in a way that helped me to learn.

12. The instructor provided feedback that helped me understand my strengths and weaknesses.

13. The instructor provided feedback in a timely fashion.

\section{Social Presence}

Affective expression

14. Getting to know other course participants gave me a sense of belonging in the course.

15. I was able to form distinct impressions of some course participants.

16. Online or web-based communication is an excellent medium for social interaction. 
Open communication

17. I felt comfortable conversing through the online medium.

18. I felt comfortable participating in the course discussions.

19. I felt comfortable interacting with other course participants.

Group cohesion

20. I felt comfortable disagreeing with other course participants while still maintaining a sense of trust.

21. I felt that my point of view was acknowledged by other course participants.

22. Online discussions help me to develop a sense of collaboration.

Triggering event

\section{Cognitive Presence}

23. Problems posed increased my interest in course issues.

24. Course activities piqued my curiosity.

25. I felt motivated to explore content related questions.

\section{Exploration}

26. I utilized a variety of information sources to explore problems posed in this course.

27. Brainstorming and finding relevant information helped me resolve content related questions.

28. Online discussions were valuable in helping me appreciate different perspectives.

Integration

29. Combining new information helped me answer questions raised in course activities.

30. Learning activities helped me construct explanations/solutions.

31. Reflection on course content and discussions helped me understand fundamental concepts in this class.

Resolution

32. I can describe ways to test and apply the knowledge created in this course.

33. I have developed solutions to course problems that can be applied in practice.

34. I can apply the knowledge created in this course to my work or other non-class related activities. 
5 point Likert-type scale

1 = strongly disagree, 2 = disagree, $3=$ neutral, 4 = agree, 5 = strongly agree 


\section{Appendix B}

Asynchronous Communication Questionnaire 


\section{Survey: Asynchronous Communication Questionnaire}

The following survey should take less than 10 minutes to complete. Please answer the questions with the current online courses in which you are enrolled at WVU Parkersburg.

You must be 18 years of age or older to participate, and currently enrolled in an online course at a community college. Your participation is voluntary and there are no consequences for non-participation. You may skip any questions you are not comfortable answering or may quit at any point and submit a partially completed questionnaire. Individual survey responses will be kept confidential. Survey results will not indicate the identity of the participants. West Virginia University's Institutional Review Board acknowledgement of this project is on file.

\section{All responses will be kept confidential.}

Individuals providing email addresses at the end of the survey will be entered into a drawing for a gasoline card given in appreciation for participating in the study. Two winners will be drawn from those submitting surveys within the first week. 


\section{Asynchronous Communication Questionnaire}

Directions: Please provide responses regarding your experiences with an online course that you have taken at WVU Parkersburg.

1. What is your age?
a. $18-24$
b. 25 or older

2. What is your gender?
a. Male
b. Female

3. What is your overall GPA?
a. Above 3.0
b. $2.0-2.9$
c. below 1.9
d. In first semester, no GPA

4. Including this semester, how many online courses have you taken at this community college? (An online course uses remote electronic delivery for 100 percent of the course content.)
a. One or two
b. Three or more

5. In what program of study are you enrolled (choose no more than two)?

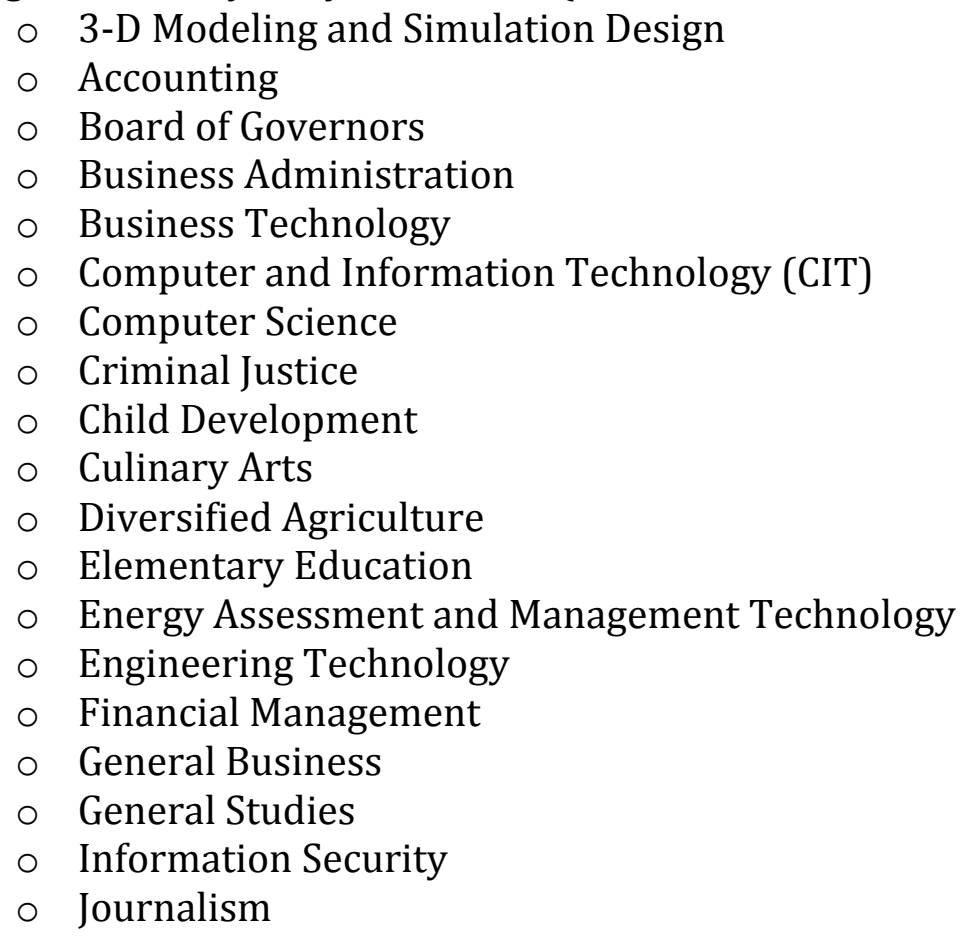




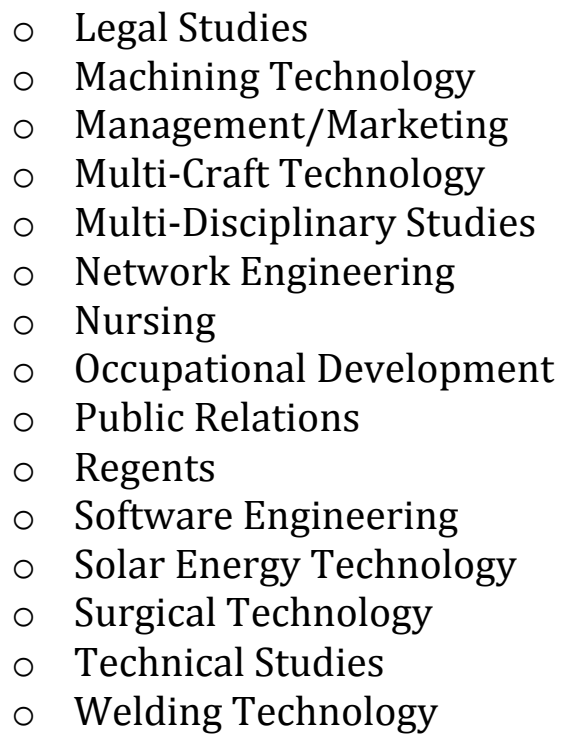

6. What type of Internet access do you have at your home?

a. I have no Internet access at home.

b. I have Internet access at home, but it runs very slowly with frequent delays and frustrations.

c. I have Internet access at home and it runs moderately quickly with only occasional delays and frustrations.

d. I have Internet access at home and it runs very quickly and reliably.

7. Asynchronous communication tools are online tools that can be used to share information about course topics, to provide directions or clarification, to provide feedback, or to interact and collaborate with other course participants. These tools are not for real-time communications. Please select which of the following tools you have used in online courses this semester. (check all that apply).

- Email, an electronic message that a user types on a screen and sends to either one or more recipients.

_ Discussion boards or forums, a general term for any online bulletin board where you can leave and expect to see responses to messages you have left.

_ Blogs or weblogs, a website that contains an online personal journal with reflections, comments and often hyperlinks provided by the writer.

_ Wikis, a web-based tool that allows many authors to edit the same document at the same time, and see each other's edits.

_ Podcasts, a broadcast of audio or video files over the Internet, which you can play back on your mobile device or personal computer.

_ $\quad$ None of these used 
(BASED ON THE REPSONSE TO \#7, THOSE TOOLS WILL APPEAR FOR THE RESPONDENT TO ANSWER FOR THE REMAINING QUESTION OF THE SURVEY IN PLACE OF THE WORD “TOOL".)

In this survey, satisfaction refers to having my expectations and communication needs fulfilled. To what extent to do you agree with the following statement:

0 - not used, $1=$ strongly disagree, $2=$ disagree, $3=$ neutral, $4=$ agree, $5=$ strongly agree

8. I am satisfied with the use of (tool) as a communication tool in my online courses this semester. It helps me to make meaningful connections with the instructor and other students, and to deeply engage with the course content

Please provide your email address if you wish to be entered into a drawing for a gasoline card. All responses will be kept confidential, even when email addresses are provided.

Email address:

Thank you for participating in this survey. 


\section{Appendix C}

E-mail requesting permission to use CoI survey instrument 


\section{W. WestVirginiaUniversity \\ College of Education and Human Services}

October 24,2013

Hello, Dr. Garrison,

I am a doctoral student at West Virginia University seeking to complete my dissertation on the following topic:

The relationship between student perceptions of satisfaction of social, teaching and cognitive presence and asynchronous tools for online learning in a Region V community college

The following Research Questions are proposed:

1. What are community college student perceptions of satisfaction of use of asynchronous communication tools in a Region V community college?

2. What are community college student perceptions of satisfaction of social, teaching and cognitive presence in a Region V community college?

3. What is the relationship between community college student perceptions of satisfaction of the use of asynchronous communication tools and community college student perceptions of satisfaction of social, teaching and cognitive presence?

I am requesting permission to utilize the Col model as a figure in my dissertation for explanation purposes as I explain the research on social, teaching and cognitive presence. I am also seeking permission to utilize the Col survey as an instrument to answer some of my research questions. I will also be devising an instrument to focus on the asynchronous tool usage in the online classroom to explore the rest of the research questions. If permitted, does a fee exist for using the survey in a research study?

Thank you for considering this request. I look forward to hearing from you soon, and to one day sharing the results of my research with you.

Sincerely,

Helen M. Hazi, Ph.D.

Professor and Committee Chair

Torie Jackson

Doctoral Candidate 


\section{Appendix D}

E-mail Granting Permission to use CoI Survey Instrument 
RE: Seeking Permission to Utilize Col model and survey instrument Inbox $x$ Helen Hazi $x$

D. Randy Garrison <garrison@ucalgary.ca>

to me $\nabla$

Torie,

You have my permission to use the Col figure and survey in your research.

There is no charge for this.

All the best with your study.

DRG

D. Randy Garrison, Professor

Education Tower, Room 602G

University of Calgary

2500 University Drive NW

Calgary, Alberta, Canada T2N 1N4

Work: (403) 220-6764

Email: garrison@ucalgary.ca

http://communitiesofinquiry.com/ 


\section{Appendix E}

Invitation to Panel Experts to Participate in Survey Review 


\section{West WringiniaUniversity \\ College of Education and Human Services}

January 16,2014

Dear Dr. Shanna Smith Jaggars:

The purpose of this letter is to seek your assistance in my research study by serving on a four-member panel of experts to review an asynchronous communication questionnaire tool I have developed.

You were selected because you are a nationally known expert of online learning in the community college environment. You also have completed much research of the Community of Inquiry framework in relation to community college online courses.

In partial fulfillment of the Educational Leadership Studies doctoral program at West Virginia University, I am required to conduct a research-based study. The purpose of my study is to examine the relationship between community college student perceptions of satisfaction with asynchronous communication tools and community college student perceptions of satisfaction with social, teaching, and cognitive presence in the online classroom. Results of this study will assist community college instructors who seek to assess student satisfaction in online courses. The results may also help educators better understand best practices of the use of asynchronous communication tools in assisting interaction in an online classroom.

A review by a panel of experts is an effective means of providing validity to a survey instrument. Asking experts to review a survey before it is administered reveals if the items are clear and easily understood, and determines the survey's relationship with the study's research questions (Suskie, 1996). Individuals selected to evaluate a survey should include those possessing familiarity with the proposed field of study and survey design.

Please find attached an abstract of the proposed research study for your review.

I sincerely appreciate your consideration as a reviewer of the questionnaire developed for this study. If you agree to review, please send an e-mail notification and I will forward the survey and response form to you. If you have further questions, contact me at tiacks10@ wvup.edu or (304) 991-8009. Thank you for your assistance.

Sincerely,

Helen M. Hazi, Ph.D.

Professor and Committee Chair

Enclosures: Abstract
Torie Jackson

Doctoral Candidate 


\section{Appendix F}

Draft Copy of Survey 


\section{Survey: Asynchronous Communication Questionnaire}

The following survey should take less than 10 minutes to complete. Please answer the questions taking into consideration your experiences with your current online course offered at WVU Parkersburg.

You must be 18 years of age or older to participate, and currently enrolled in an online course at a community college. Your participation is voluntary and there are no consequences for non-participation. You may skip any questions you are not comfortable answering or may quit at any point and submit a partially completed questionnaire. Individual survey responses will be kept confidential. Survey results will not indicate the identity of the participants. West Virginia University's Institutional Review Board acknowledgement of this project is on file.

\section{All responses will be kept confidential.}

Individuals providing email addresses at the end of the survey will be entered into a drawing for a gasoline card given in appreciation for participating in the study. Two winners will be drawn from those submitting surveys within the first week. 


\section{Asynchronous Communication Questionnaire}

Directions: Please provide responses regarding your experiences with an online course that you have taken at WVU Parkersburg.

7. What is your age?
a. $17-24$
b. 25 or older

8. What is your gender?
a. Male
b. Female

9. What is your overall GPA?
a. Above 3.0
b. $2.0-2.9$
c. below 1.9

10. How many online courses have you taken at a community college?
a. One
b. Two
c. Three or four
d. Five or more

11. In what degree program are you enrolled (choose no more than two)?

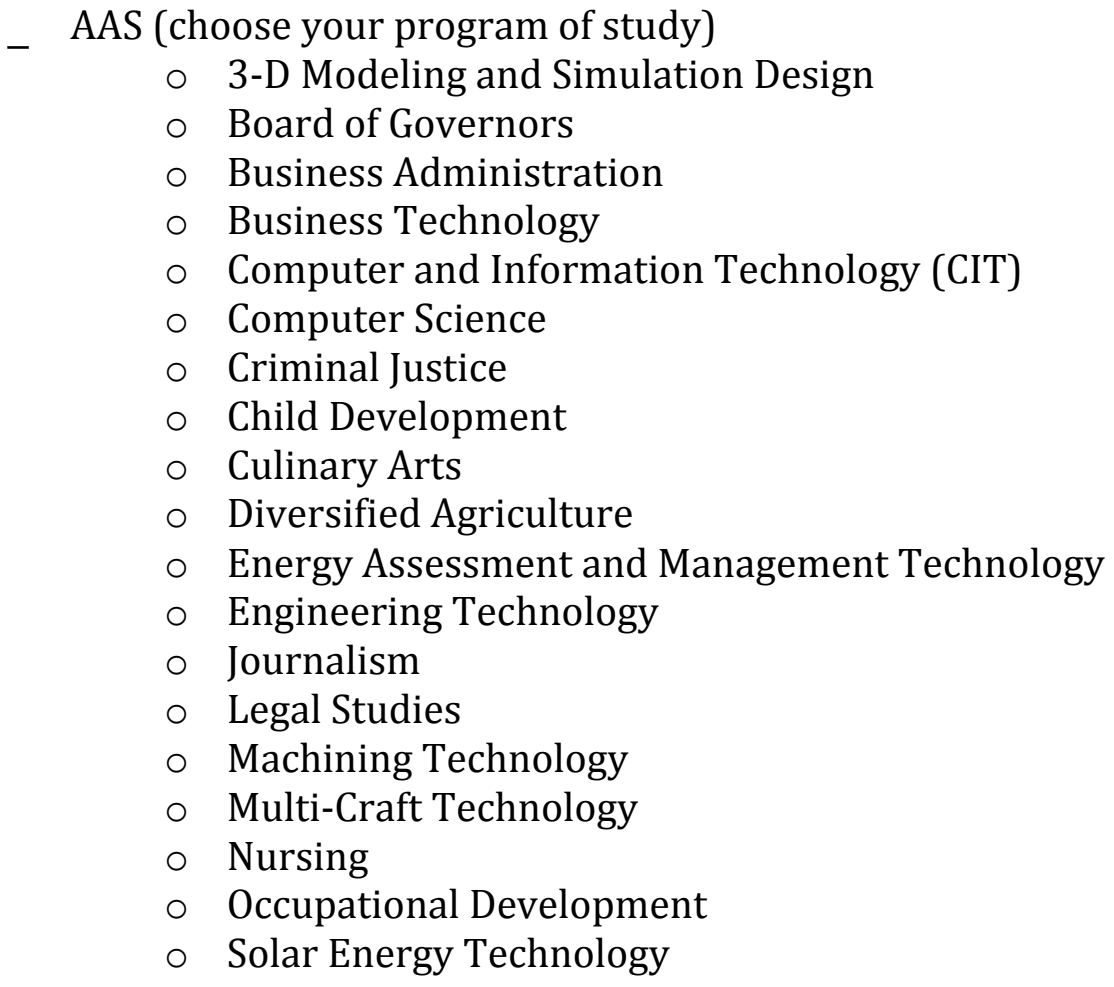




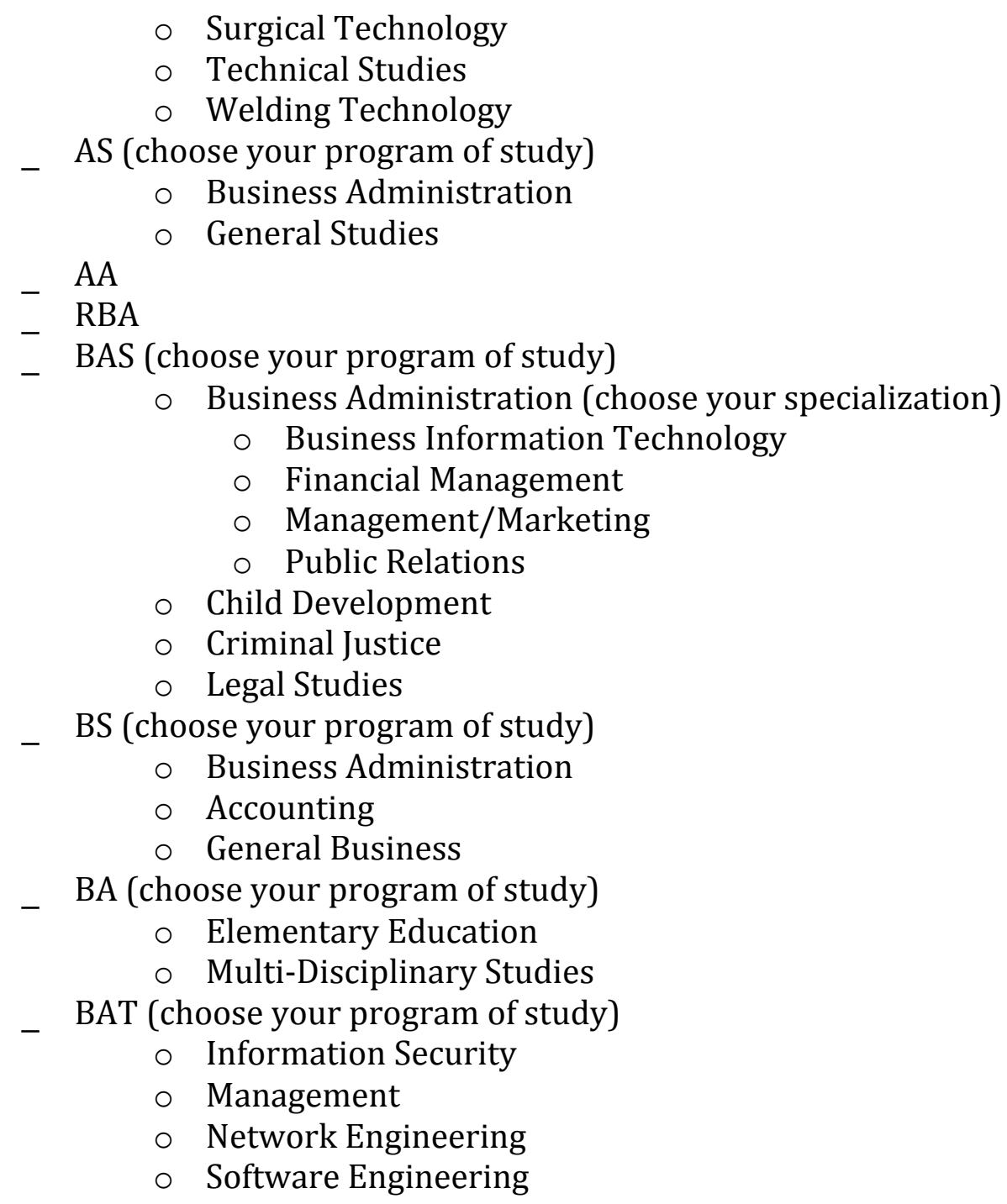

12. Asynchronous communication tools are online tools that can be used to share information about course topics, to provide directions or clarification, to provide feedback, or to interact and collaborate with other course participants. Please select which of the following tools you have used in online courses (check all that apply).

_ Email, an electronic message that a user types on a screen and sends to either one or more recipients.

_ Discussion boards or forums, a general term for any online bulletin board where you can leave and expect to see responses to messages you have left.

_ Blogs or weblogs, a website that contains an online personal journal with reflections, comments and often hyperlinks provided by the writer.

- Wikis, a web-based tool that allows for many authors to work on projects together with shared editing capabilities of the digital document. 
_ $\quad$ Podcasts, a broadcast of audio or video files over the Internet using syndication feeds for playback on mobile devices and personal computers.

_ $\quad$ None of these used

(BASED ON THE REPSONSE TO \#6, THOSE TOOLS WILL APPEAR FOR THE RESPONDENT TO ANSWER FOR THE REMAINING QUESTION OF THE SURVEY IN PLACE OF THE WORD "TOOL".)

Answer the following question based on tool usage in your online course using a 5-point Likert-type scale:

0 - not used, $1=$ strongly disagree, 2 = disagree, $3=$ neutral, $4=$ agree, $5=$ strongly agree

13. I am satisfied with the use of (tool) as a communication tool for my online course.

Please provide your email address if you wish to be entered into a drawing for a gasoline card. All responses will be kept confidential, even when email addresses are provided.

Email address:

Thank you for participating in this survey. 


\section{Appendix G}

Panel of Experts Response Form 
Directions to Panel of Experts Reviewing the Proposed Survey Instrument

\section{Asynchronous Communication Questionnaire}

Directions: Please review the survey instrument Asynchronous Communication Questionnaire (attached). The invitation will be distributed via email to all students currently enrolled in an online course at a particular Region V community college during the Spring 2014 semester. Those invited will receive a link to a URL hosting the survey instrument.

As you review the documents, please complete the attached response form following the directions provided at the top of the form. You will be asked to consider the following questions as you review the survey:

- Is each survey item clear and easily understood?

- Is each survey item related to the study's topics and goals?

- Is each survey item important to the research aims?

- Are there survey items you believe should be deleted? If so, which one(s)?

- Are there survey items you believe should be modified? If so, which one(s)?

- Are there additional survey items you would recommend? If so, please describe the item(s) and provide a rationale.

- Are the instructions to respondents clear and easily understood?

- Do respondents have adequate assurance of confidentiality and anonymity?

- Is there an unreasonable cost or burden to the respondent population?

Please contact Torie Jackson at tjacks10@wvup.edu or 304-991-8009 if you have any questions. Your input is valuable in improving the survey instrument. Please provide your feedback to tiacks10@wvup.edu no later than DATE, 2014.

Thank you for taking time to review this survey instrument. 


\section{Survey Item Review}

\section{Asynchronous Communication Questionnaire}

Directions: Please enter the words "Yes" or "No" in each space in the first three columns indicating your opinion of the item. In Column 4, please indicate if the item should be kept, deleted, or modified. Please enter any comments, suggestions, or modifications in Column 5. The survey has a total of 7 questions.

1. What is your age?

$$
\begin{array}{ll}
- & 17-24 \\
- & 25 \text { or older }
\end{array}
$$

\begin{tabular}{|l|l|c|c|c|}
\hline $\begin{array}{c}\text { Clear \& easily } \\
\text { understood? }\end{array}$ & $\begin{array}{c}\text { Related to the } \\
\text { topic \& goals? }\end{array}$ & $\begin{array}{c}\text { Important to } \\
\text { the research } \\
\text { aims? }\end{array}$ & $\begin{array}{c}\text { Keep, Delete, } \\
\text { or Modify? }\end{array}$ & $\begin{array}{c}\text { Comments or Suggested } \\
\text { Modifications }\end{array}$ \\
\hline & & & & \\
\hline
\end{tabular}

2. What is your gender?

$\begin{array}{ll} & \text { Male } \\ \text { - } & \text { Female }\end{array}$

\begin{tabular}{|l|l|l|l|l|}
\hline $\begin{array}{c}\text { Clear \& easily } \\
\text { understood? }\end{array}$ & $\begin{array}{c}\text { Related to the } \\
\text { topic \& goals? }\end{array}$ & $\begin{array}{c}\text { Important to } \\
\text { the research } \\
\text { aims? }\end{array}$ & $\begin{array}{c}\text { Keep, Delete, } \\
\text { or Modify? }\end{array}$ & $\begin{array}{c}\text { Comments or Suggested } \\
\text { Modifications }\end{array}$ \\
\hline & & & & \\
\hline
\end{tabular}

3. What is your overall GPA?

$\begin{array}{ll} & \text { Above } 3.0 \\ - & 2.0-2.9 \\ - & \text { below } 1.9\end{array}$

\begin{tabular}{|l|l|c|c|c|}
\hline $\begin{array}{c}\text { Clear \& easily } \\
\text { understood? }\end{array}$ & $\begin{array}{c}\text { Related to the } \\
\text { topic \& goals? }\end{array}$ & $\begin{array}{c}\text { Important to } \\
\text { the research } \\
\text { aims? }\end{array}$ & $\begin{array}{c}\text { Keep, Delete, } \\
\text { or Modify? }\end{array}$ & $\begin{array}{c}\text { Comments or Suggested } \\
\text { Modifications }\end{array}$ \\
\hline & & & & \\
& & & & \\
\hline
\end{tabular}


4. How many online courses have you taken at a community college?

$\begin{array}{ll} & \text { One } \\ - & \text { Two } \\ - & \text { Three or four } \\ - & \text { Five or more }\end{array}$

\begin{tabular}{|l|l|c|c|c|}
\hline $\begin{array}{c}\text { Clear \& easily } \\
\text { understood? }\end{array}$ & $\begin{array}{c}\text { Related to the } \\
\text { topic \& goals? }\end{array}$ & $\begin{array}{c}\text { Important to } \\
\text { the research } \\
\text { aims? }\end{array}$ & $\begin{array}{c}\text { Keep, Delete, } \\
\text { or Modify? }\end{array}$ & $\begin{array}{c}\text { Comments or Suggested } \\
\text { Modifications }\end{array}$ \\
\hline & & & & \\
\hline
\end{tabular}

5. In what degree program are you enrolled (choose no more than two)?

_ AAS (choose your program of study)

○ 3-D Modeling and Simulation Design

○ Board of Governors

- Business Administration

- Business Technology

- Computer and Information Technology (CIT)

- Computer Science

- Criminal Justice

○ Child Development

- Culinary Arts

○ Diversified Agriculture

- Energy Assessment and Management Technology

○ Engineering Technology

- Journalism

○ Legal Studies

- Machining Technology

- Multi-Craft Technology

- Nursing

- Occupational Development

- Solar Energy Technology

- Surgical Technology

- Technical Studies

○ Welding Technology

_ AS (choose your program of study)

- Business Administration

- General Studies

- $\mathrm{AA}$

- RBA

- $\quad$ BAS (choose your program of study) 
- Business Administration (choose your specialization)

- Business Information Technology

- Financial Management

- Management/Marketing

○ Public Relations

○ Child Development

- Criminal Justice

- Legal Studies

_ BS (choose your program of study)

- Business Administration

- Accounting

○ General Business

_ BA (choose your program of study)

○ Elementary Education

○ Multi-Disciplinary Studies

_ BAT (choose your program of study)

○ Information Security

- Management

○ Network Engineering

o Software Engineering

\begin{tabular}{|l|l|c|c|c|}
\hline $\begin{array}{c}\text { Clear \& easily } \\
\text { understood? }\end{array}$ & $\begin{array}{c}\text { Related to the } \\
\text { topic \& goals? }\end{array}$ & $\begin{array}{c}\text { Important to } \\
\text { the research } \\
\text { aims? }\end{array}$ & $\begin{array}{c}\text { Keep, Delete, } \\
\text { or Modify? }\end{array}$ & $\begin{array}{c}\text { Comments or Suggested } \\
\text { Modifications }\end{array}$ \\
\hline & & & & \\
\hline
\end{tabular}

6. Asynchronous communication tools are online tools that can be used to share information about course topics, to provide directions or clarification, to provide feedback, or to interact and collaborate with other course participants. Please select which of the following tools you have used in online courses (check all that apply).

- Email, an electronic message that a user types on a screen and sends to either one or more recipients.

_ Discussion boards or forums, a general term for any online bulletin board where you can leave and expect to see responses to messages you have left.

_ Blogs or weblogs, a website that contains an online personal journal with reflections, comments and often hyperlinks provided by the writer.

_ Wikis, a web-based tool that allows for may authors to work on projects together with shared editing capabilities of the digital document. 
- $\quad$ Podcasts, a broadcast of audio or video files over the Internet using syndication feeds for playback on mobile devices and personal computers.

_ $\quad$ None of these used

\begin{tabular}{|l|l|c|c|c|}
\hline $\begin{array}{c}\text { Clear \& easily } \\
\text { understood? }\end{array}$ & $\begin{array}{c}\text { Related to the } \\
\text { topic \& goals? }\end{array}$ & $\begin{array}{c}\text { Important to } \\
\text { the research } \\
\text { aims? }\end{array}$ & $\begin{array}{c}\text { Keep, Delete, } \\
\text { or Modify? }\end{array}$ & $\begin{array}{c}\text { Comments or Suggested } \\
\text { Modifications }\end{array}$ \\
\hline & & & & \\
& & & & \\
\hline
\end{tabular}

(BASED ON THE REPSONSE TO \#6, THOSE TOOLS WILL APPEAR FOR THE RESPONDENT TO ANSWER FOR THE REMAINING QUESTION OF THE SURVEY IN PLACE OF THE WORD “TOOL".)

Answer the following questions based on tool usage in your online course using a 5-point Likert-type scale:

0 - not used, $1=$ strongly disagree, 2 = disagree, $3=$ neutral, $4=$ agree, $5=$ strongly agree

7. I am satisfied with the use of (tool) as a communication tool for my online course.

\begin{tabular}{|l|l|c|c|c|}
\hline $\begin{array}{c}\text { Clear \& easily } \\
\text { understood? }\end{array}$ & $\begin{array}{c}\text { Related to the } \\
\text { topic \& goals? }\end{array}$ & $\begin{array}{c}\text { Important to } \\
\text { the research } \\
\text { aims? }\end{array}$ & $\begin{array}{c}\text { Keep, Delete, } \\
\text { or Modify? }\end{array}$ & $\begin{array}{c}\text { Comments or Suggested } \\
\text { Modifications }\end{array}$ \\
\hline & & & & \\
\hline
\end{tabular}




\begin{tabular}{|l|l|l|l|}
\hline $\begin{array}{l}\text { Overall } \\
\text { consideration: }\end{array}$ & $\begin{array}{l}\text { Please indicate by } \\
\text { Yes or No }\end{array}$ & $\begin{array}{l}\text { If no, please explain } \\
\text { needed modifications }\end{array}$ & $\begin{array}{l}\text { Any other comments or } \\
\text { suggestions }\end{array}$ \\
\hline $\begin{array}{l}\text { Are the } \\
\text { instructions to } \\
\text { respondents clear } \\
\text { and easily }\end{array}$ & & & \\
understood? & & & \\
\hline
\end{tabular}

Thank you for evaluating in this survey. 


\section{Appendix $\mathbf{H}$}

Letter to Survey Participants 


\section{Wr. WestVirginiaUniversity College of Education and Human Services}

March 17, 2014

Dear Student:

In partial fulfillment of the educational leadership studies doctoral program at West Virginia University, I am required to conduct a research-based study. The purpose of my study is to examine the relationship between community college student perceptions of satisfaction with asynchronous communication tools and community college student perceptions of satisfaction with social, teaching, and cognitive presence in the online classroom. Results of this research will assist community college instructors who seek to assess student satisfaction in online courses. The results may also help educators better understand best practices of the use of asynchronous communication tools in assisting interaction in an online classroom.

The purpose of this letter is to seek your participation in the study be completing an electronic survey. The survey will take less than 10 minutes of your time. You must be 18 years of age or older to participate, and currently enrolled in an online course at a community college. Your participation is voluntary and there are no consequences for non-participation. You may skip any questions you are not comfortable answering or may quit at any point and submit a partially completed questionnaire. Individual survey responses will be kept confidential. Survey results will not indicate the identity of the participants. West Virginia University's Institutional Review Board acknowledgement of this project is on file.

The online survey can be accessed at the following site: https:/www.surveymonkey.com/s/2RPDKTK

When you are answering the survey questions, please answer in regards to your current online course.

In appreciation for your involvement, all respondents who provide an e-mail address at the end of the survey will be entered into a drawing for three gasoline cards, each for $\$ 25$. Please don't delay - two of the cards will be awarded to those responding by March 23, 2014 and the third will be awarded on March 30, 2014. I sincerely appreciate your consideration regarding participation in this study.

Please complete the survey no later than March 30, 2014. If you have further questions, contact me at tjacks10@wvup.edu or (304) 424-8247.

Sincerely,

Helen M. Hazi, Ph.D.

Torie Jackson

Professor and Committee Chairperson

Doctoral Candidate

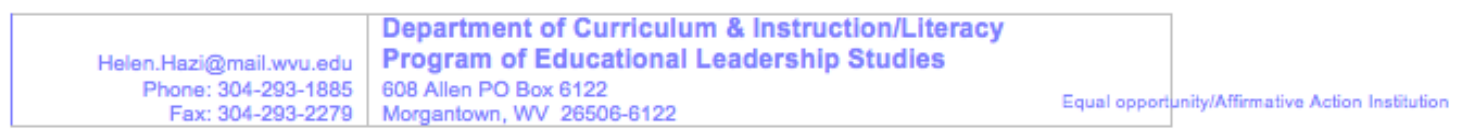




\section{Appendix I}

Frequency of Responses to Asynchronous Communication Questionnaire 
Table I.1.

Frequency of Responses to ACQ Questions

\begin{tabular}{lcccccc}
\hline & & \multicolumn{2}{c}{ Dissatisfaction } & Neutral & \multicolumn{2}{c}{ Satisfaction } \\
\hline Tool & $M$ & 1 & 2 & 3 & 4 & 5 \\
\hline E-mail & 3.69 & 8 & 7 & 28 & 40 & 33 \\
Discussion & 3.52 & 9 & 9 & 25 & 44 & 30 \\
Blogs & 3.18 & 7 & 4 & 13 & 11 & 7 \\
Wikis & 3.10 & 5 & 5 & 11 & 9 & 2 \\
Podcasts & 3.60 & 7 & 8 & 25 & 54 & 30 \\
\hline
\end{tabular}




\section{Appendix J}

Repeated Measures ANOVA and Post-Hoc Test Results for Asynchronous Communication Questionnaire 
Table J.1.

Repeated Measures Analysis of Variance for Tools

\begin{tabular}{lcccccc}
\hline Tool & $M$ & $D f$ & $\mathrm{~F}$ & $p$ & $\begin{array}{c}\text { Mauchly's } \\
\text { Sphericity }\end{array}$ & $\begin{array}{c}\text { Greenhouse- } \\
\text { Geisser }\end{array}$ \\
\hline E-mail & 3.69 & 3.195 & 2.516 & 0.042 & 0.546 & 0.055 \\
Discussions & 3.52 & & & & & \\
Podcasts & 3.70 & & & & & \\
Blogs & 3.18 & & & & & \\
Wikis & 3.10 & & & & & \\
\hline
\end{tabular}

${ }^{*} p<0.05$

Table J.2.

Bonferroni Correction for Repeated Measure ANOVA for Tools

\begin{tabular}{llcc}
\hline Tool & Comparison Tool & Mean Difference & $P$ \\
\hline E-mail & Discussions & 0.183 & 0.179 \\
& Blogs & 0.268 & 0.118 \\
& Wikis & 0.183 & 0.179 \\
& Podcasts & -0.099 & 0.457 \\
\hline Discussions & E-mail & -0.183 & 0.179 \\
& Blogs & 0.085 & 0.427 \\
& Wikis & 0.000 & 1.000 \\
& Podcasts & -0.282 & 0.003 \\
\hline \multirow{2}{*}{ Blogs } & E-mail & -0.268 & 0.118 \\
& Discussions & -0.085 & 0.427 \\
& Wikis & -0.085 & 0.587 \\
& Podcasts & -0.366 & 0.011 \\
\hline Wikis & E-mail & -0.183 & 0.179 \\
& Discussions & 0.000 & 1.000 \\
& Blogs & 0.085 & 0.587 \\
& Podcasts & -0.282 & 0.036 \\
\hline Podcasts & E-mail & 0.099 & 0.457 \\
& Discussions & 0.282 & 0.003 \\
& Blogs & 0.366 & 0.011 \\
& Wikis & 0.282 & 0.036 \\
\hline
\end{tabular}

$* p<0.05$ 


\section{Appendix K}

Independent T-Test Results Comparing Tools with Demographics 
Table K.1.

Comparison of Perceptions Regarding E-mail and Age

\begin{tabular}{ccccccc}
\hline Age & $n$ & $M$ & Difference & SD & $t$ & Significance* $^{*}$ \\
\hline $18-24$ & 155 & 3.59 & -0.16 & 1.32 & -1.35 & 0.178 \\
$25+$ & 212 & 3.75 & & 1.22 & & \\
\hline
\end{tabular}

$* p<0.05$

Table K.2.

Comparison of Perceptions Regarding E-mail and Gender

\begin{tabular}{ccccccc}
\hline Gender & $n$ & $M$ & Difference & SD & $t$ & Significance* $^{*}$ \\
\hline Female & 279 & 3.68 & -0.02 & 1.30 & -0.14 & 0.891 \\
Male & 81 & 3.70 & & 1.19 & & \\
\hline
\end{tabular}

${ }^{*} p<0.05$

Table K.3.

Comparison of Perceptions Regarding E-mail and Amount of Online Courses Taken

\begin{tabular}{ccccccc}
\hline Courses & $n$ & $M$ & Difference & SD & $t$ & Significance* $^{*}$ \\
\hline $1-2$ & 111 & 3.46 & -0.33 & 1.36 & -2.50 & 0.013 \\
$3+$ & 256 & 3.79 & & 1.20 & & \\
\hline
\end{tabular}

${ }^{*} p<0.05$ 
Table K.4.

Comparison of Perceptions Regarding Discussions and Age

\begin{tabular}{ccccccc}
\hline Age & $n$ & $M$ & Difference & SD & $t$ & Significance* $^{*}$ \\
\hline $18-24$ & 145 & 3.48 & -0.07 & 1.27 & -0.62 & 0.534 \\
$25+$ & 208 & 3.55 & & 1.38 & & \\
\hline
\end{tabular}

$* p<0.05$

Table K.5.

Comparison of Perceptions Regarding Discussions and Gender

\begin{tabular}{ccccccc}
\hline Gender & $n$ & $M$ & Difference & SD & $t$ & Significance* \\
\hline Female & 274 & 3.52 & -0.01 & 1.33 & -0.09 & 0.928 \\
Male & 79 & 3.53 & & 1.33 & & \\
\hline
\end{tabular}

$* p<0.05$

Table K.6.

Comparison of Perceptions Regarding Discussions and Amount of Online Courses Taken

\begin{tabular}{ccccccc}
\hline Courses & $n$ & $M$ & Difference & SD & $t$ & Significance* $^{*}$ \\
\hline $1-2$ & 104 & 3.30 & -0.32 & 1.45 & -2.35 & 0.019 \\
$3+$ & 246 & 3.62 & & 1.24 & & \\
\hline
\end{tabular}

$* p<0.05$ 
Table K.7.

Comparison of Perceptions Regarding Blogs and Age

\begin{tabular}{ccccccc}
\hline Age & $n$ & $M$ & Difference & SD & $t$ & Significance* $^{*}$ \\
\hline $18-24$ & 39 & 2.97 & -0.38 & 1.24 & -1.51 & 0.134 \\
$25+$ & 48 & 3.35 & & 1.51 & & \\
\hline
\end{tabular}

$* p<0.05$

Table K.8.

Comparison of Perceptions Regarding Blogs and Gender

\begin{tabular}{ccccccc}
\hline Gender & $n$ & $M$ & Difference & SD & $t$ & Significance* \\
\hline Female & 61 & 3.10 & -0.32 & 1.42 & -1.09 & 0.280 \\
Male & 24 & 3.42 & & 1.47 & & \\
\hline
\end{tabular}

$* p<0.05$

Table K.9.

Comparison of Perceptions Regarding Blogs and Amount of Online Courses Taken

\begin{tabular}{ccccccc}
\hline Courses & $n$ & $M$ & Difference & SD & $t$ & Significance* $^{*}$ \\
\hline $1-2$ & 28 & 3.11 & -0.15 & 1.58 & 0.54 & 0.591 \\
$3+$ & 58 & 3.26 & & 1.28 & & \\
\hline
\end{tabular}

$* p<0.05$ 
Table K.10.

Comparison of Perceptions Regarding Wikis and Age

\begin{tabular}{ccccccc}
\hline Age & $n$ & $M$ & Difference & SD & $t$ & Significance* $^{*}$ \\
\hline $18-24$ & 35 & 3.09 & -0.02 & 0.85 & -0.08 & 0.934 \\
$25+$ & 38 & 3.11 & & 1.18 & & \\
\hline
\end{tabular}

${ }^{*} p<0.05$

Table K.11.

Comparison of Perceptions Regarding Wikis and Gender

\begin{tabular}{ccccccc}
\hline Gender & $n$ & $M$ & Difference & SD & $t$ & Significance* \\
\hline Female & 48 & 3.04 & -0.21 & 1.02 & -0.84 & 0.407 \\
Male & 24 & 3.25 & & 0.98 & & \\
\hline
\end{tabular}

${ }^{*} p<0.05$

Table K.12.

Comparison of Perceptions Regarding Wikis and Amount of Online Courses Taken

\begin{tabular}{ccccccc}
\hline Courses & $n$ & $M$ & Difference & SD & $t$ & Significance* $^{*}$ \\
\hline $1-2$ & 23 & 3.22 & 0.18 & 1.09 & 0.69 & 0.496 \\
$3+$ & 50 & 3.04 & & 0.98 & & \\
\hline
\end{tabular}

${ }^{*} p<0.05$ 
Table K.13.

Comparison of Perceptions Regarding Podcasts and Age

\begin{tabular}{ccccccc}
\hline Age & $n$ & $M$ & Difference & SD & $t$ & Significance* $^{*}$ \\
\hline $18-24$ & 48 & 3.58 & -0.13 & 1.31 & -0.62 & 0.535 \\
$25+$ & 76 & 3.71 & & 1.09 & & \\
\hline
\end{tabular}

${ }^{*} p<0.05$

Table K.14.

Comparison of Perceptions Regarding Podcasts and Gender

\begin{tabular}{ccccccc}
\hline Gender & $n$ & $M$ & Difference & SD & $t$ & Significance $^{*}$ \\
\hline Female & 103 & 3.78 & 0.22 & 1.02 & 0.95 & 0.349 \\
Male & 34 & 3.56 & & 1.47 & & \\
\hline
\end{tabular}

${ }^{*} p<0.05$

Table K.15.

Comparison of Perceptions Regarding Podcasts and Amount of Online Courses Taken

\begin{tabular}{ccccccc}
\hline Courses & $n$ & $M$ & Difference & SD & $t$ & Significance $^{*}$ \\
\hline $1-2$ & 34 & 3.47 & -0.31 & 1.17 & -1.45 & 0.154 \\
$3+$ & 104 & 3.78 & & 1.16 & & \\
\hline
\end{tabular}

${ }^{*} p<0.05$ 


\section{Appendix L}

Single-Factor ANOVA Results for GPA and Internet Access 
Table L.1.

Single-Factor Analysis of Variance for GPA

\begin{tabular}{lcccccc}
\hline GPA & $N$ & $D f$ & $M S$ & $F$ & $p$ & F crit \\
\hline Above 3.0 & 237 & 3 & 2.560 & 1.996 & 0.114 & 2.630 \\
$2.0-2.9$ & 103 & & & & & \\
Below 1.9 & 2 & & & & & \\
None & 12 & & & & & \\
\hline
\end{tabular}

$* p<0.05$

Table L.2.

Single-Factor Analysis of Variance for Internet Access

\begin{tabular}{lcccccc}
\hline Internet Access & $N$ & $D f$ & $M S$ & $F$ & $p$ & F crit \\
\hline No Access & 11 & 3 & 1.051 & 0.828 & 0.479 & 2.630 \\
Slow Access & 21 & & & & & \\
Moderate & 164 & & & & & \\
Access & & & & & & \\
Quick Access & 162 & & & & & \\
$*{ }^{*} p<0.05$ & & & & & &
\end{tabular}




\section{Appendix M}

Frequency of Responses to CoI Survey 
Table M.1.

Frequency of Responses to CoI Questions

\begin{tabular}{|c|c|c|c|c|c|c|c|}
\hline \multirow[b]{2}{*}{ Presence } & \multirow[b]{2}{*}{ Question } & \multirow[b]{2}{*}{$M$} & \multicolumn{2}{|c|}{ Dissatisfaction } & \multirow{2}{*}{$\frac{\text { Neutral }}{3}$} & \multicolumn{2}{|c|}{ Satisfaction } \\
\hline & & & 1 & 2 & & 4 & 5 \\
\hline \multirow[t]{21}{*}{ Teaching } & & 3.62 & & & & & \\
\hline & $\begin{array}{l}\text { Design and } \\
\text { Organization }\end{array}$ & & & & & & \\
\hline & Q1 & & 11 & 9 & 22 & 55 & 36 \\
\hline & Q2 & & 9 & 9 & 21 & 52 & 41 \\
\hline & Q3 & & 9 & 14 & 27 & 42 & 39 \\
\hline & Q4 & & 10 & 9 & 19 & 42 & 52 \\
\hline & Facilitation & & & & & & \\
\hline & Q5 & & 12 & 13 & 31 & 52 & 25 \\
\hline & Q6 & & 13 & 15 & 24 & 49 & 31 \\
\hline & Q7 & & 9 & 21 & 30 & 42 & 30 \\
\hline & Q8 & & 15 & 15 & 29 & 43 & 30 \\
\hline & Q9 & & 12 & 15 & 23 & 52 & 29 \\
\hline & Q10 & & 14 & 16 & 28 & 46 & 27 \\
\hline & Direct Instruc & & & & & & \\
\hline & Q11 & & 13 & 14 & 23 & 50 & 33 \\
\hline & Q12 & & 18 & 18 & 20 & 40 & 36 \\
\hline & Q13 & & 13 & 12 & 29 & 40 & 38 \\
\hline & $\begin{array}{l}\text { Total Teachi } \\
\text { Presence }\end{array}$ & & & & & & \\
\hline & & & 158 & 180 & 326 & 605 & 447 \\
\hline & Indicating & & & & & \multicolumn{2}{|c|}{ (Column 4+5) } \\
\hline & Satisfaction & & & & & \multicolumn{2}{|c|}{$1,052(61.3 \%)$} \\
\hline
\end{tabular}




\begin{tabular}{|c|c|c|c|c|c|c|c|}
\hline \multirow{2}{*}{ Presence } & \multirow[b]{2}{*}{ Question } & \multirow[b]{2}{*}{ M } & \multicolumn{2}{|c|}{ Dissatisfaction } & \multirow{2}{*}{$\begin{array}{c}\text { Neutral } \\
3\end{array}$} & \multicolumn{2}{|c|}{ Satisfaction } \\
\hline & & & 1 & 2 & & 4 & 5 \\
\hline \multirow[t]{19}{*}{ Social } & & 3.63 & & & & & \\
\hline & Affective & & & & & & \\
\hline & Organization & & & & & & \\
\hline & Q14 & & 11 & 19 & 37 & 44 & 19 \\
\hline & Q15 & & 12 & 17 & 35 & 46 & 20 \\
\hline & Q16 & & 14 & 13 & 39 & 44 & 20 \\
\hline & Open & & & & & & \\
\hline & Communication & & & & & & \\
\hline & Q17 & & 10 & 6 & 26 & 58 & 31 \\
\hline & Q18 & & 9 & 6 & 27 & 56 & 33 \\
\hline & Q19 & & 8 & 6 & 26 & 58 & 33 \\
\hline & Group Cohesion & & & & & & \\
\hline & Q20 & & 7 & 10 & 42 & 50 & 22 \\
\hline & Q21 & & 5 & 6 & 32 & 58 & 30 \\
\hline & Q22 & & 10 & 16 & 33 & 43 & 28 \\
\hline & Total Social & & & & & & \\
\hline & Presence & & 86 & 99 & 297 & 457 & 236 \\
\hline & Indicating & & & & & \multicolumn{2}{|c|}{ (Column 4+5) } \\
\hline & Satisfaction & & & & & \multicolumn{2}{|c|}{$693(59.0 \%)$} \\
\hline \multirow[t]{21}{*}{ Cognitive } & & 3.64 & & & & & \\
\hline & \multicolumn{7}{|l|}{ Triggering Event } \\
\hline & Q23 & & 12 & 9 & 52 & 37 & 14 \\
\hline & Q24 & & 9 & 14 & 35 & 45 & 19 \\
\hline & Q25 & & 11 & 12 & 34 & 42 & 25 \\
\hline & \multicolumn{7}{|l|}{ Exploration } \\
\hline & Q26 & & 6 & 9 & 23 & 52 & 34 \\
\hline & Q27 & & 6 & 12 & 24 & 51 & 30 \\
\hline & Q28 & & 14 & 9 & 20 & 51 & 29 \\
\hline & \multicolumn{7}{|l|}{ Integration } \\
\hline & Q29 & & 7 & 9 & 25 & 61 & 22 \\
\hline & Q30 & & 6 & 9 & 23 & 63 & 23 \\
\hline & Q31 & & 8 & 7 & 26 & 59 & 24 \\
\hline & \multicolumn{7}{|l|}{ Resolution } \\
\hline & Q32 & & 6 & 9 & 24 & 62 & 24 \\
\hline & Q33 & & 5 & 6 & 30 & 58 & 26 \\
\hline & Q34 & & 6 & 2 & 28 & 58 & 31 \\
\hline & \multicolumn{7}{|l|}{ Total Cognitive } \\
\hline & Presence & & 96 & 107 & 344 & 639 & 301 \\
\hline & Indicating & & & & & \multirow{2}{*}{\multicolumn{2}{|c|}{$\begin{array}{c}\text { (Column } 4+5) \\
940(63.2 \%)\end{array}$}} \\
\hline & Satisfaction & & & & & & \\
\hline
\end{tabular}




\section{Appendix N}

Repeated Measures ANOVA and Post-Hoc Test Results for CoI Survey 
Table N.1.

Repeated Measures Analysis of Variance for Presences

\begin{tabular}{lcccccc}
\hline Presence & $M$ & $D f$ & $\mathrm{~F}$ & $P$ & $\begin{array}{c}\text { Mauchly's } \\
\text { Sphericity }\end{array}$ & $\begin{array}{c}\text { Greenhouse- } \\
\text { Geisser }\end{array}$ \\
\hline Social & 3.63 & 1.413 & 0.136 & 0.798 & 0.585 & 0.798 \\
Teaching & 3.62 & & & & & \\
Cognitive & 3.64 & & & & & \\
\hline${ }^{*} p<0.05$ & & & & & &
\end{tabular}

Table N.2.

Bonferroni Correction for Repeated Measure ANOVA for Presences

\begin{tabular}{llcc}
\hline Presence & Comparison Presence & Mean Difference & $P$ \\
\hline \multirow{2}{*}{ Teaching } & Social & 0.007 & 0.784 \\
& Cognitive & -0.013 & 0.792 \\
\hline \multirow{2}{*}{ Social } & Teaching & -0.007 & 0.784 \\
& Cognitive & -0.020 & 0.605 \\
\hline \multirow{2}{*}{ Cognitive } & Teaching & 0.013 & 0.792 \\
& Social & 0.020 & 0.605
\end{tabular}

$* p<0.05$ 


\section{Appendix 0}

Independent T-Test Results Comparing Presences with Demographics 
Table 0.1.

Comparison of Perceptions Regarding Social Presence and Age

\begin{tabular}{ccccccc}
\hline Age & $n$ & $M$ & Difference & SD & $t$ & Significance* $^{*}$ \\
\hline $18-24$ & 40 & 3.82 & 0.29 & 0.61 & 1.75 & 0.084 \\
$25+$ & 85 & 3.53 & & 0.95 & & \\
\hline
\end{tabular}

$* p<0.05$

Table 0.2.

Comparison of Perceptions Regarding Social Presence and Gender

\begin{tabular}{ccccccc}
\hline Gender & $n$ & $M$ & Difference & SD & $t$ & Significance $^{*}$ \\
\hline Female & 91 & 3.68 & 0.16 & 0.82 & 0.81 & 0.424 \\
Male & 32 & 3.52 & & 0.92 & & \\
\hline
\end{tabular}

$* p<0.05$

Table 0.3.

Comparison of Perceptions Regarding Social Presence and Amount of Online Courses Taken

\begin{tabular}{ccccccc}
\hline Courses & $n$ & $M$ & Difference & SD & $t$ & Significance* $^{*}$ \\
\hline $1-2$ & 28 & 3.36 & -0.34 & 0.77 & -1.75 & 0.087 \\
$3+$ & 96 & 3.70 & & 0.86 & & \\
\hline
\end{tabular}

$* p<0.05$ 
Table 0.4.

Comparison of Perceptions Regarding Teaching Presence and Age

\begin{tabular}{ccccccc}
\hline Age & $n$ & $M$ & Difference & SD & $t$ & Significance* $^{*}$ \\
\hline $18-24$ & 40 & 3.83 & 0.29 & 0.82 & 1.58 & 0.117 \\
$25+$ & 85 & 3.54 & & 1.22 & & \\
\hline
\end{tabular}

$* p<0.05$

Table 0.5.

Comparison of Perceptions Regarding Teaching Presence and Gender

\begin{tabular}{ccccccc}
\hline Gender & $n$ & $M$ & Difference & SD & $t$ & Significance* $^{*}$ \\
\hline Female & 91 & 3.70 & 0.16 & 1.00 & 0.69 & 0.495 \\
Male & 32 & 3.54 & & 1.31 & & \\
\hline$* p<0.05$ & & & & & &
\end{tabular}

Table 0.6.

Comparison of Perceptions Regarding Teaching Presence and Amount of Online Courses Taken

\begin{tabular}{ccccccc}
\hline Courses & $n$ & $M$ & Difference & SD & $t$ & Significance* \\
\hline $1-2$ & 28 & 3.34 & -0.37 & 0.98 & -1.71 & 0.094 \\
$3+$ & 96 & 3.71 & & 1.13 & & \\
\hline$* p<0.05$ & & & & &
\end{tabular}

$* p<0.05$ 
Table 0.7.

Comparison of Perceptions Regarding Cognitive Presence and Age

\begin{tabular}{ccccccc}
\hline Age & $n$ & $M$ & Difference & SD & $t$ & Significance* $^{*}$ \\
\hline $18-24$ & 40 & 3.74 & 0.15 & 0.67 & 0.89 & 0.377 \\
$25+$ & 85 & 3.59 & & 0.98 & & \\
\hline
\end{tabular}

$* p<0.05$

Table 0.8.

Comparison of Perceptions Regarding Cognitive Presence and Gender

\begin{tabular}{ccccccc}
\hline Gender & $n$ & $M$ & Difference & SD & $t$ & Significance* $^{*}$ \\
\hline Female & 91 & 3.67 & 0.05 & 0.84 & 0.23 & 0.816 \\
Male & 32 & 3.62 & & 1.02 & & \\
\hline
\end{tabular}

$* p<0.05$

Table 0.9.

Comparison of Perceptions Regarding Cognitive Presence and Amount of Online Courses Taken

\begin{tabular}{ccccccc}
\hline Courses & $n$ & $M$ & Difference & SD & $t$ & Significance* $^{*}$ \\
\hline $1-2$ & 28 & 3.36 & -0.36 & 0.78 & -1.85 & 0.071 \\
$3+$ & 96 & 3.72 & & 0.90 & & \\
\hline
\end{tabular}

$* p<0.05$ 


\section{Appendix P}

Single-Factor ANOVA Results for GPA and Internet Access 
Table P.1.

Single-Factor Analysis of Variance for GPA

\begin{tabular}{lcccccc}
\hline GPA & $N$ & $D f$ & $M S$ & $F$ & $p$ & F crit \\
\hline Above 3.0 & 237 & 3 & 2.560 & 1.996 & 0.114 & 2.630 \\
$2.0-2.9$ & 103 & & & & & \\
Below 1.9 & 2 & & & & & \\
None & 12 & & & & & \\
\hline
\end{tabular}

$* p<0.05$

Table P.2.

Single-Factor Analysis of Variance for Internet Access

\begin{tabular}{lcccccc}
\hline Internet Access & $N$ & $D f$ & $M S$ & $F$ & $p$ & F crit \\
\hline No Access & 11 & 3 & 1.051 & 0.828 & 0.479 & 2.630 \\
Slow Access & 21 & & & & & \\
Moderate & 164 & & & & & \\
Access & & & & & & \\
Quick Access & 162 & & & & & \\
$*{ }^{*} p<0.05$ & & & & & &
\end{tabular}

